Figure S1. Photographs of the most developed uredinia produced on the various taxa.

Photographs of the most developed uredinia produced on the various taxa at three weeks after inoculation with Puccinia psidii s.l. (ex Australia, DAR81284). 


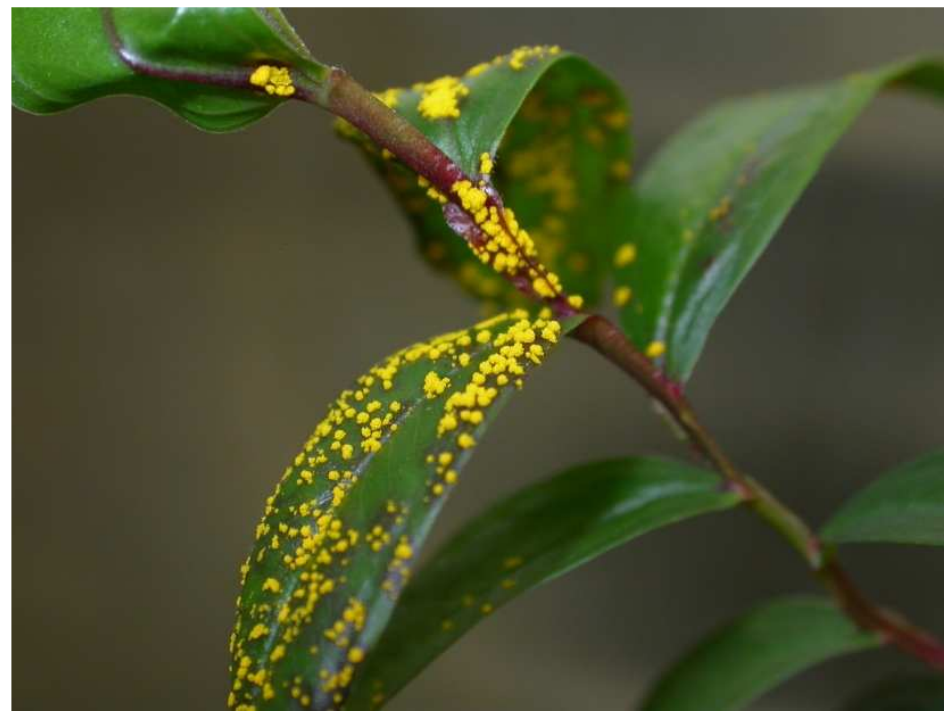

Agonis flexuosa 'Afterdark'

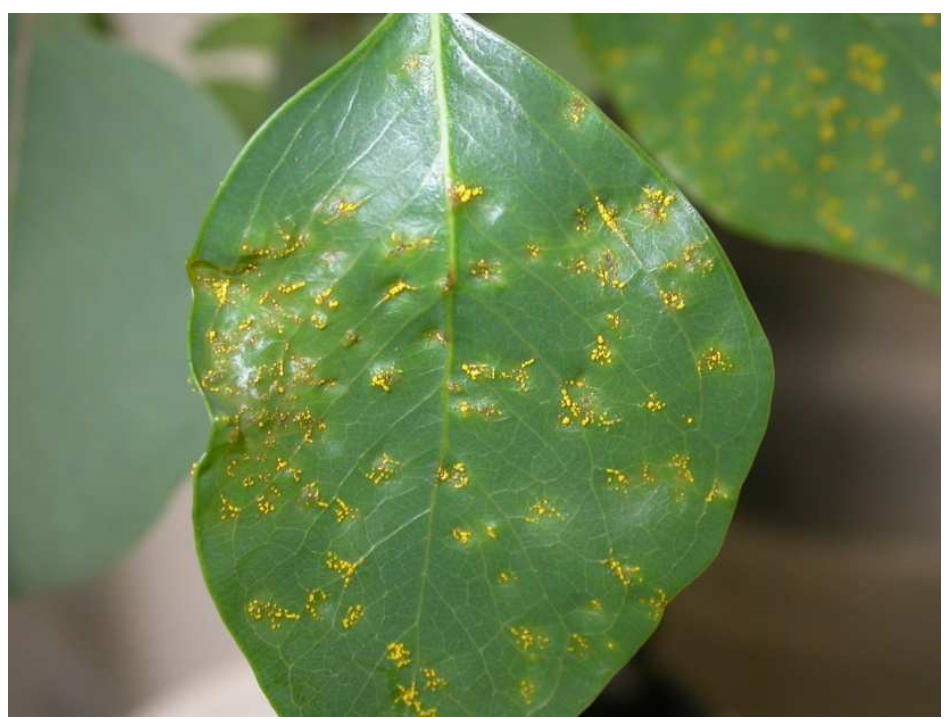

Allosyncarpia ternata

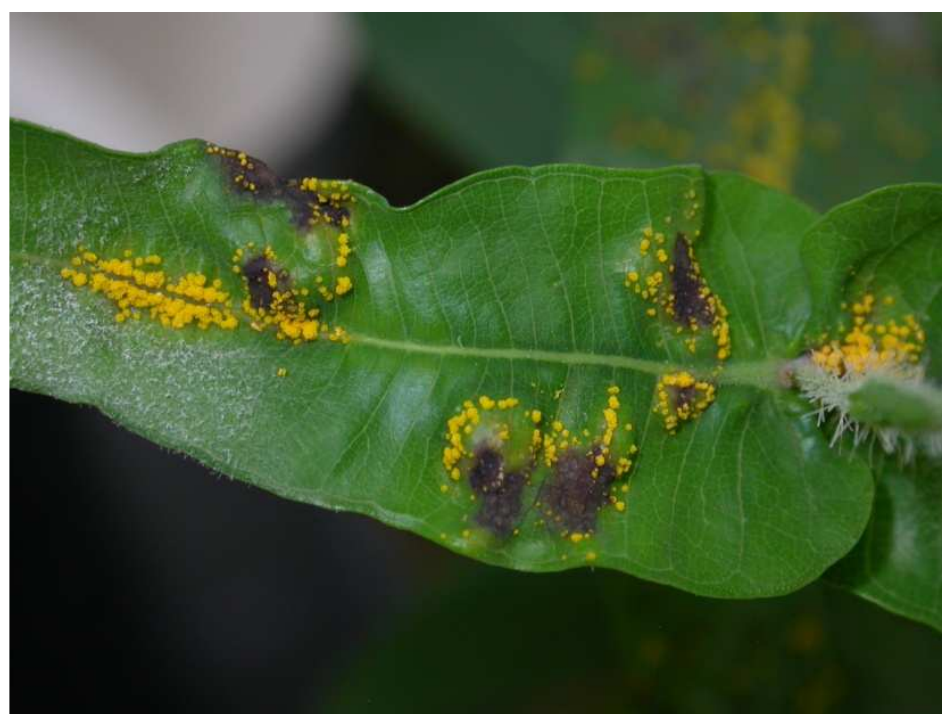

Angophora floribunda

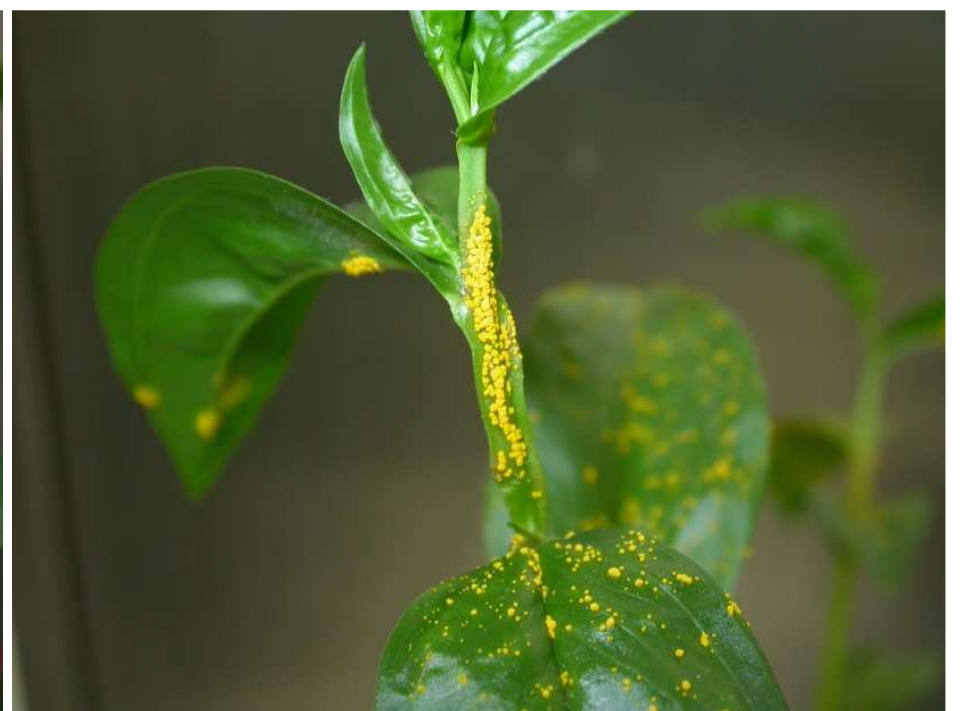

Agonis flexuosa (wild accession)

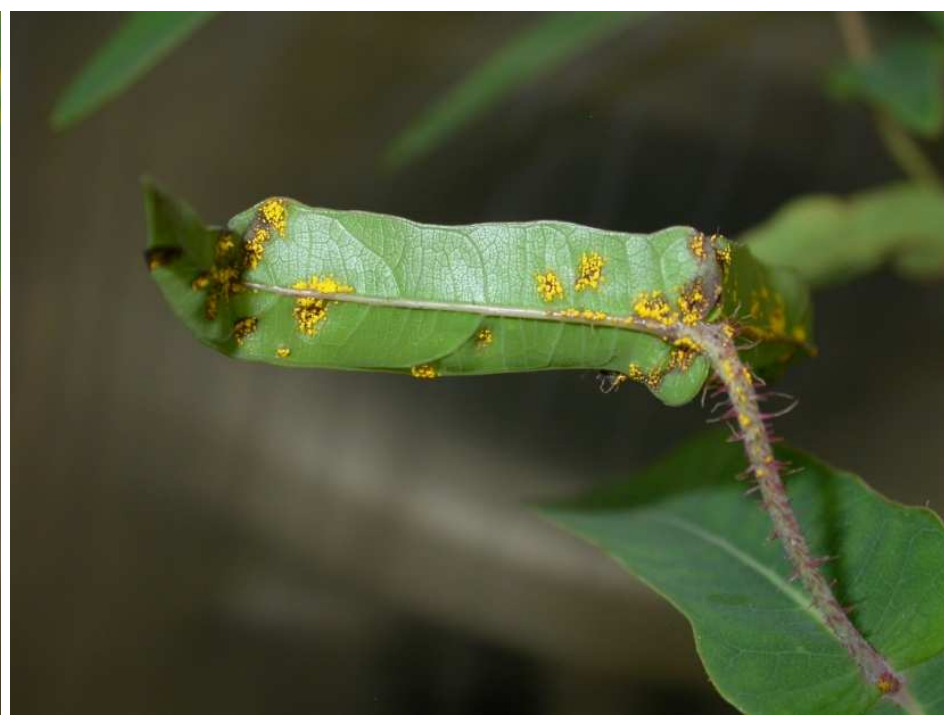

Angophora costata

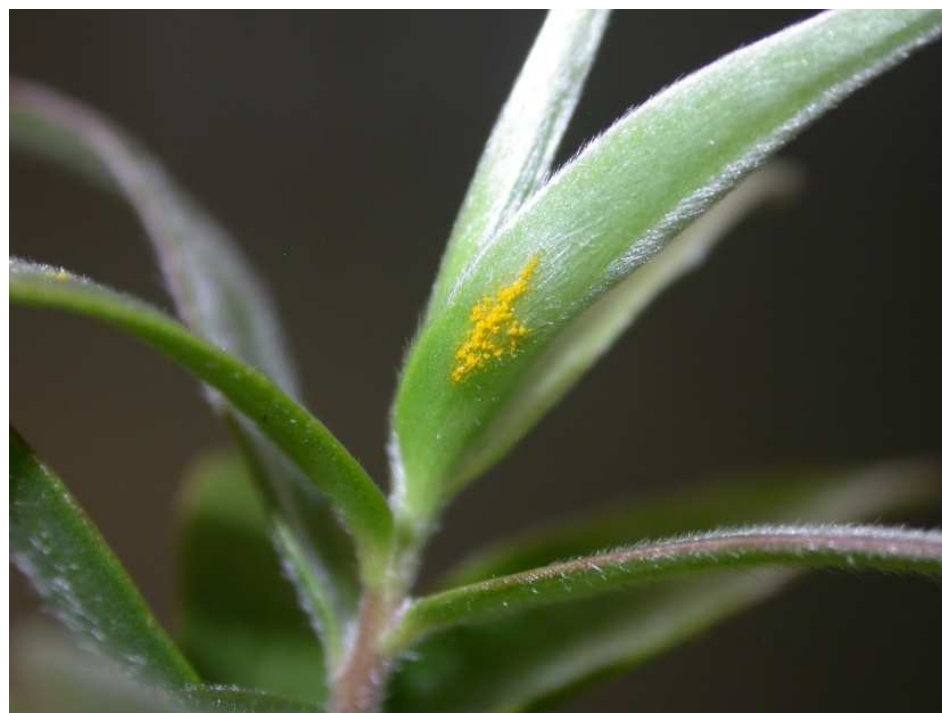

Asteromyrtus magnifica 

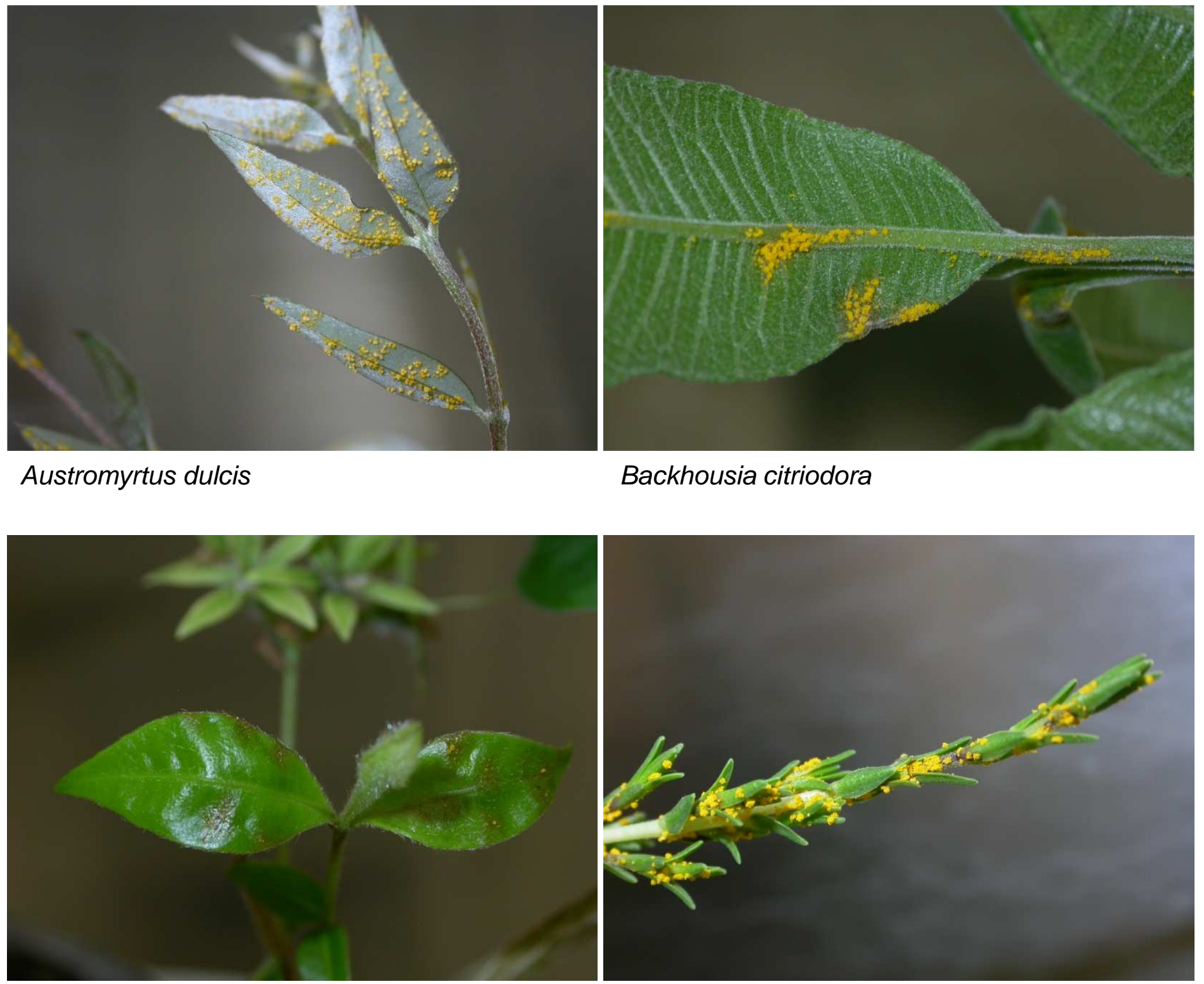

Beaufortia schaueri
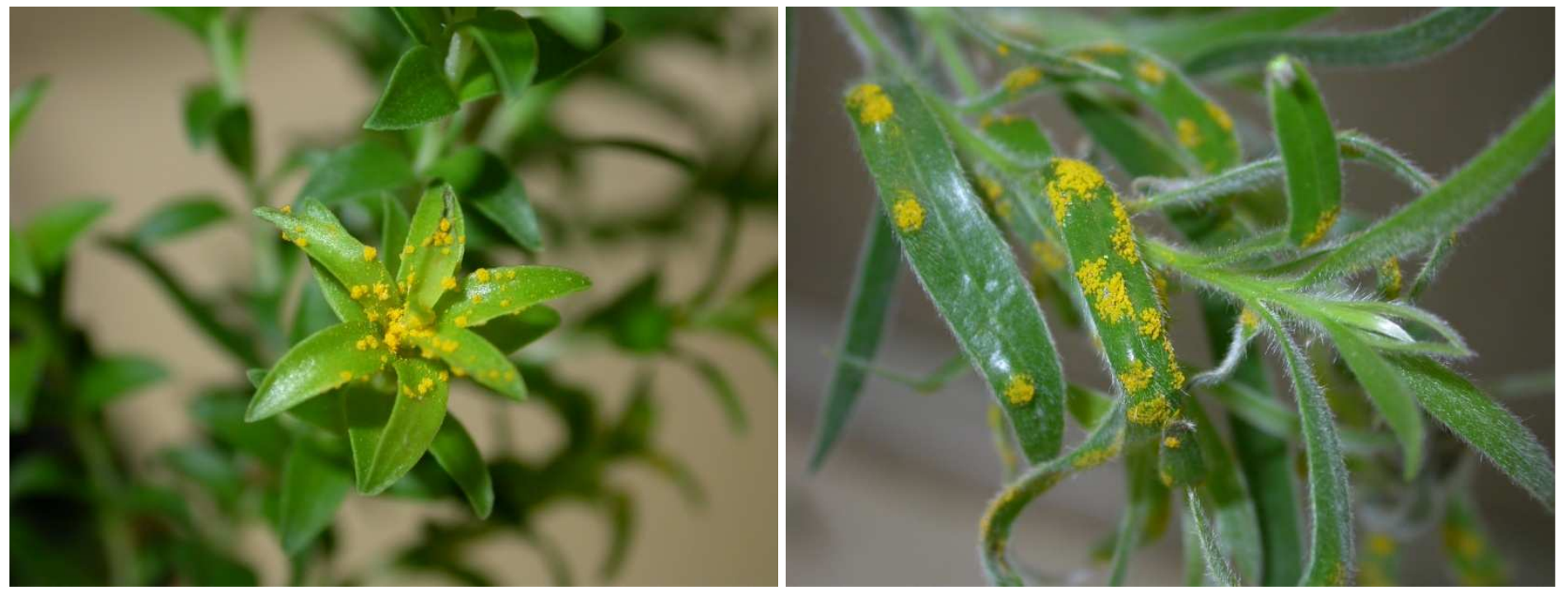

Callistemon 'Hannah Ray' 


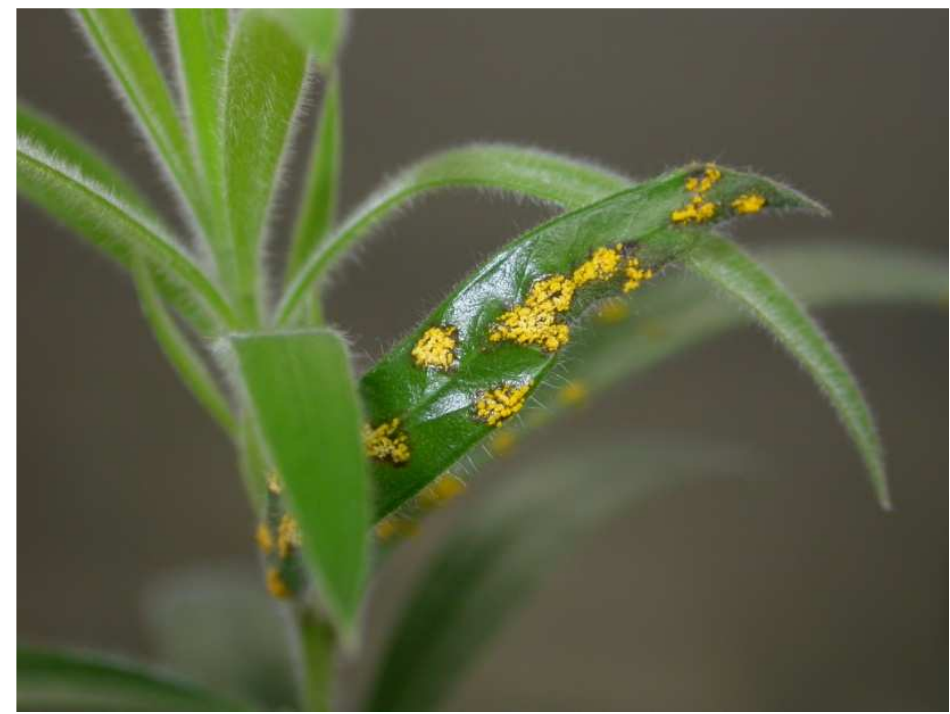

Callistemon 'Kings Park Special'

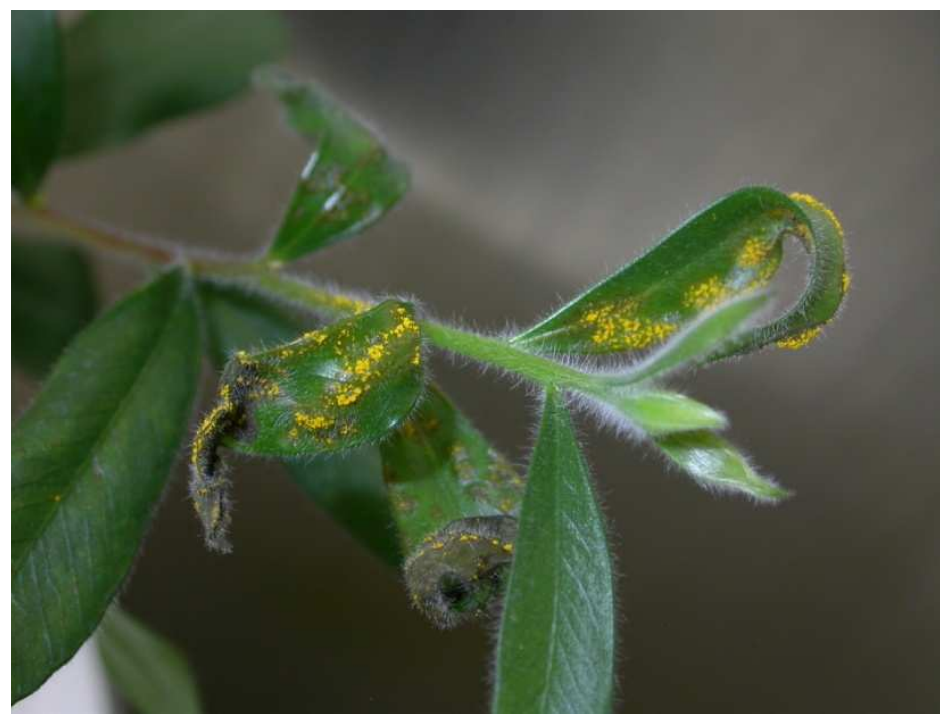

Callistemon linearifolius

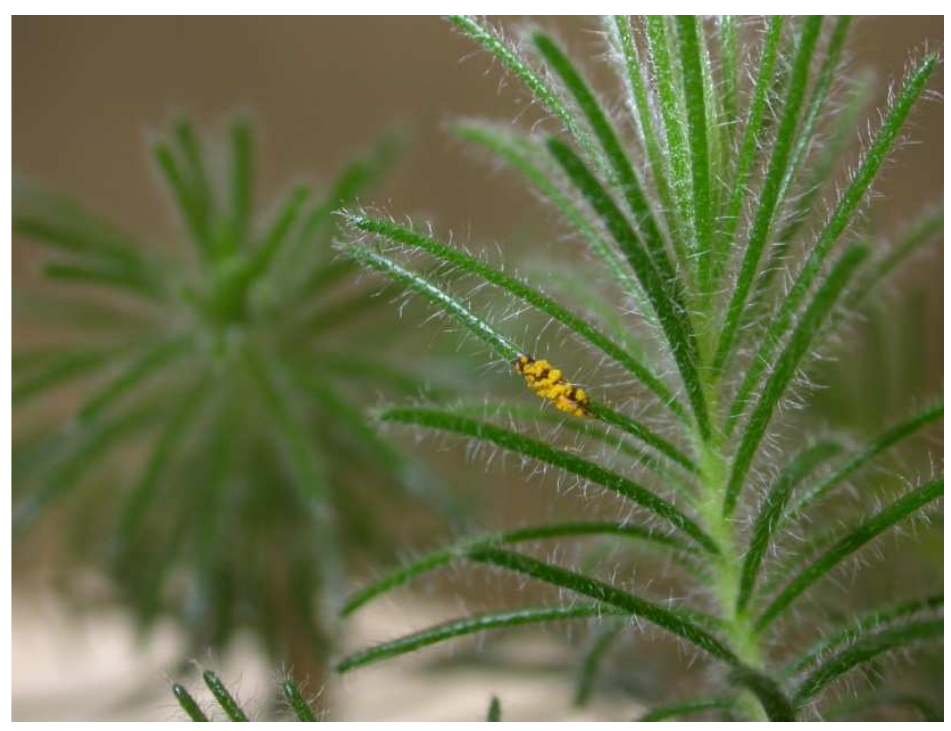

Calothamnus quadrifidus

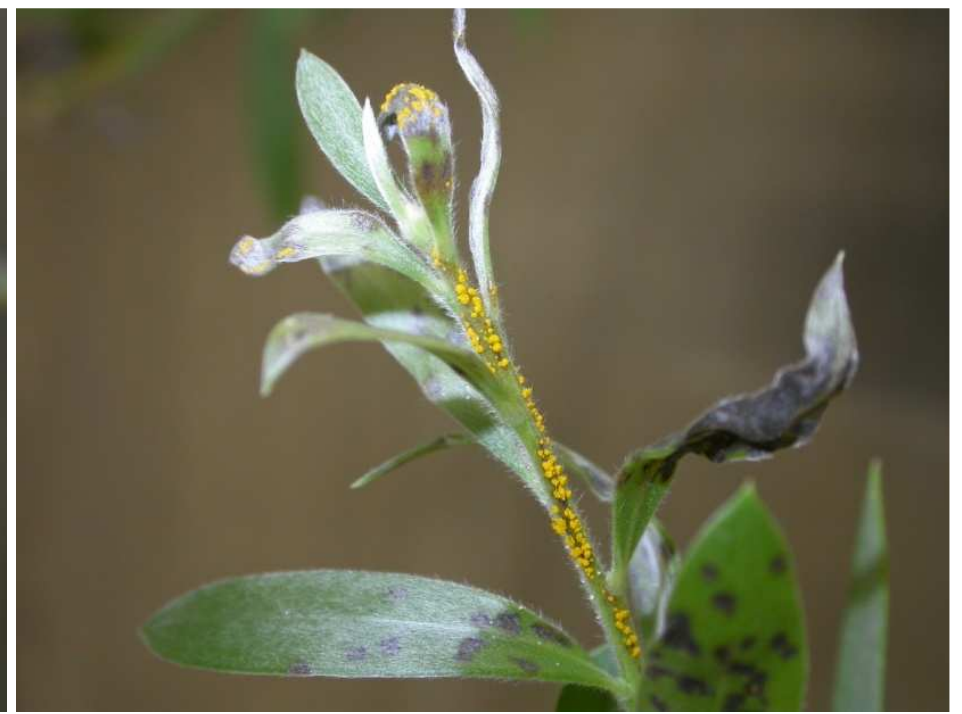

Callistemon citrinus 'White Anzac'

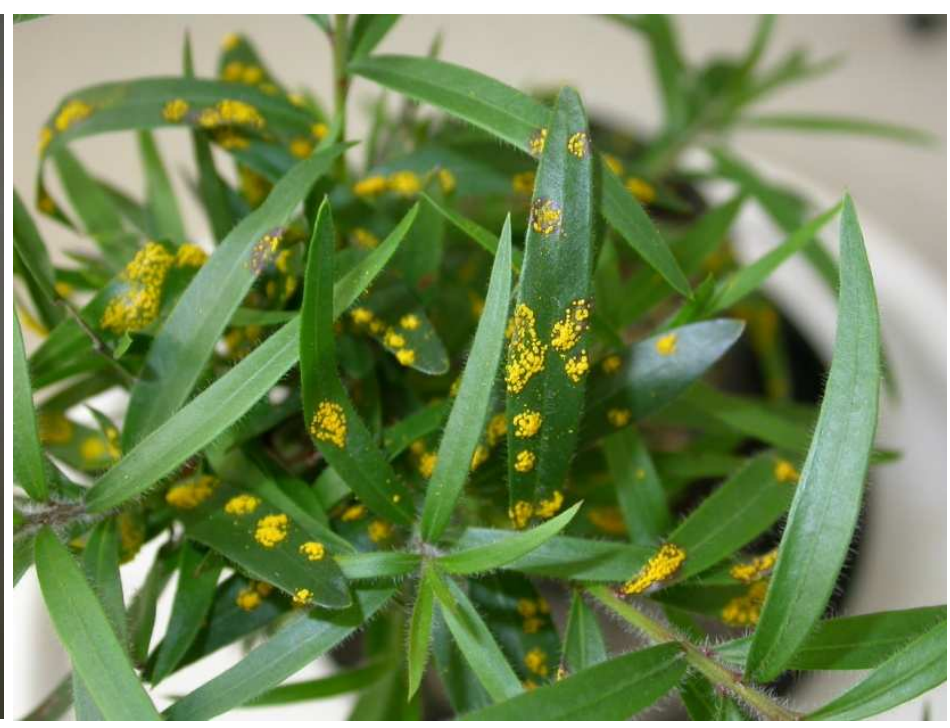

Callistemon viminalis

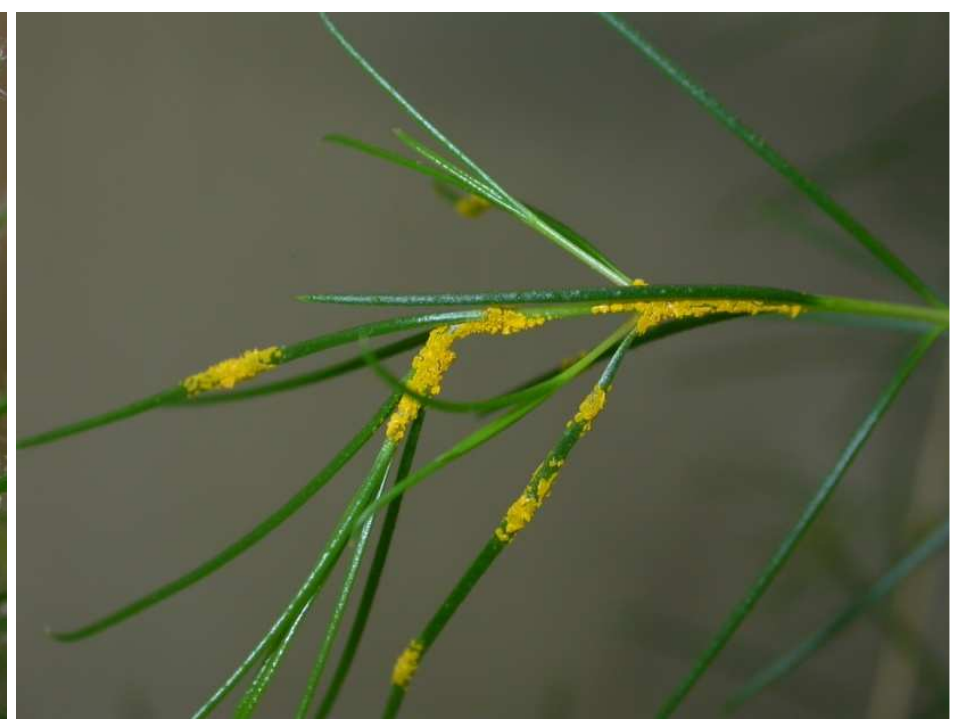

Chamelaucium uncinatum 


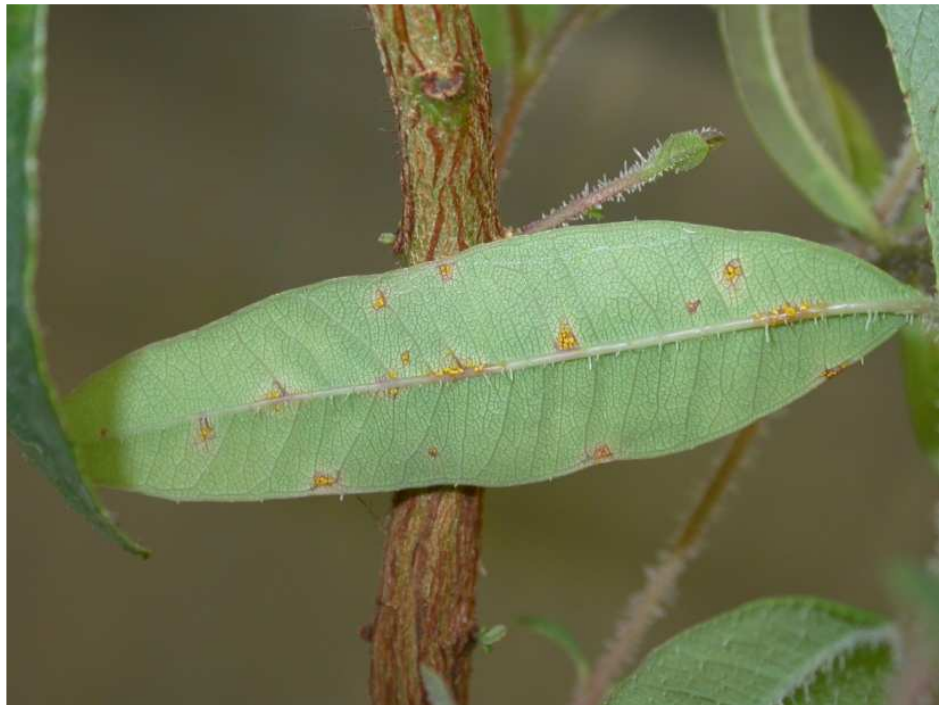

Corymbia citriodora (accession no 1)

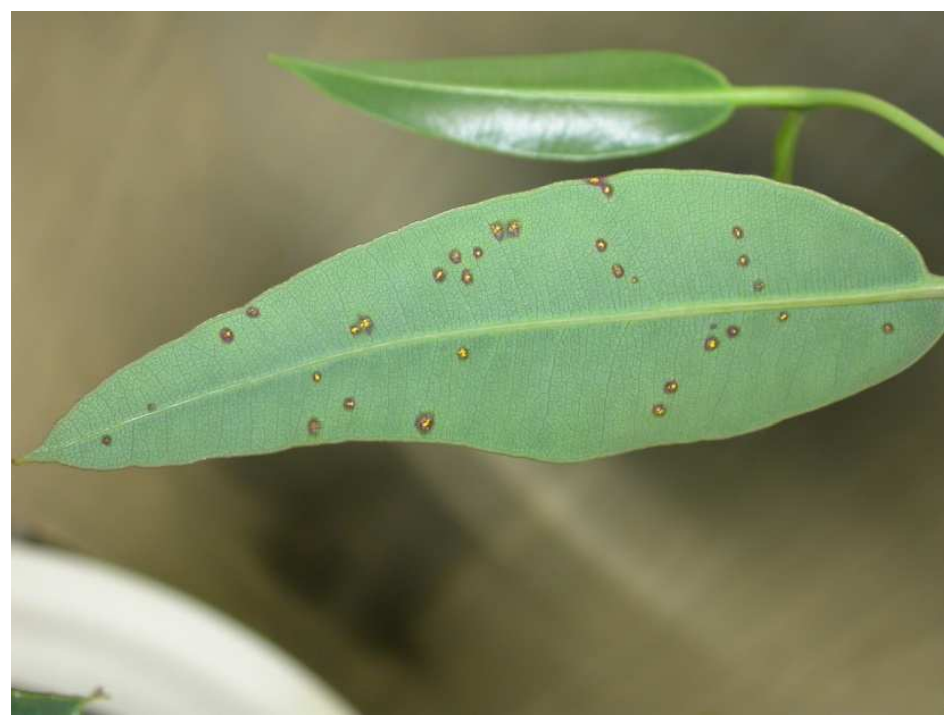

Corymbia ficifolia

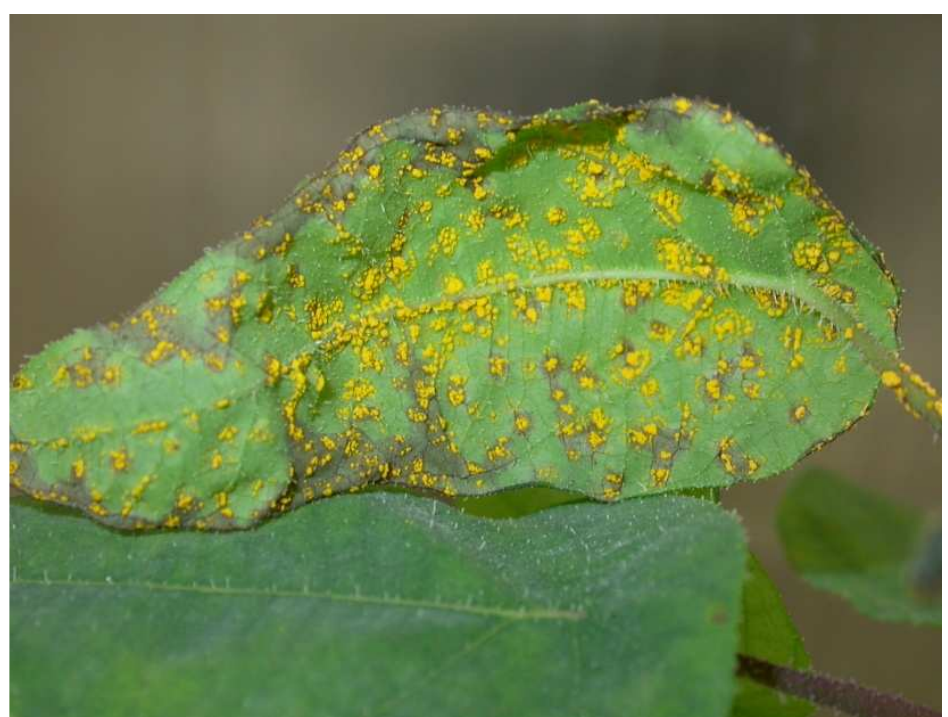

Corymbia henryi

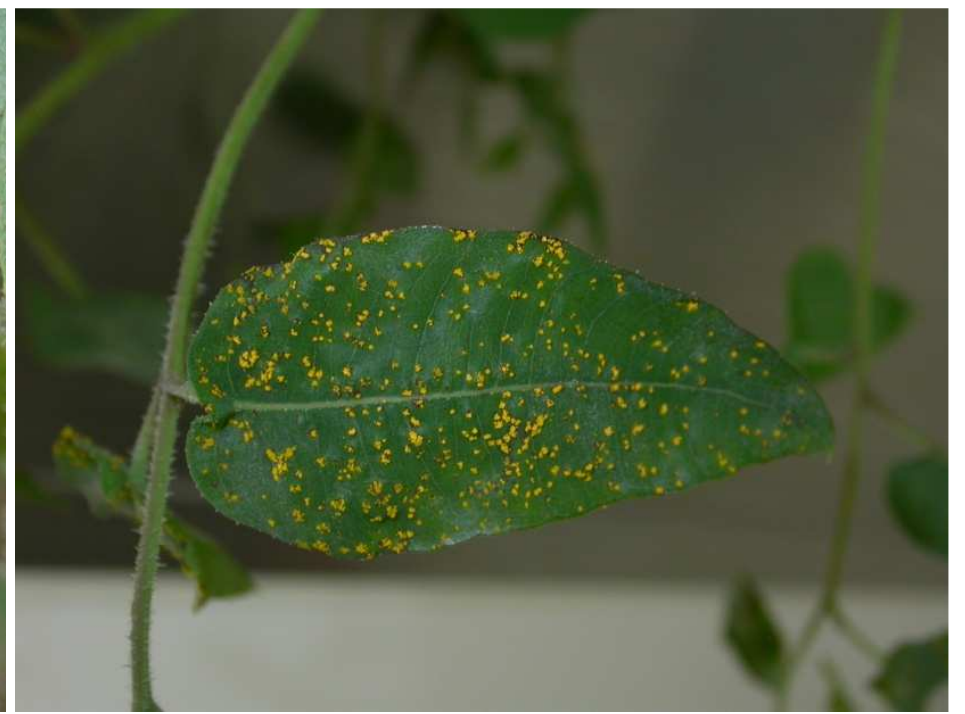

Corymbia citriodora (accession no 2)

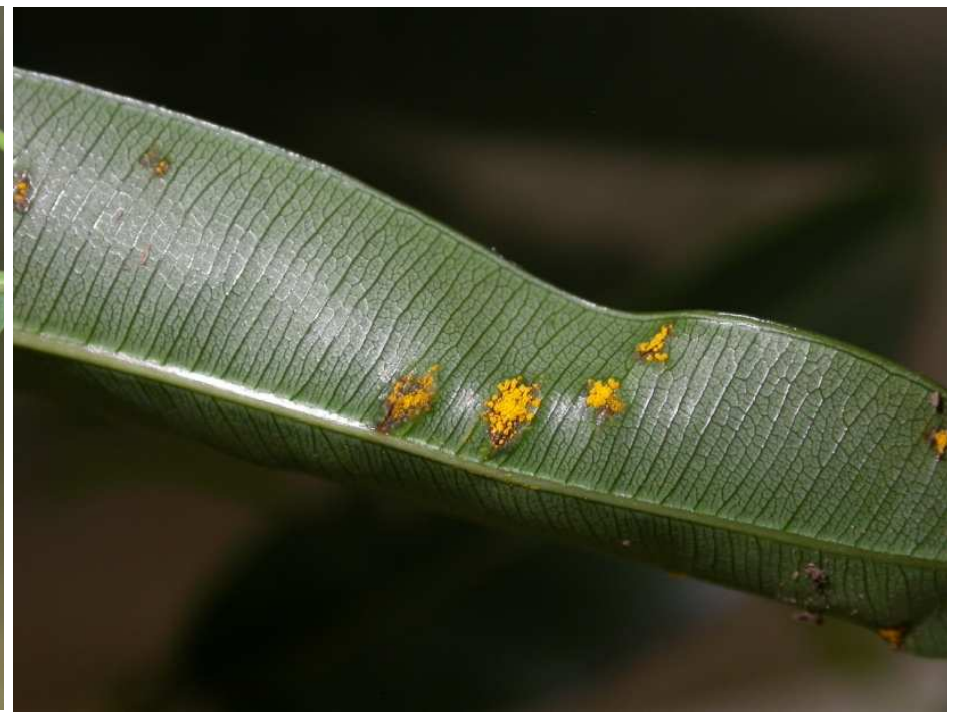

Corymbia gummifera

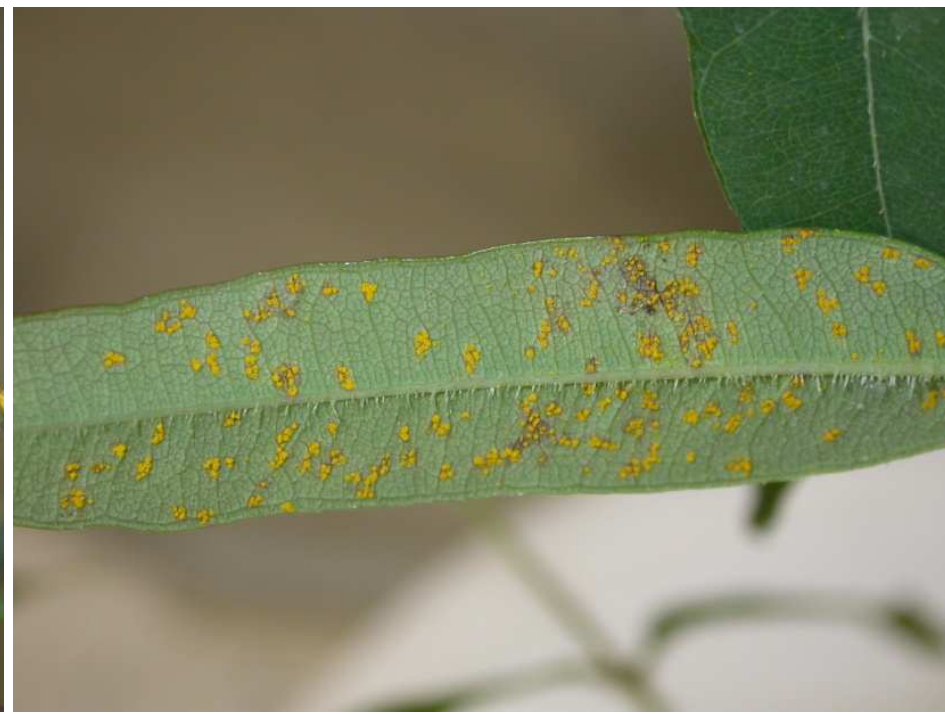

Corymbia intermedia 


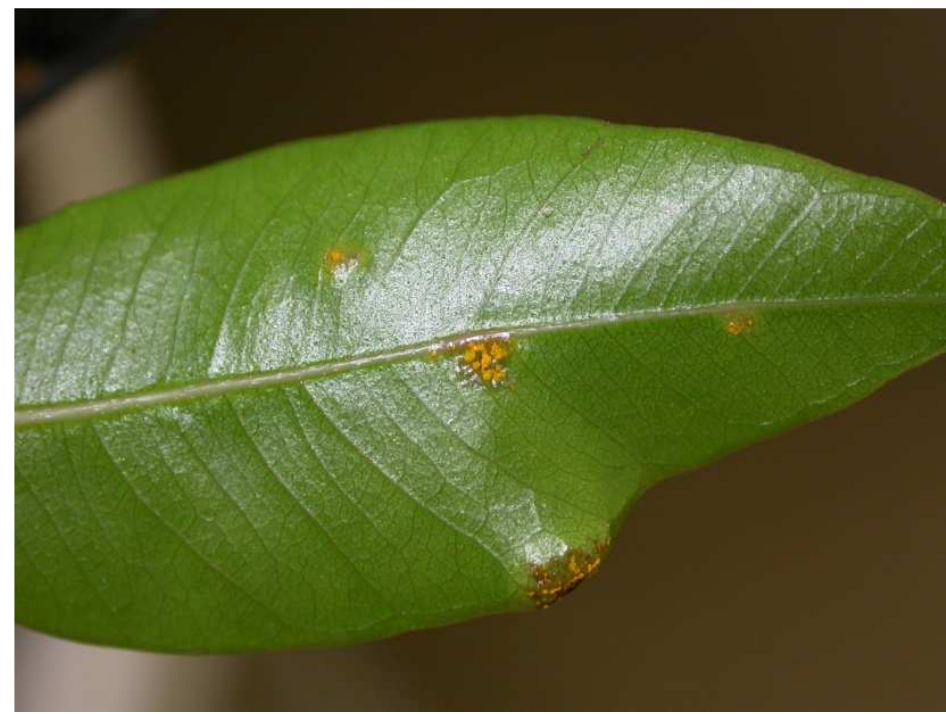

Corymbia maculata

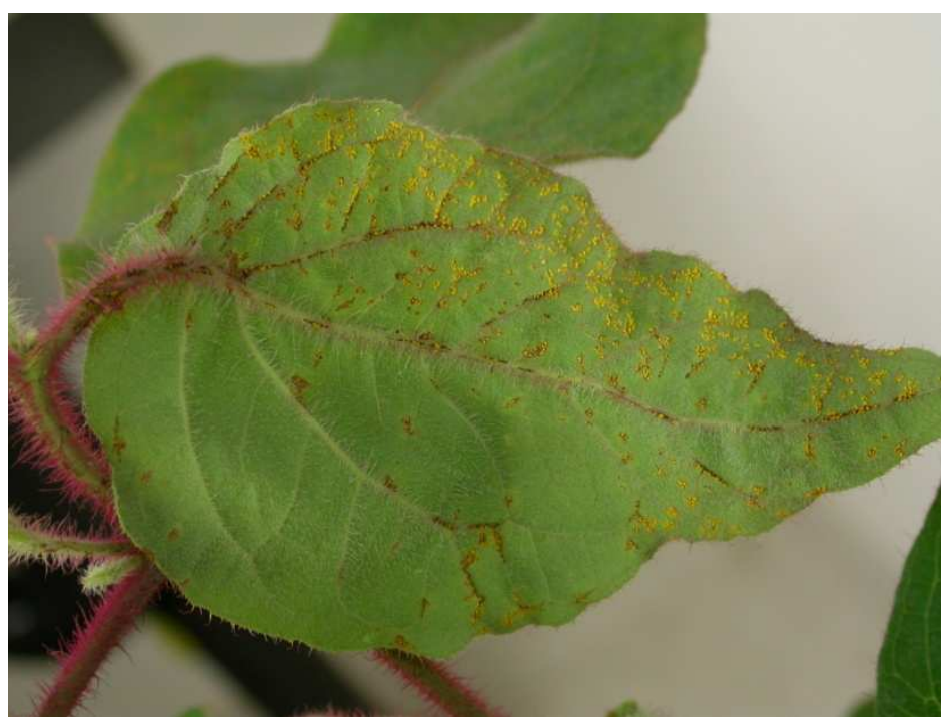

Corymbia torelliana

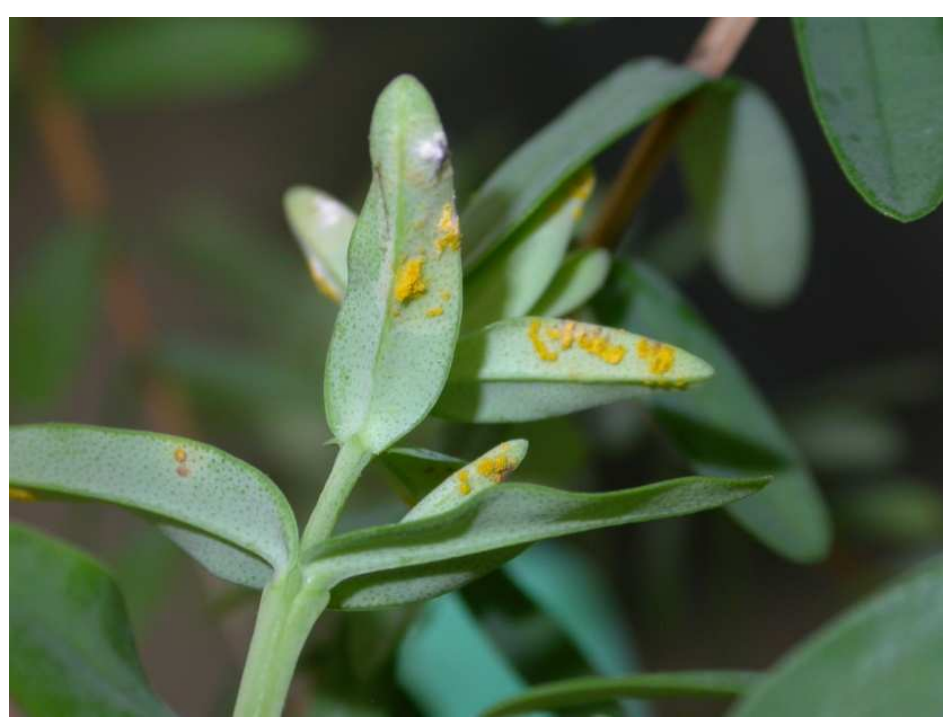

Darwinia citriodora

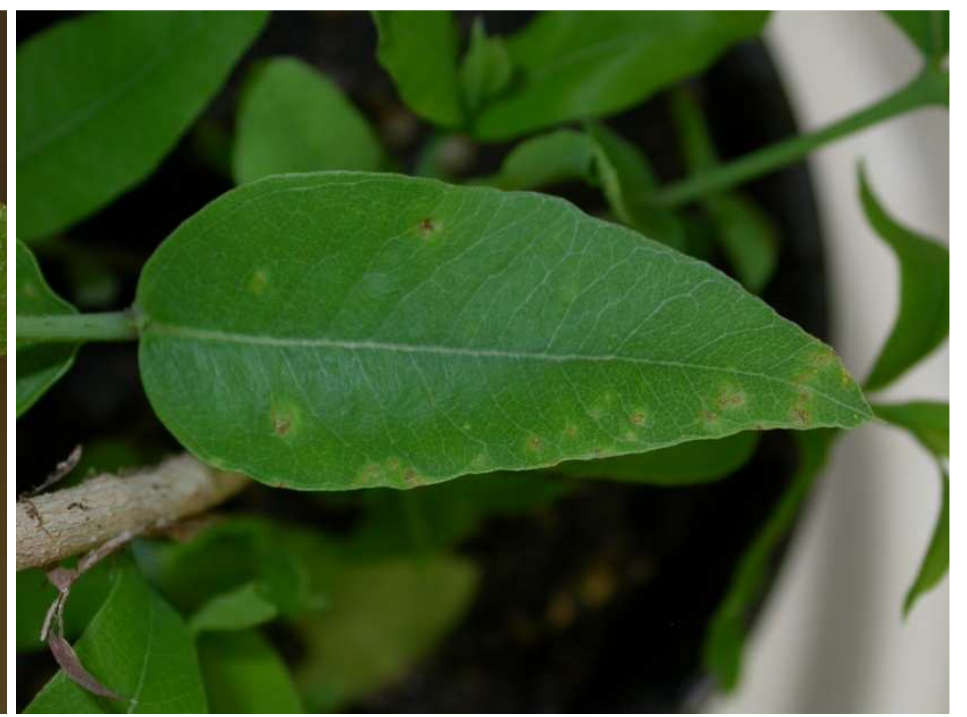

Corymbia tessellaris

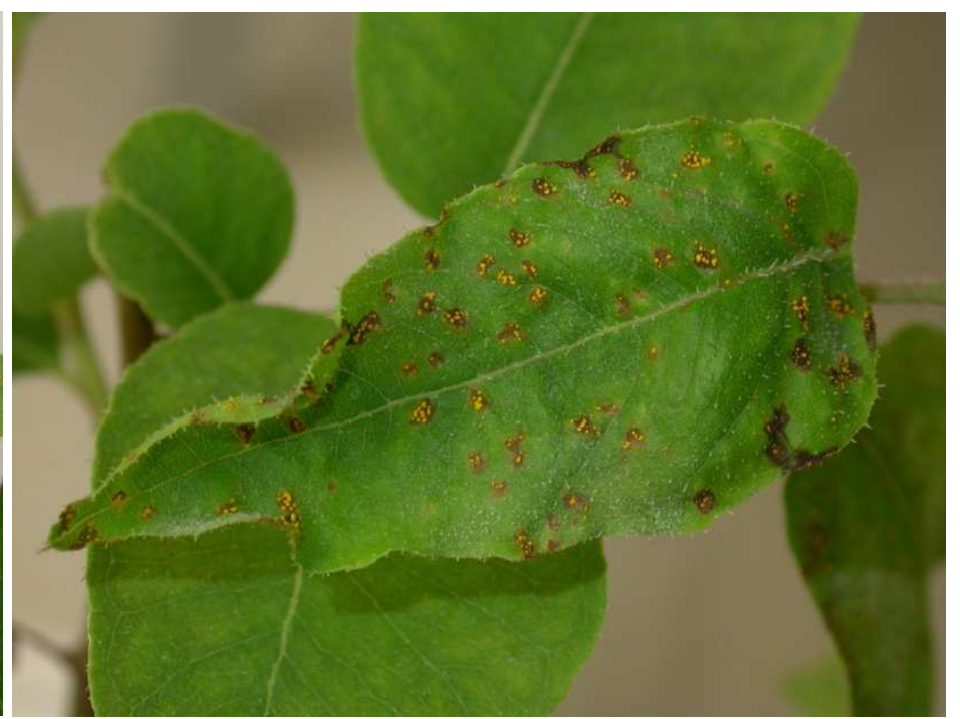

Corymbia variegata $\times$ torelliana

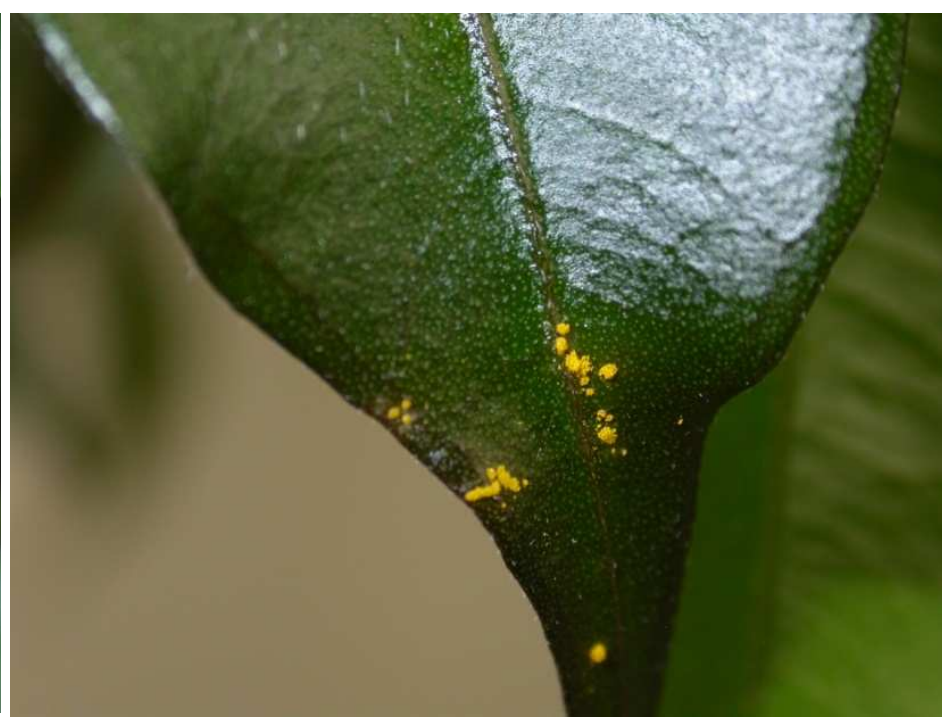

Decaspermum humile 


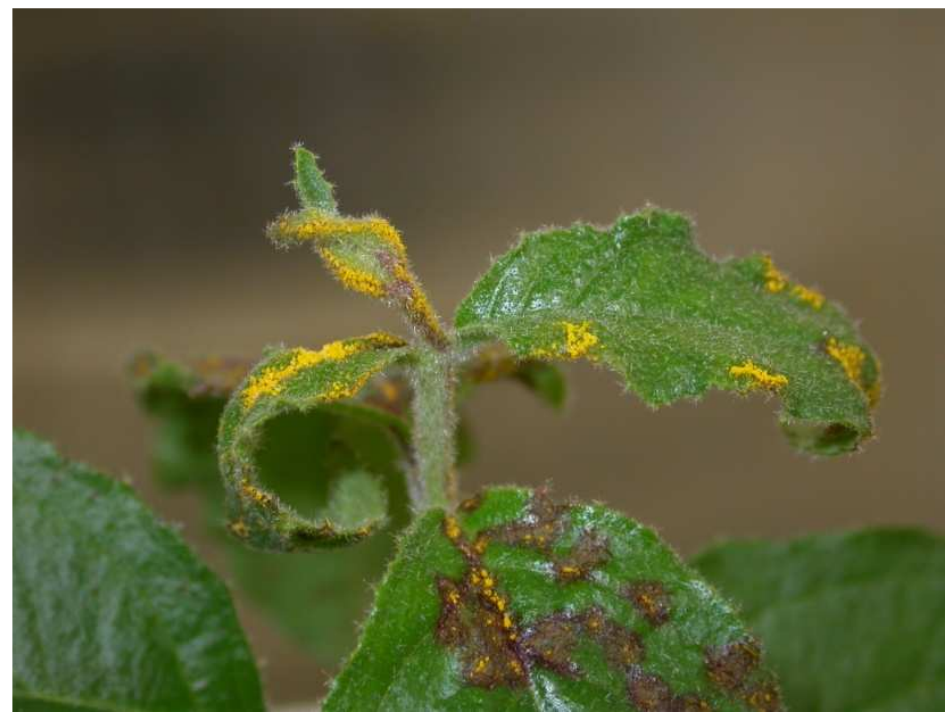

Eucalyptus agglomerata

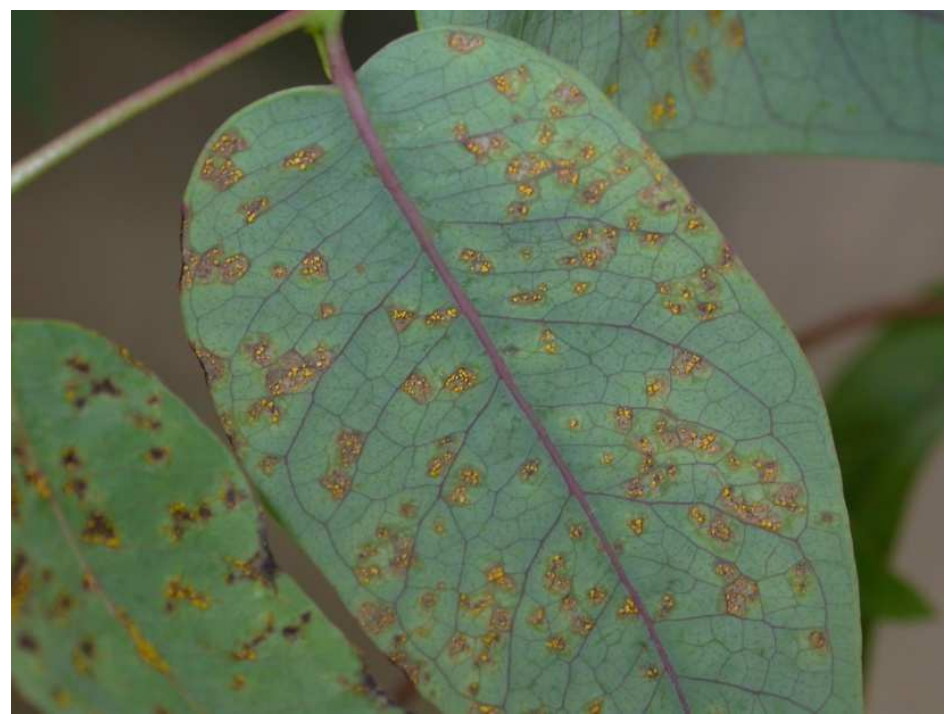

Eucalyptus campanulata

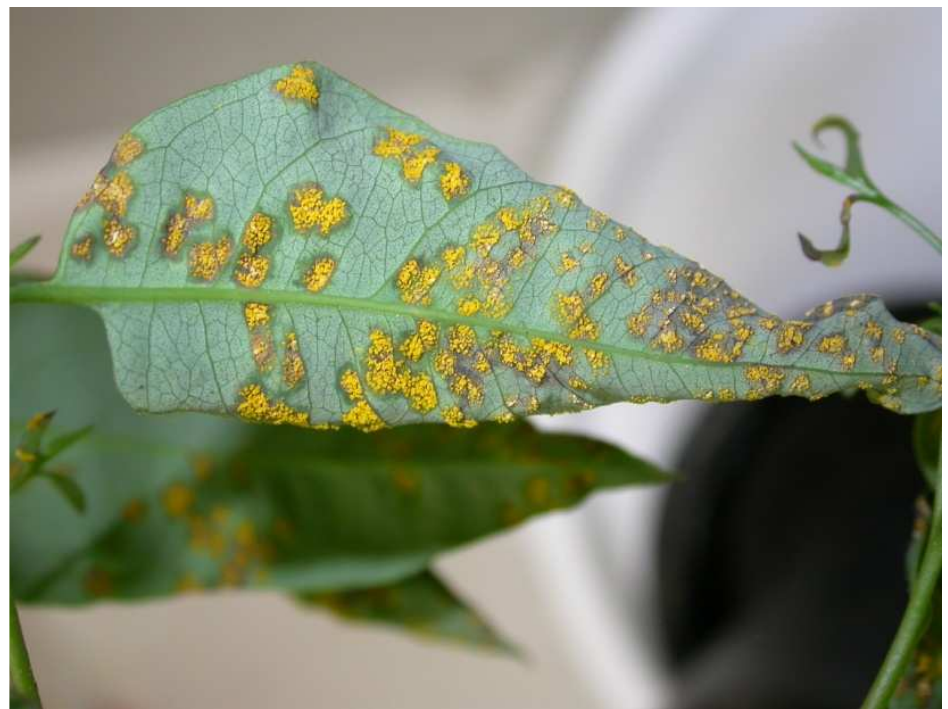

Eucalyptus cloeziana

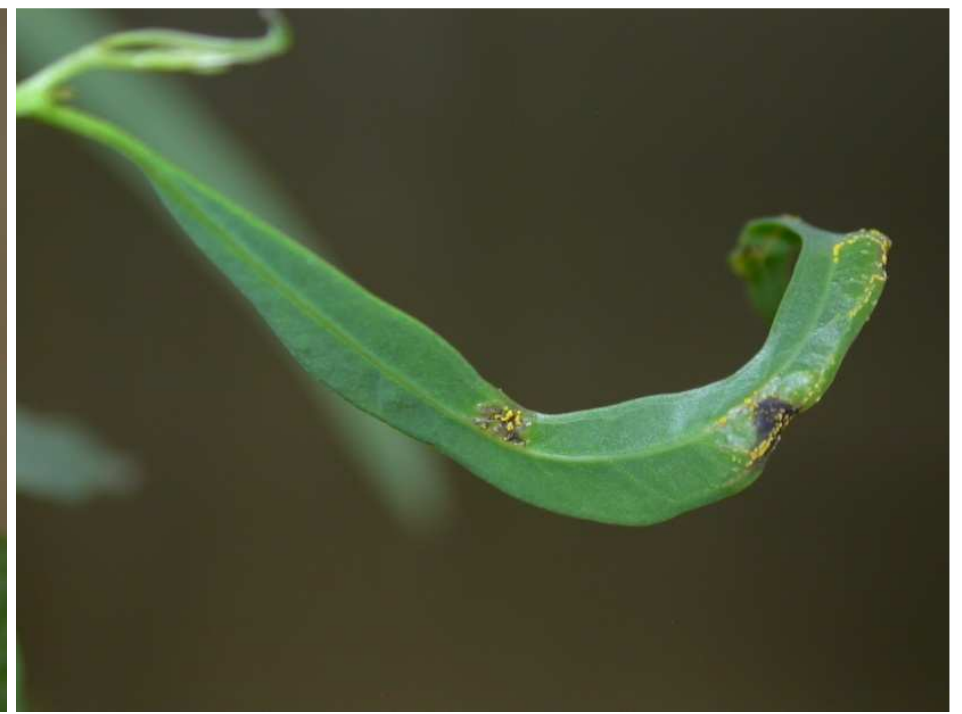

Eucalyptus argophloia

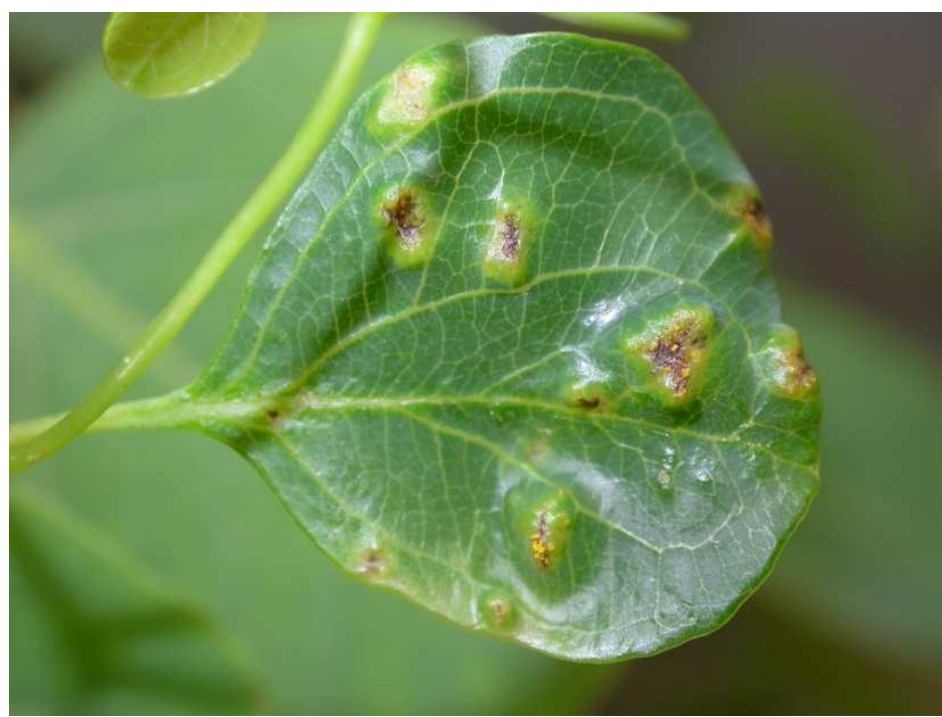

Eucalyptus cladocalyx

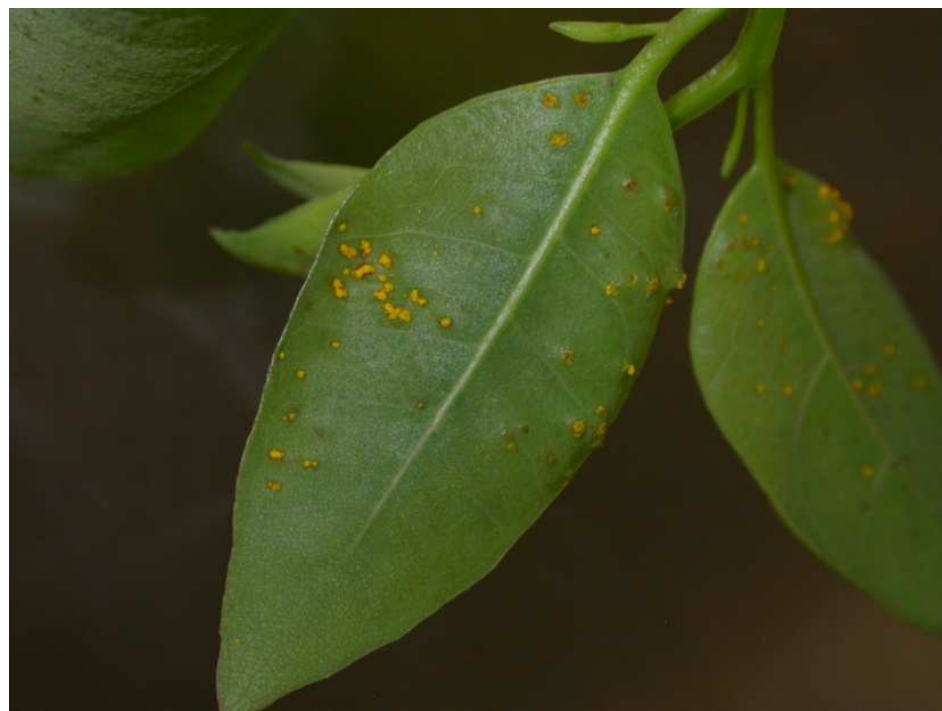

Eucalyptus diversicolor 


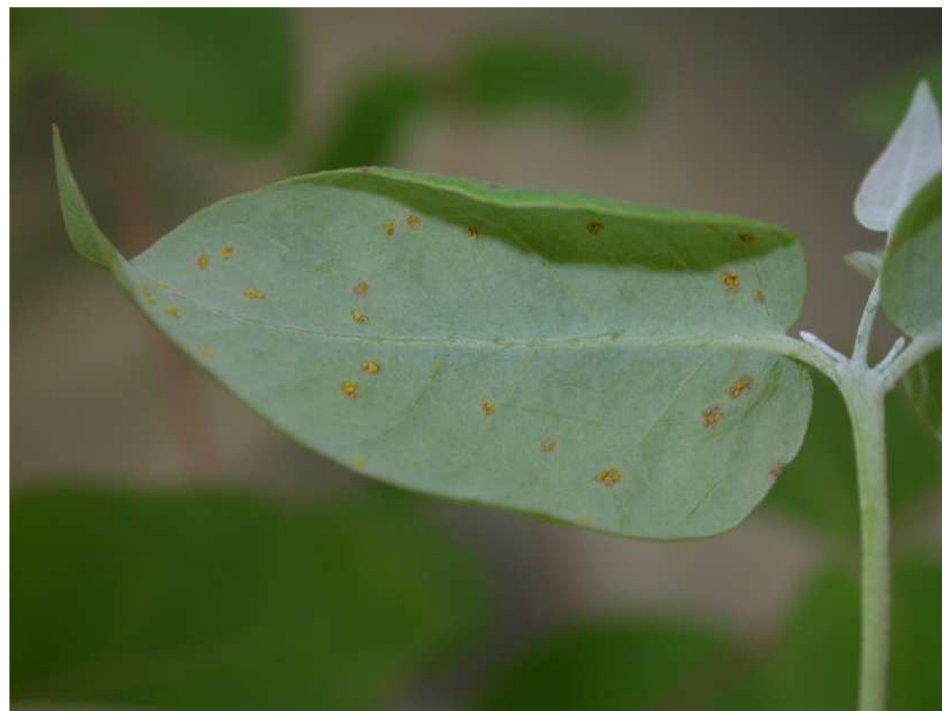

Eucalyptus dunnii

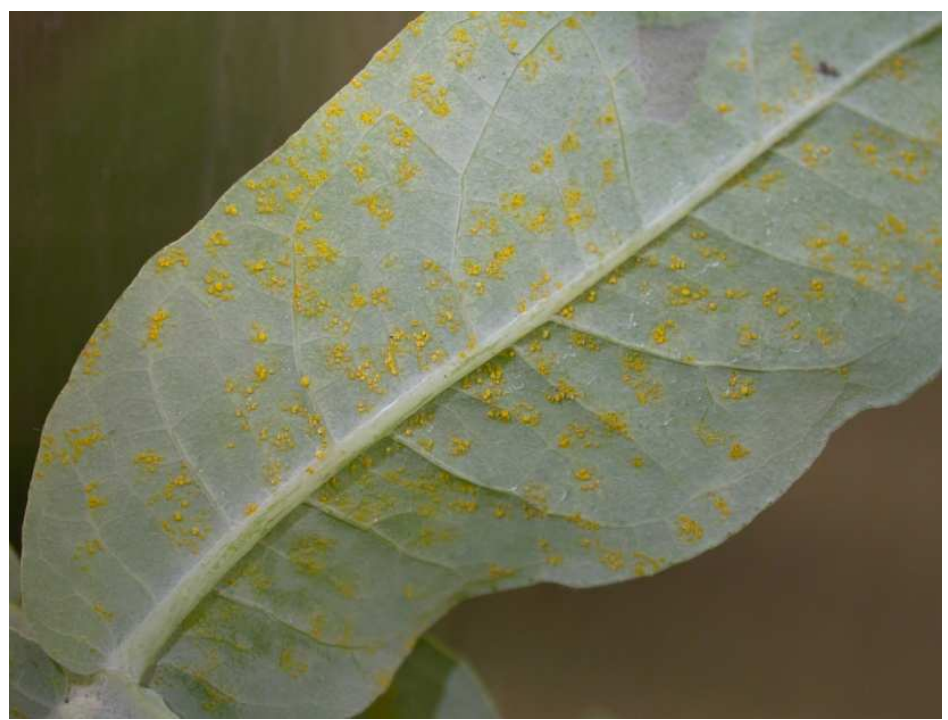

Eucalyptus globulus subsp. globulus

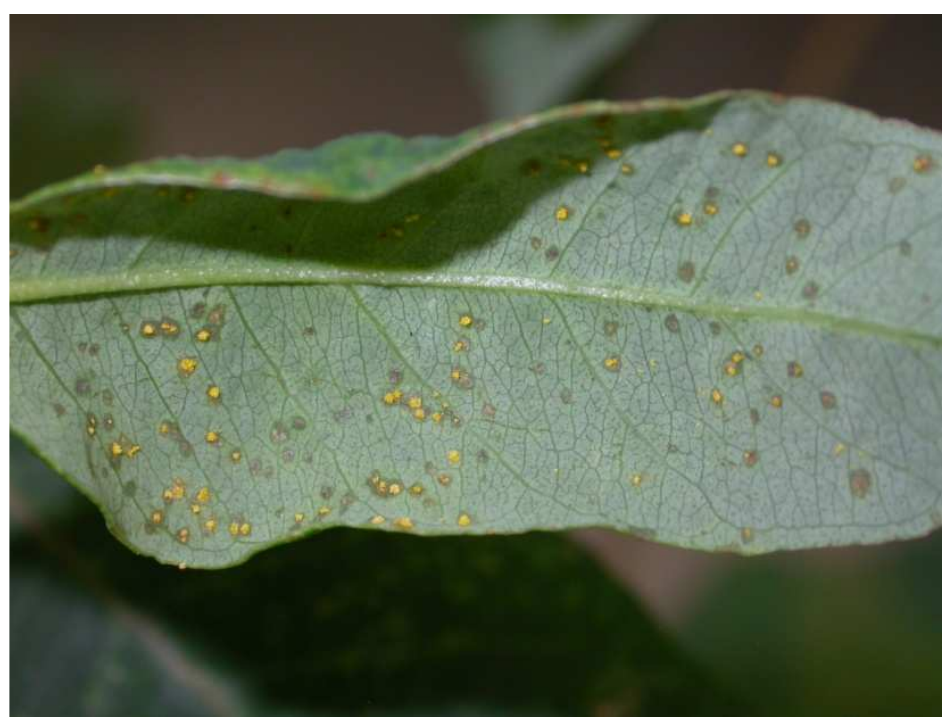

Eucalyptus grandis

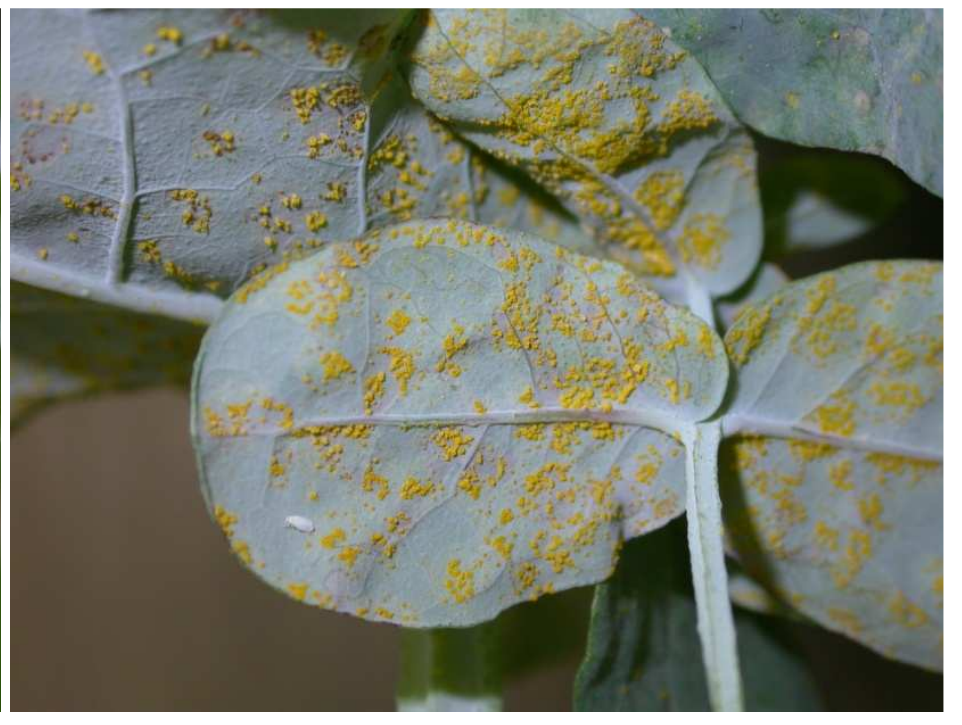

Eucalyptus globulus subsp. bicostata

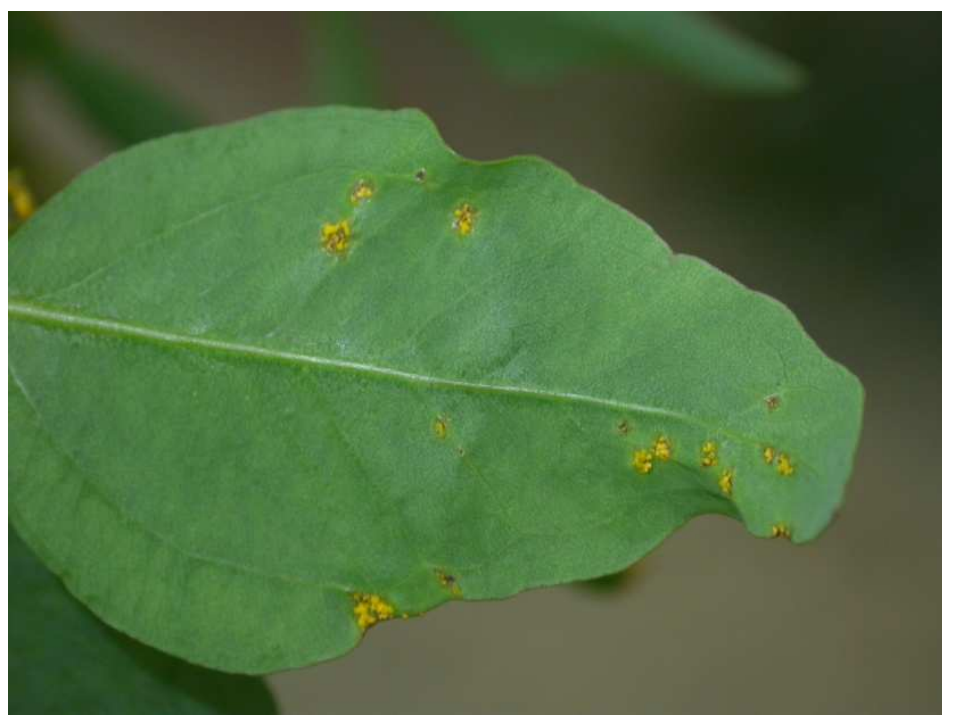

Eucalyptus gomphocephala

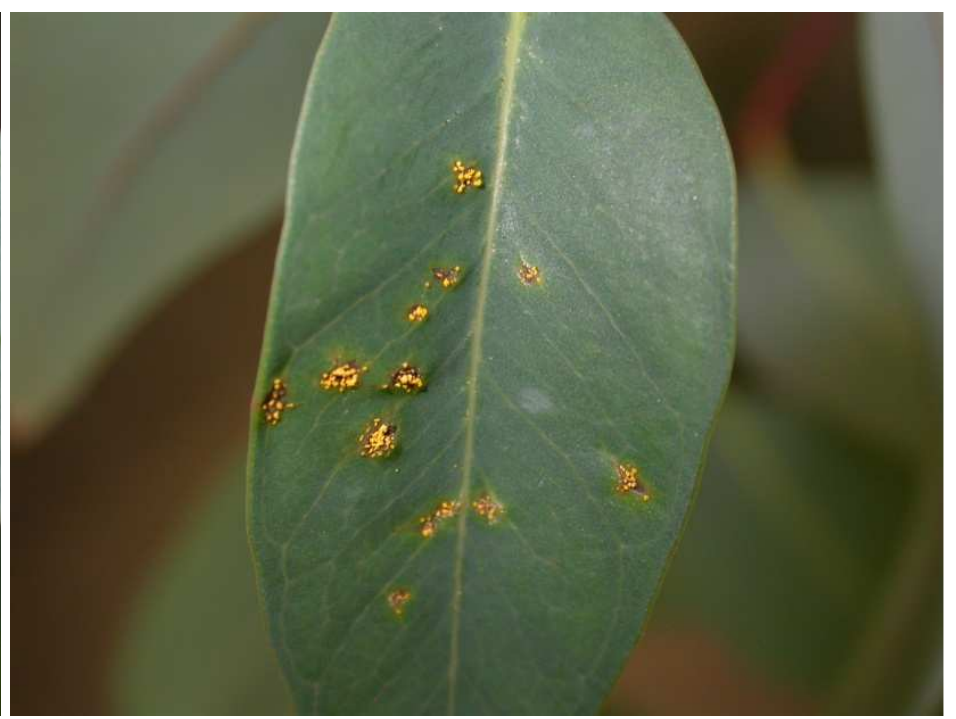

Eucalyptus haemastoma 


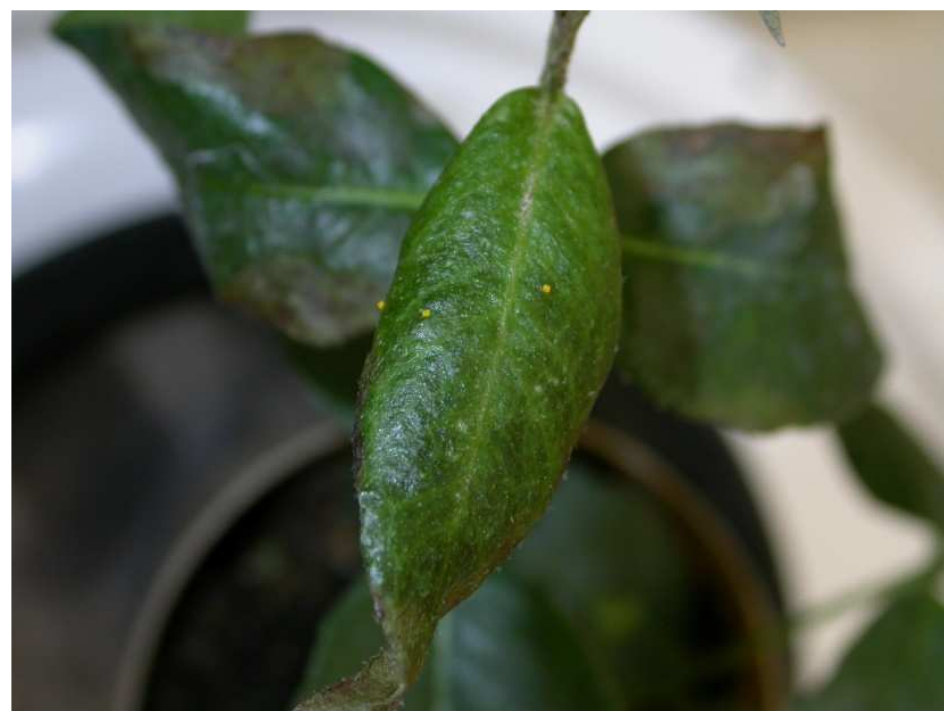

Eucalyptus laevopinea

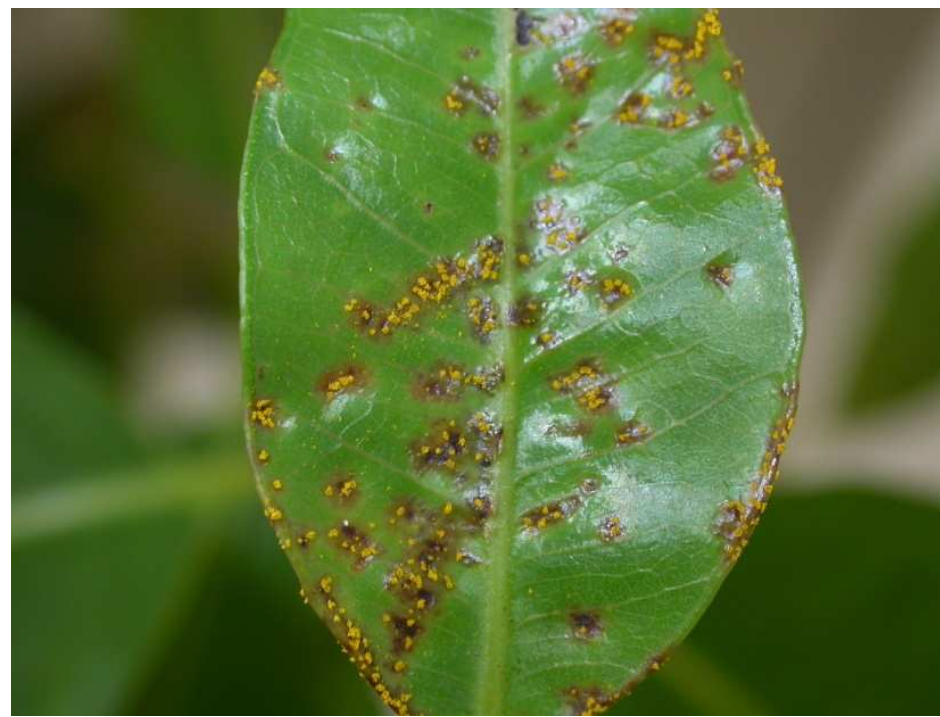

Eucalyptus marginata subsp. marginata

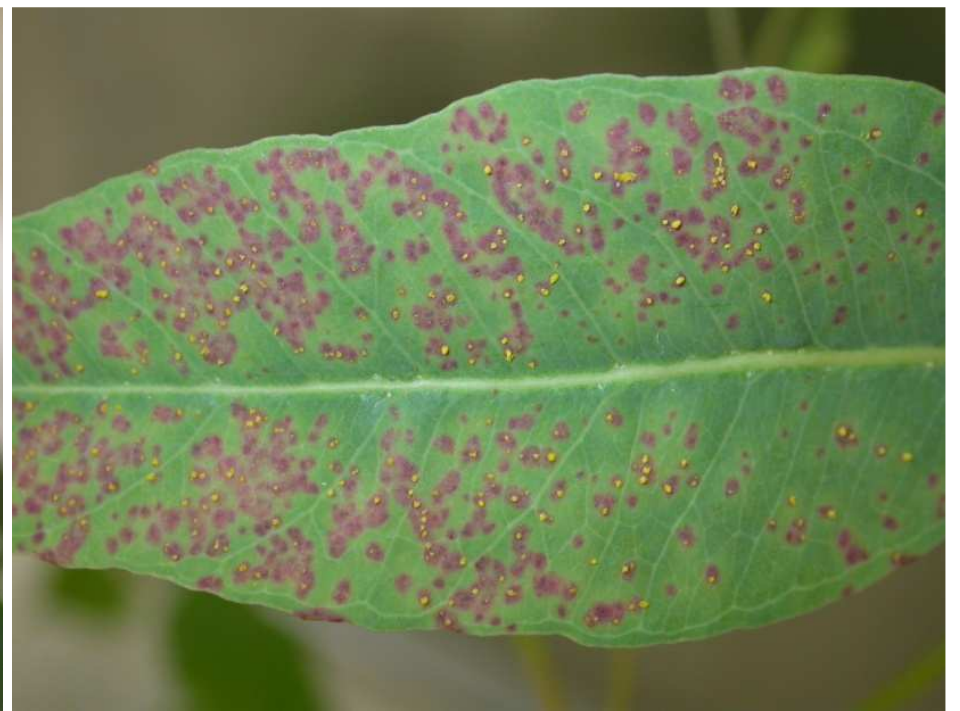

Eucalyptus longirostrata

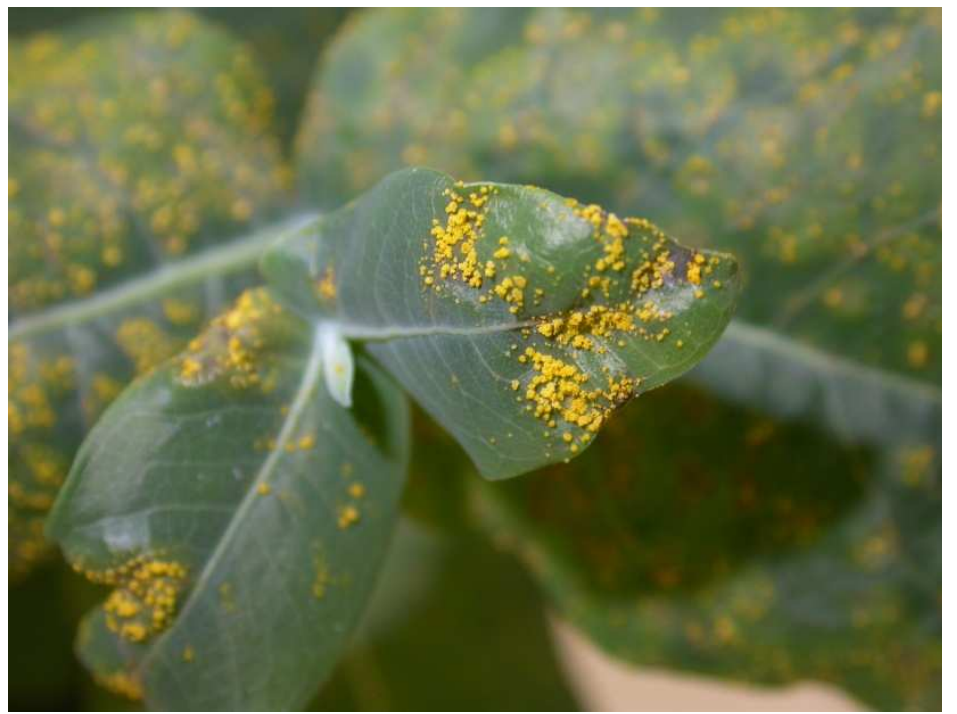

Eucalyptus nitens

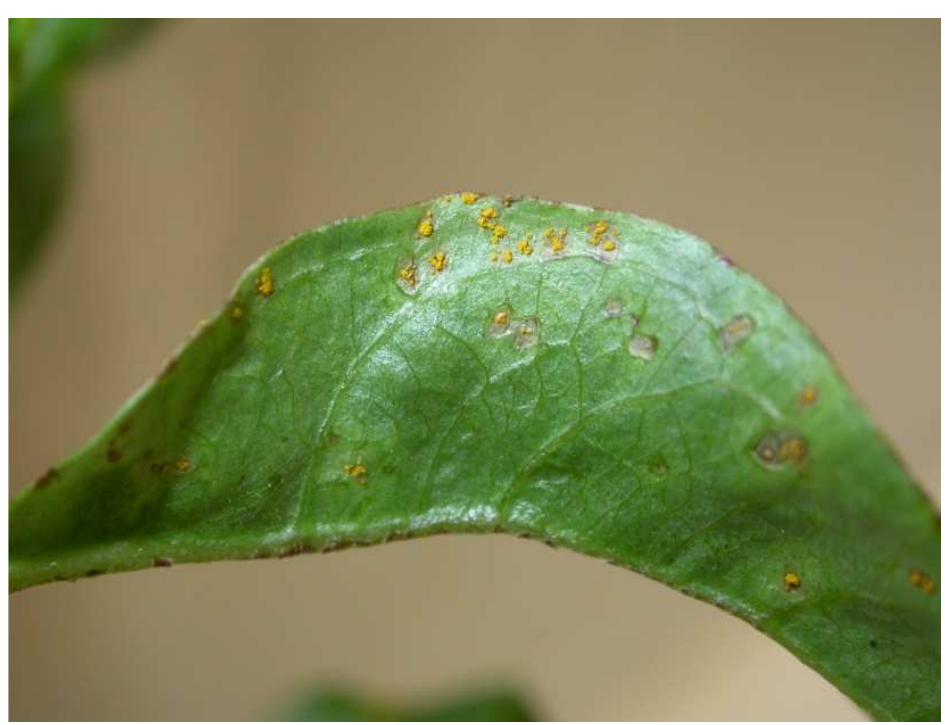

Eucalyptus obliqua

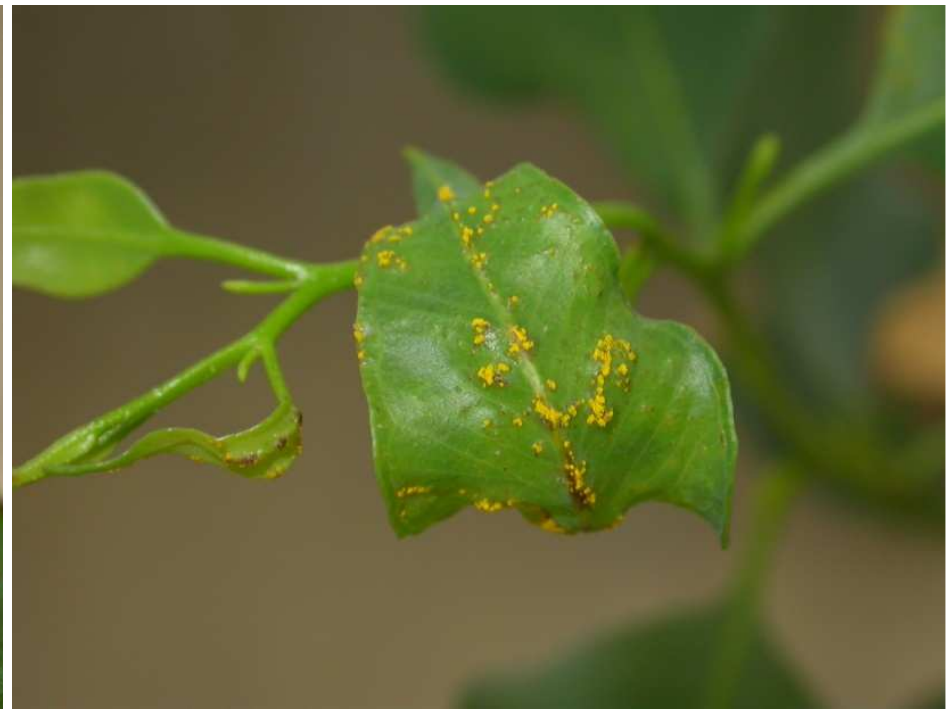

Eucalyptus occidentalis 


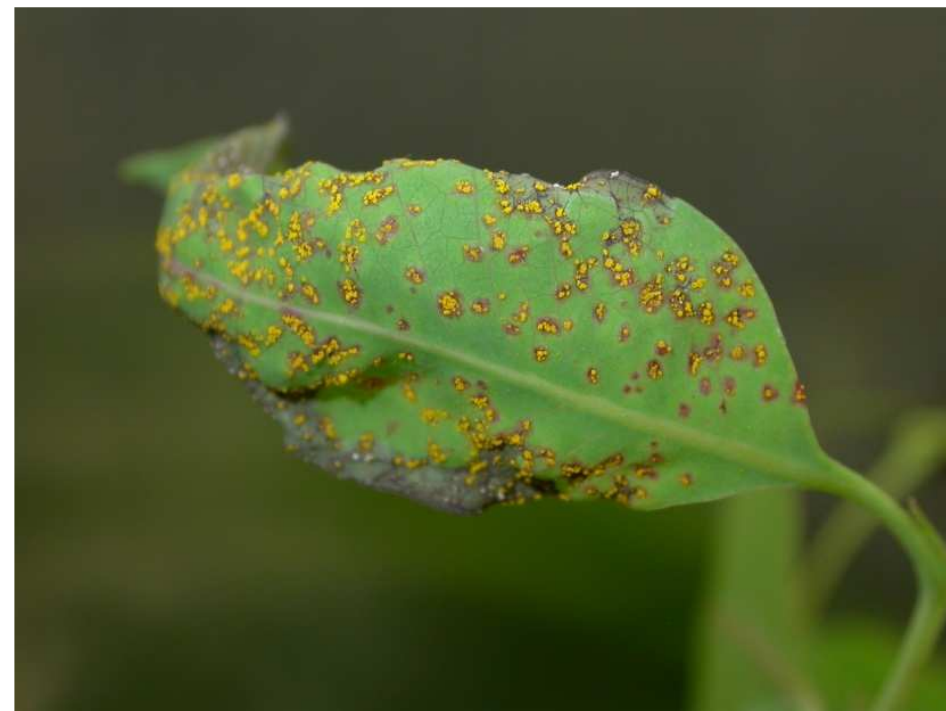

Eucalyptus olida

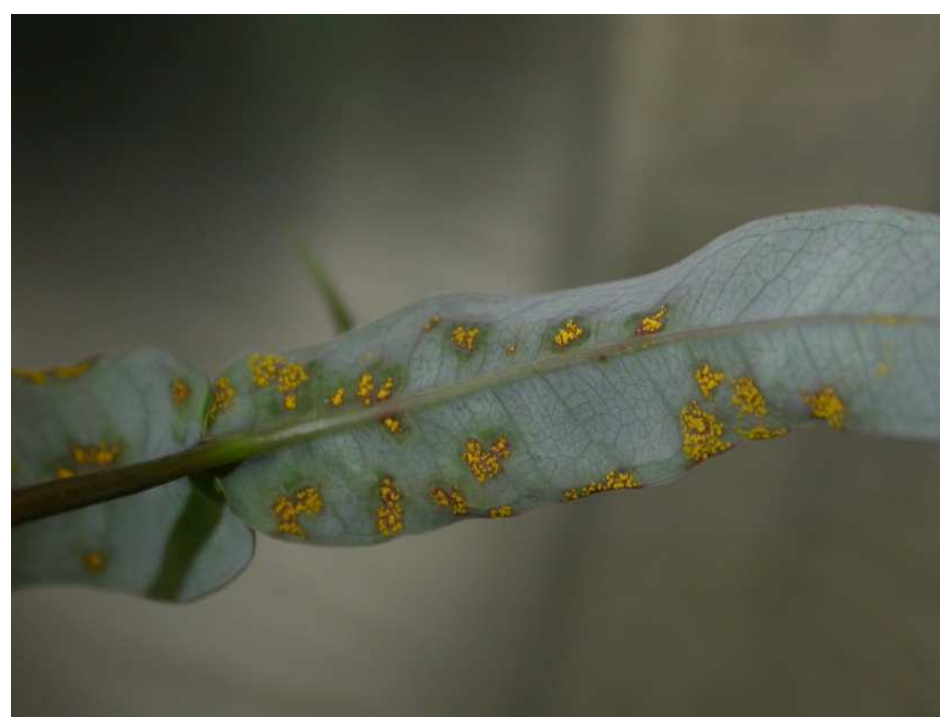

Eucalyptus pilularis

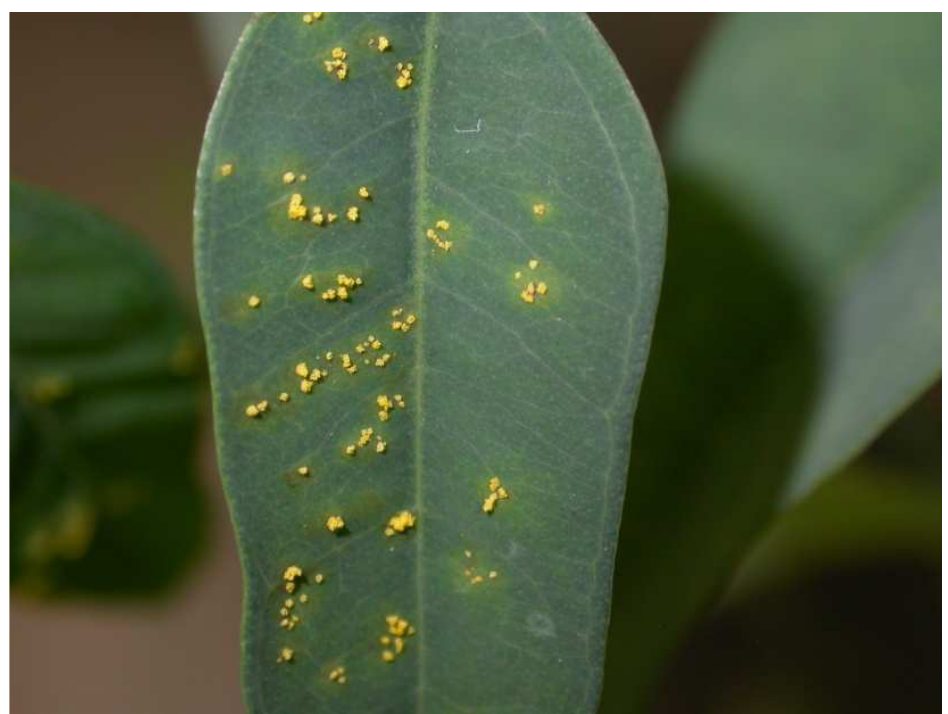

Eucalyptus punctata

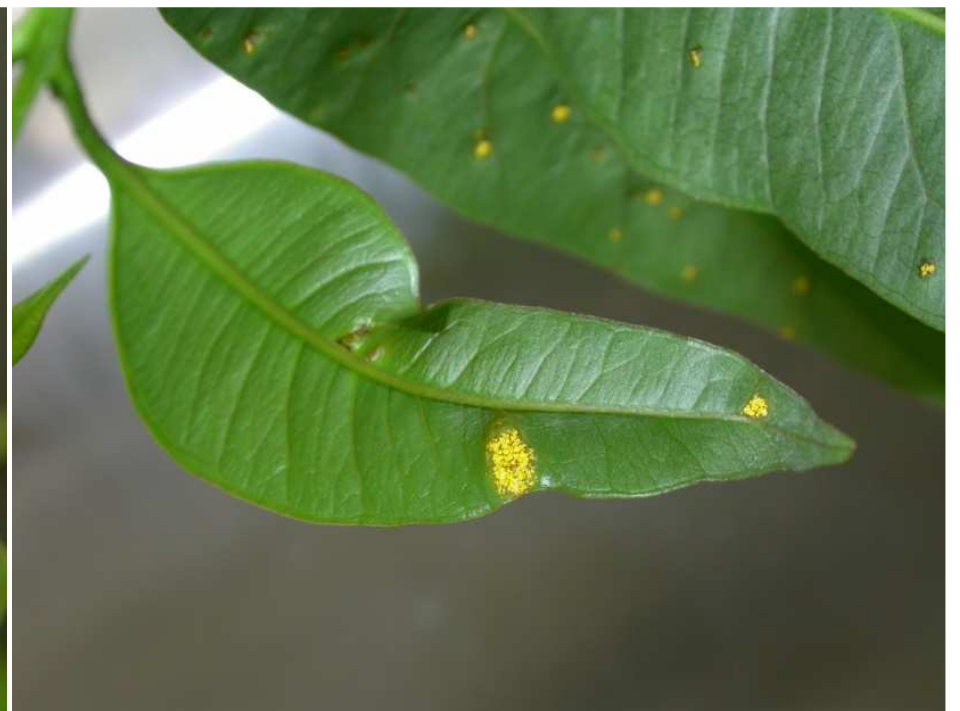

Eucalyptus pellita

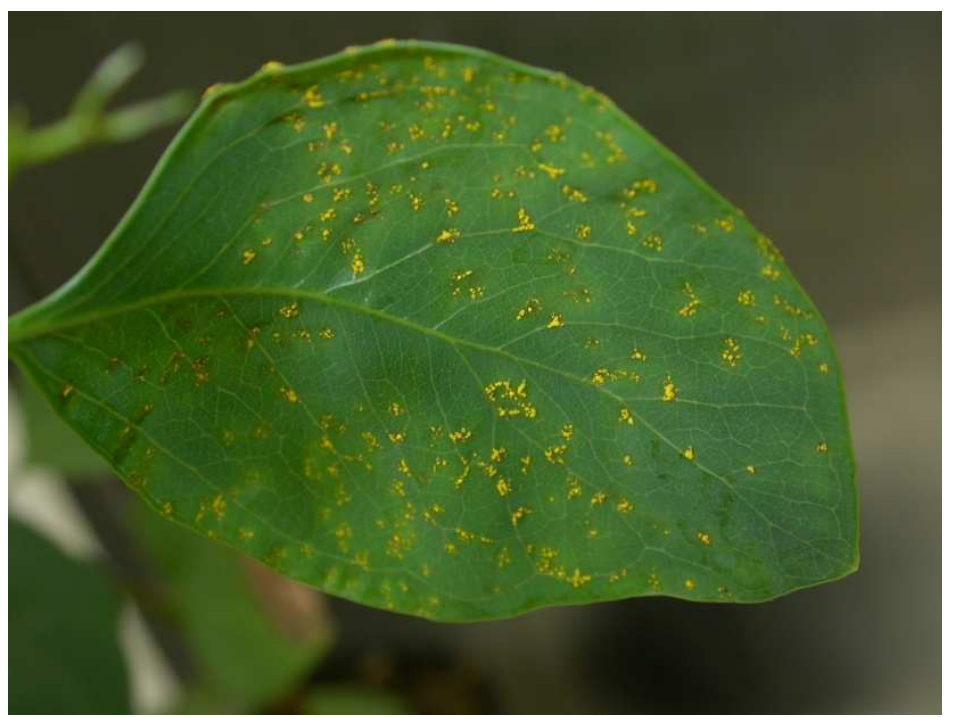

Eucalyptus populnea

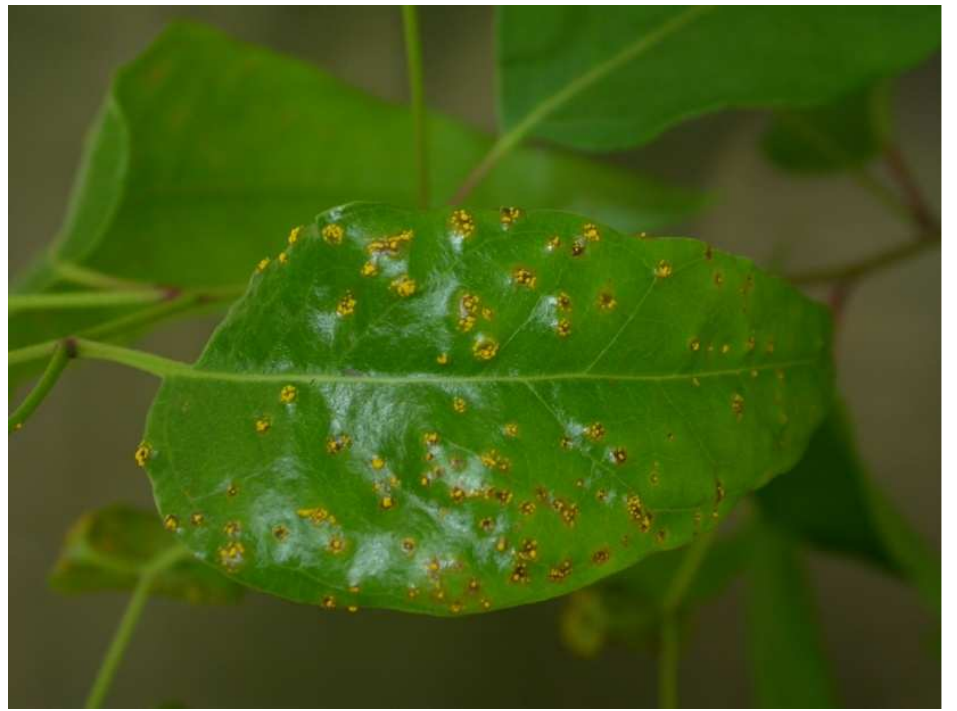

Eucalyptus regnans 

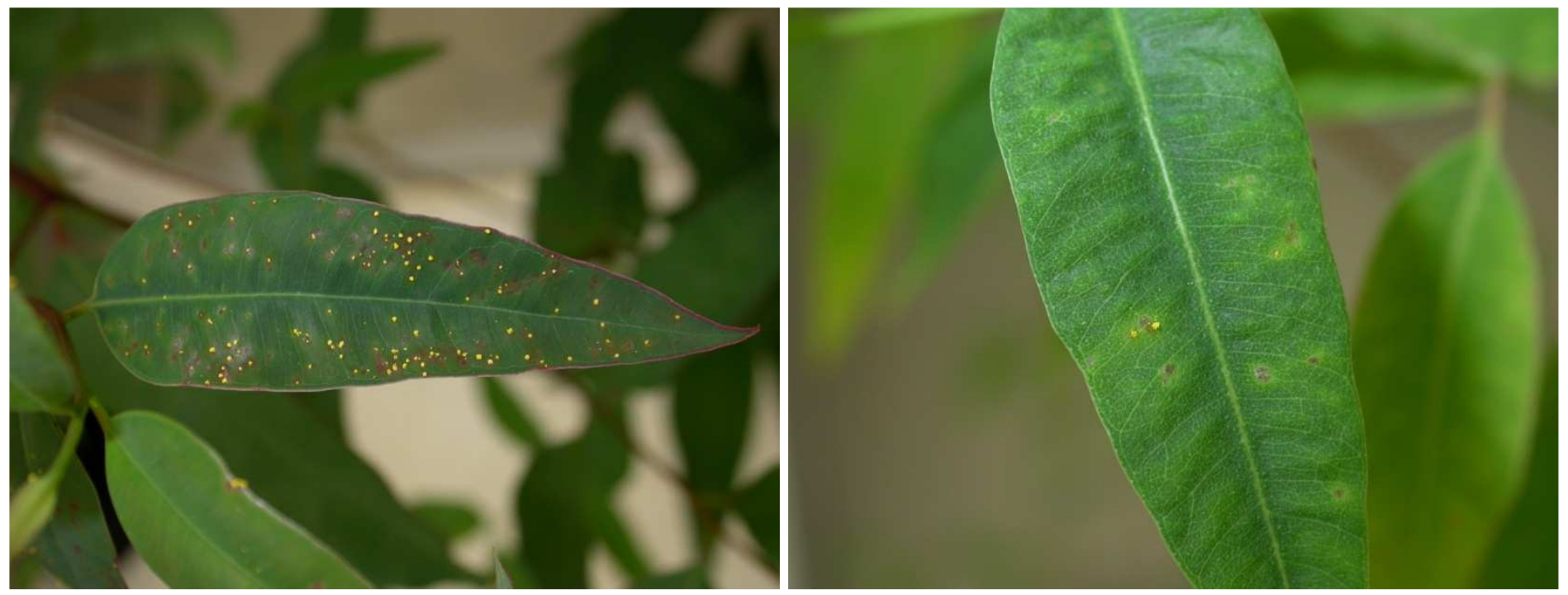

Eucalyptus resinifera subsp. hemilampra

Eucalyptus saligna

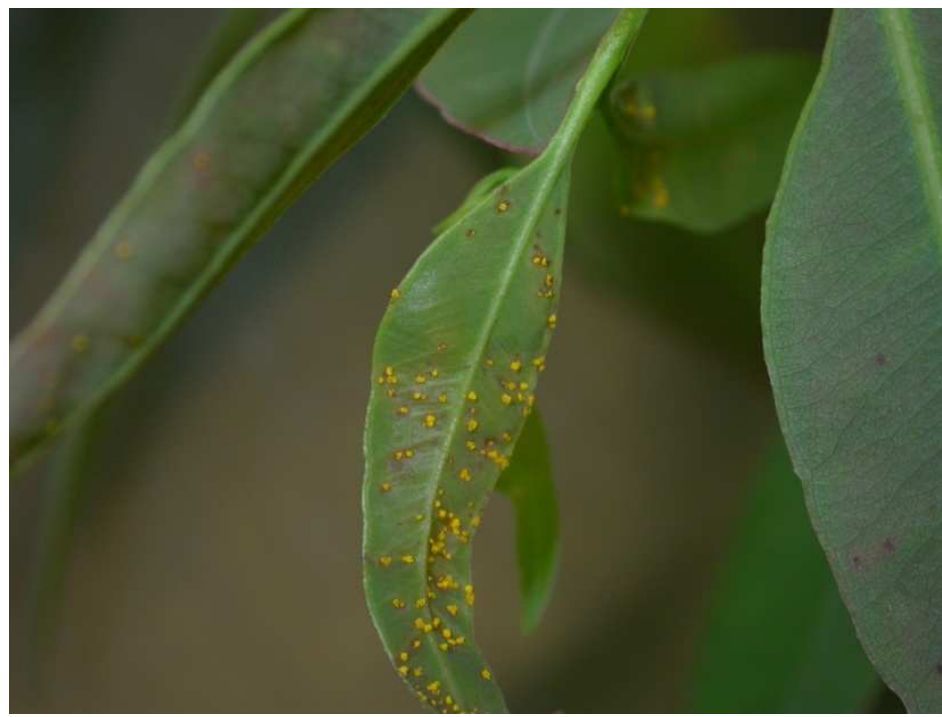

Eucalyptus siderophloia

Eucalyptus smithii

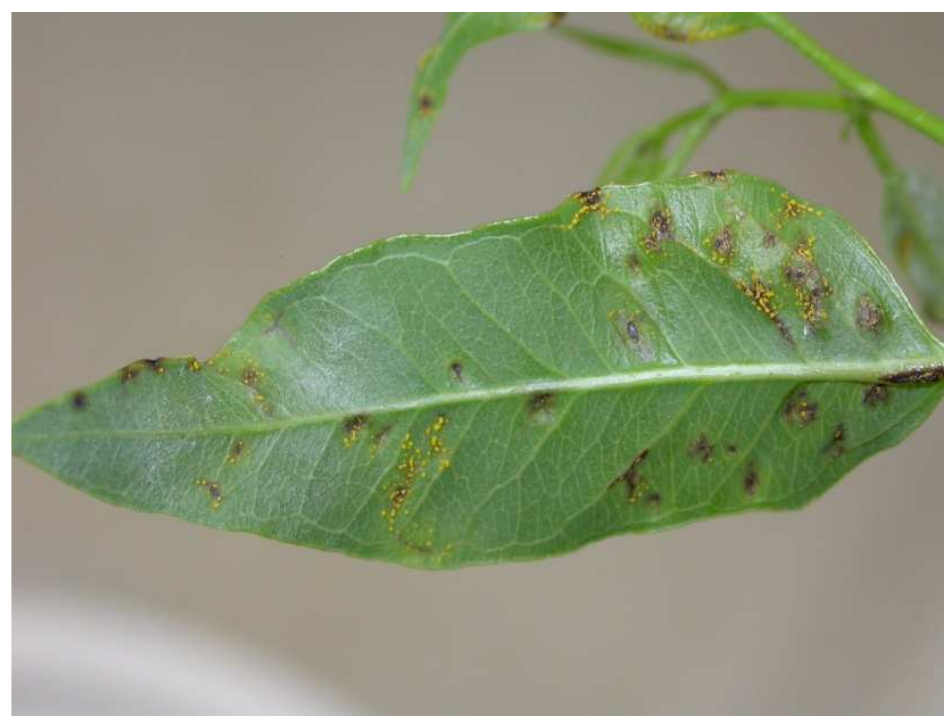

Eucalyptus tereticornis
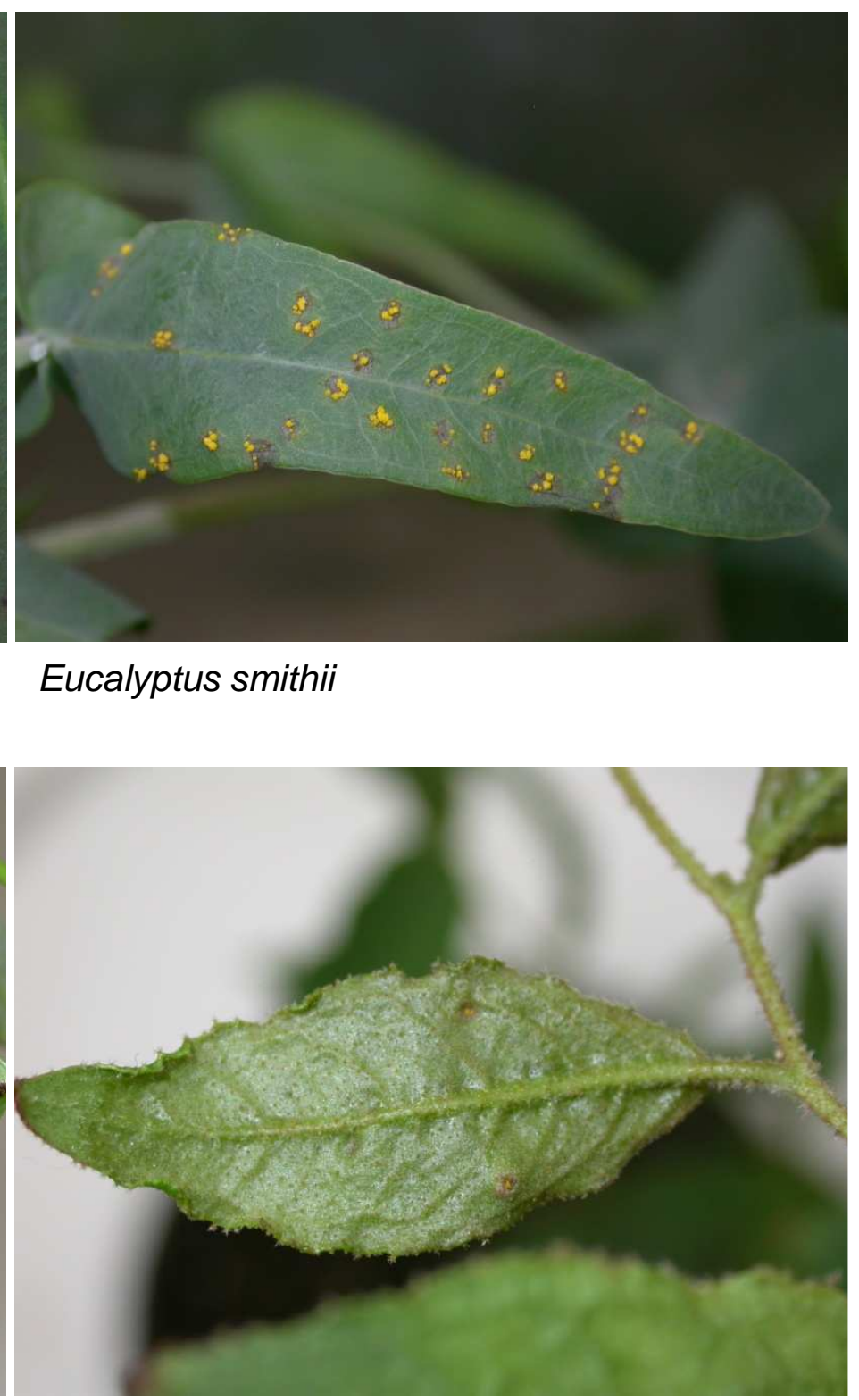

Eucalyptus tindaliae 


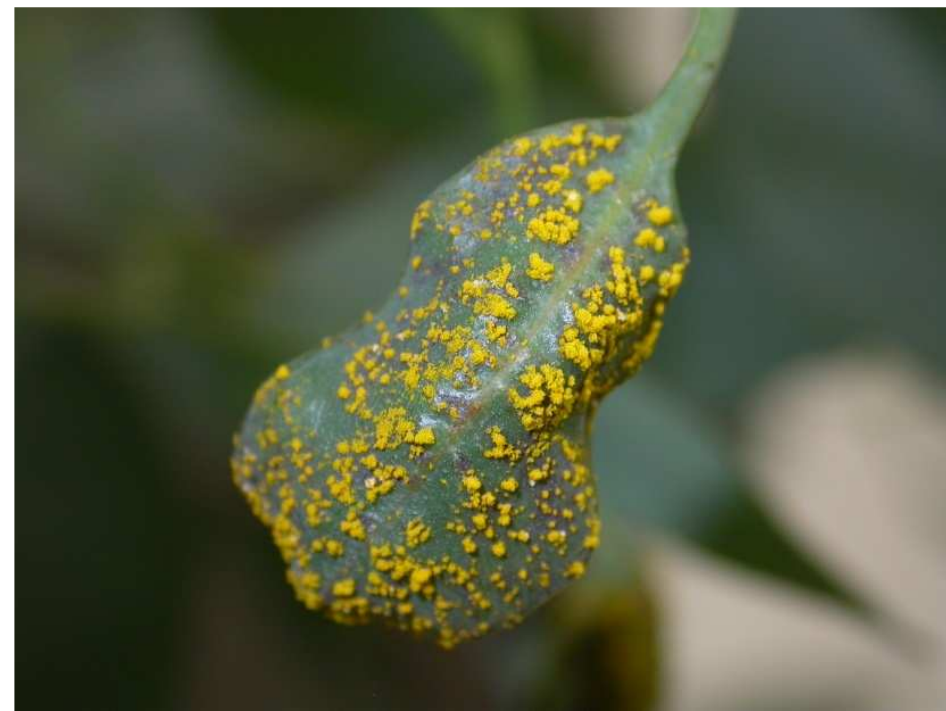

Eucalyptus wandoo subsp. wandoo

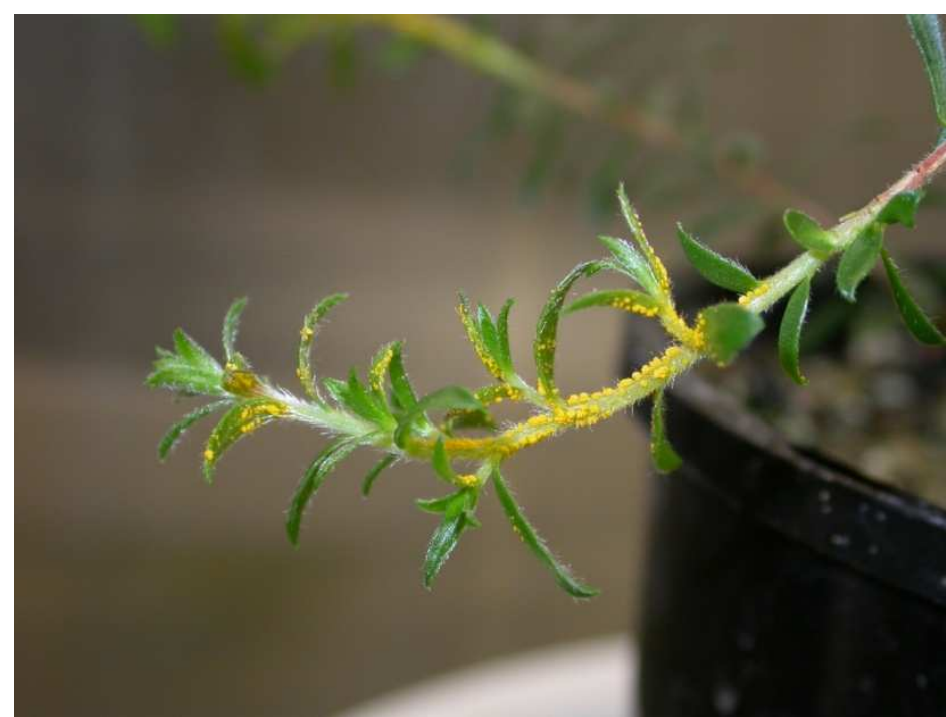

Kunzea ambigua hybrid

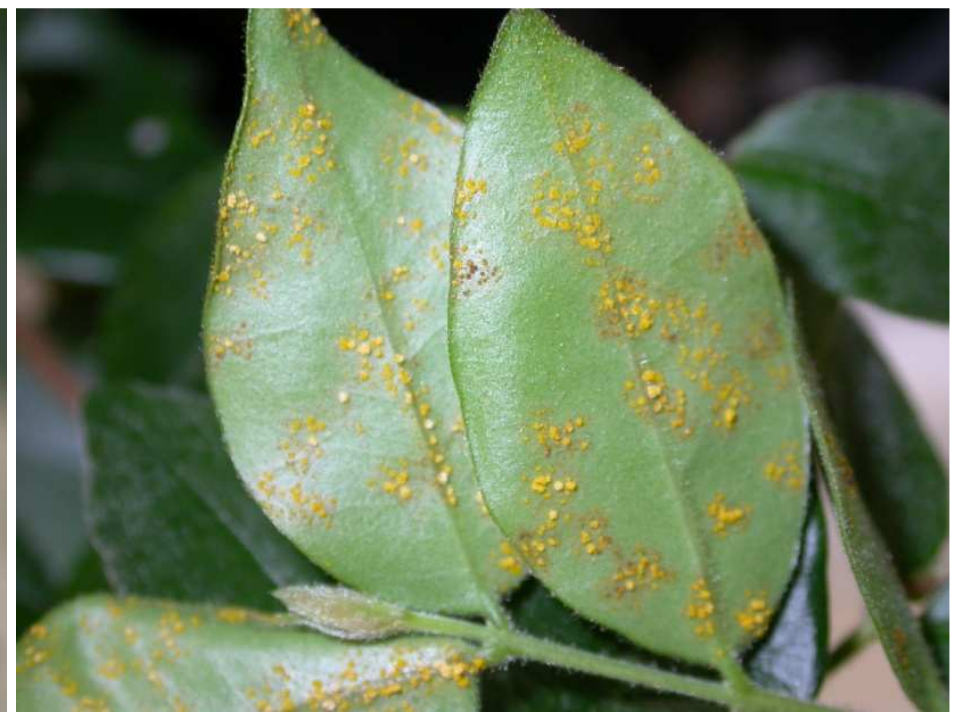

Gossia inophloia

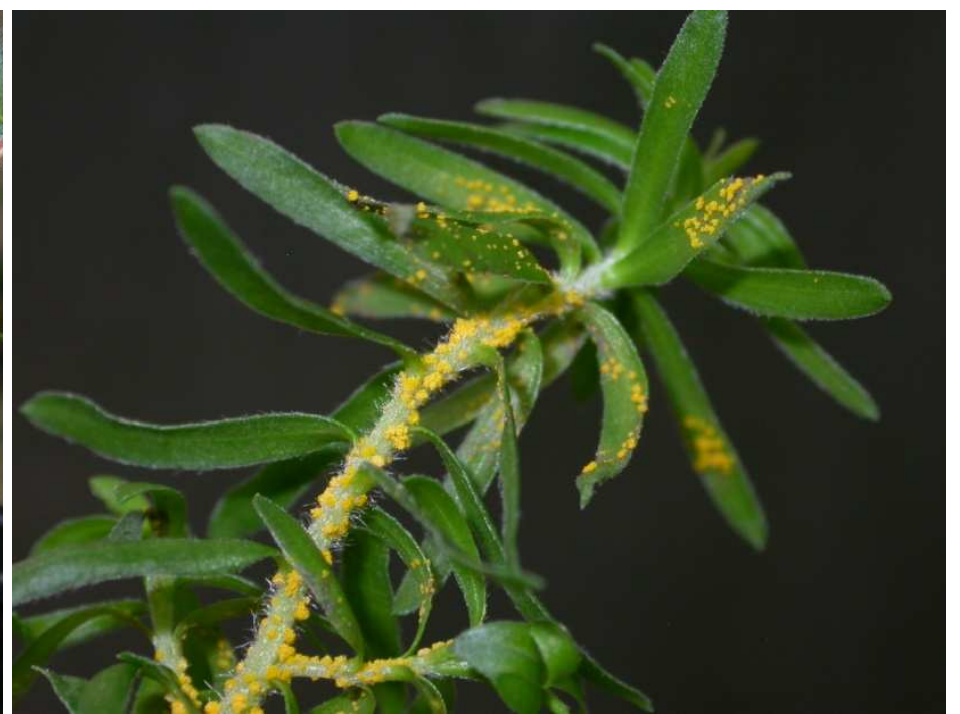

Kunzea baxteri
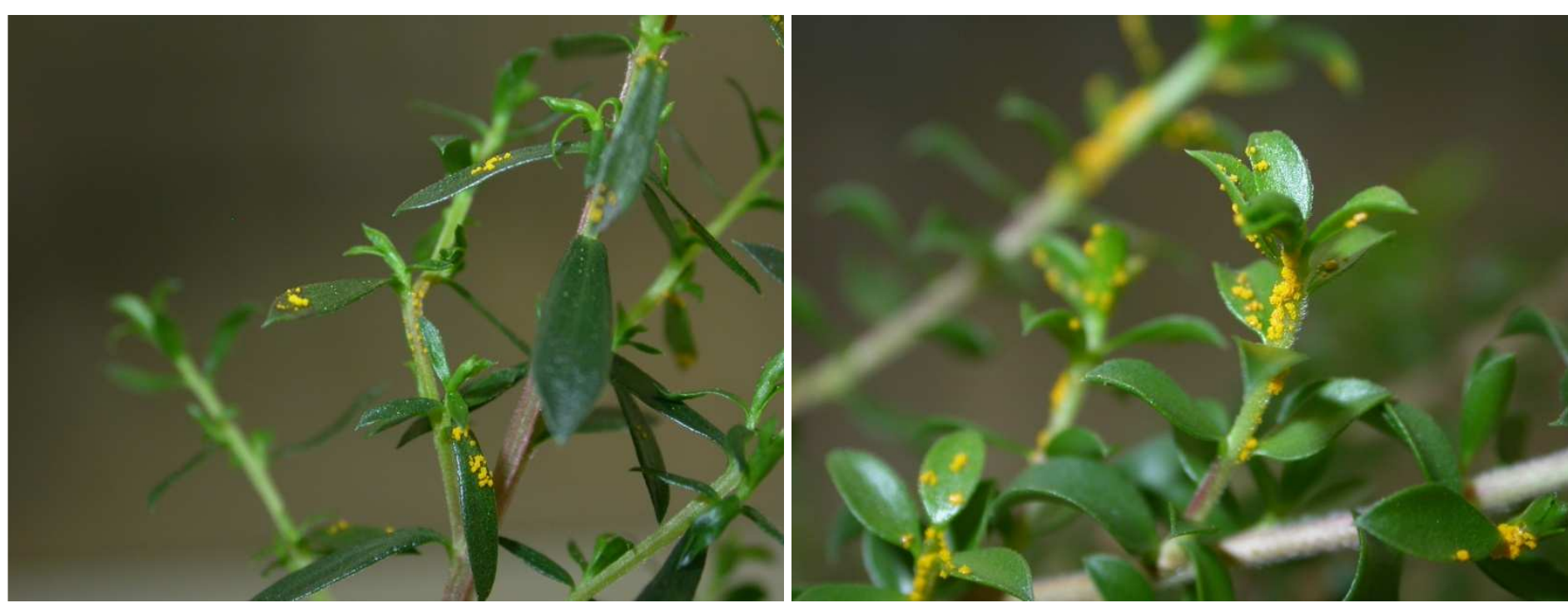

Kunzea pomifera 


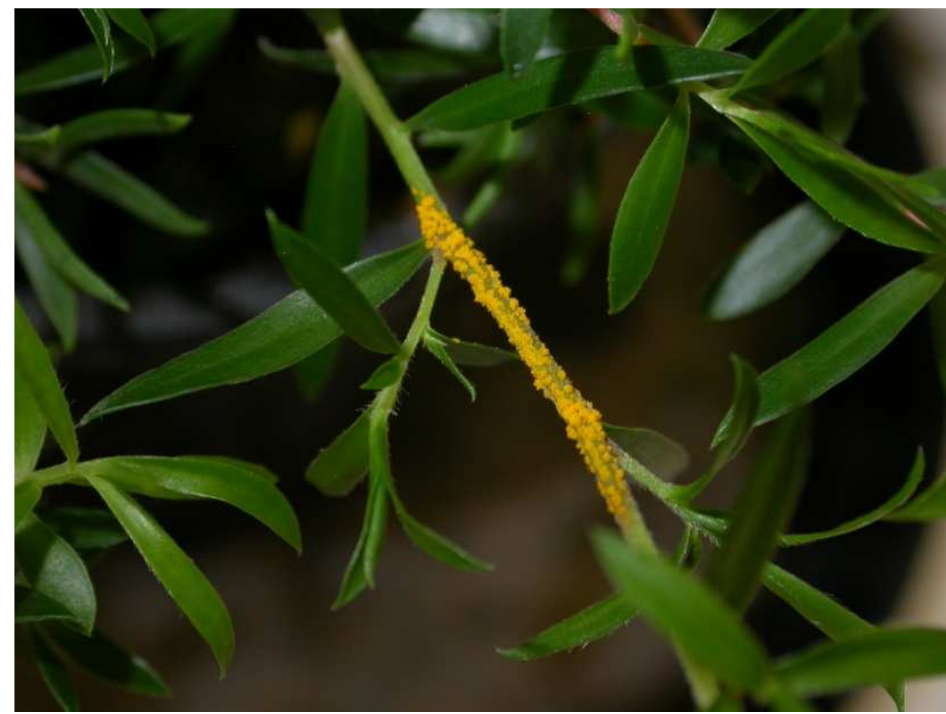

Leptospermum 'Day Dream'

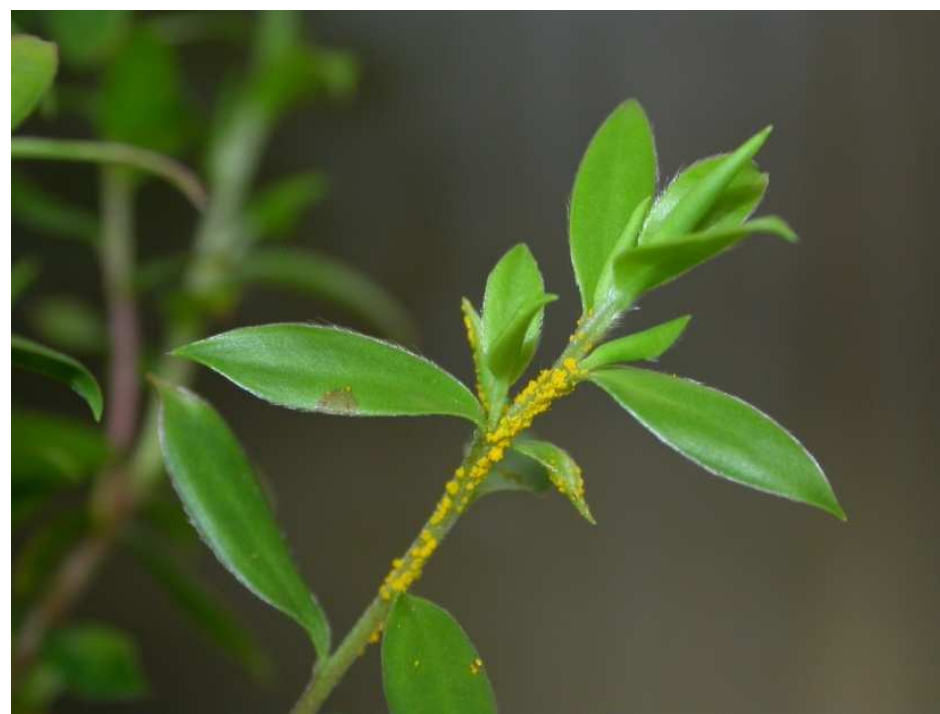

Leptospermum 'Lipstick'

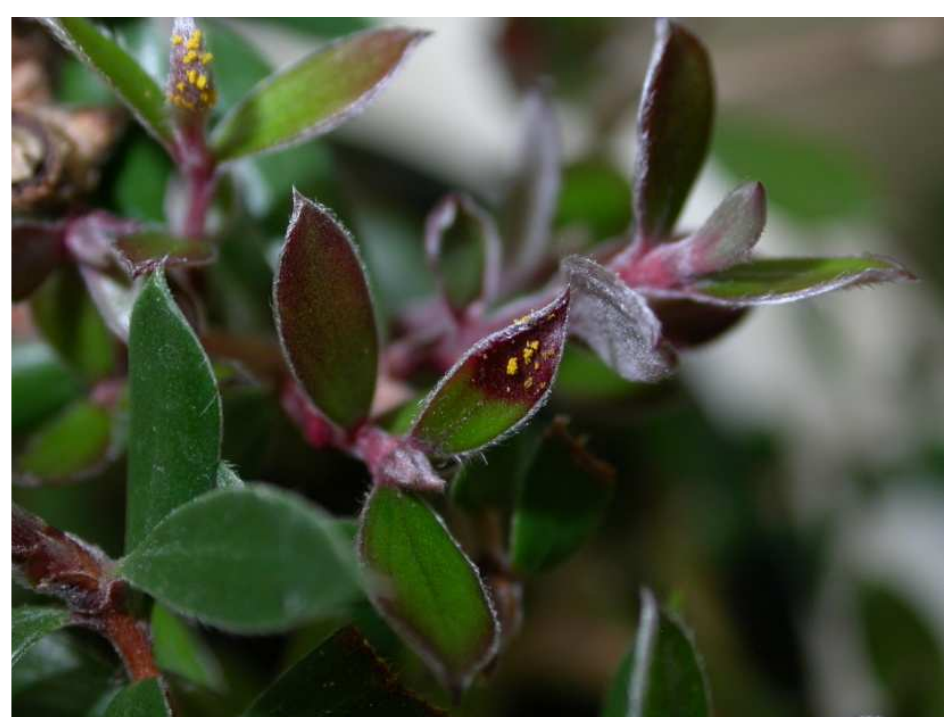

Leptospermum 'Mesmer Eyes'

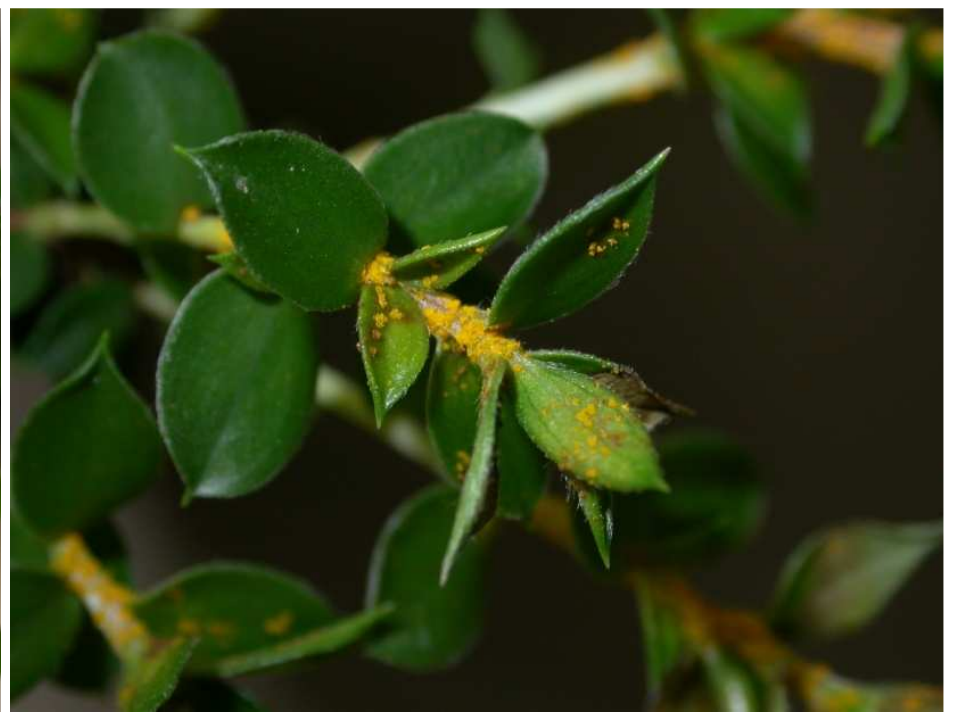

Leptospermum continentale 'Horizontalis'

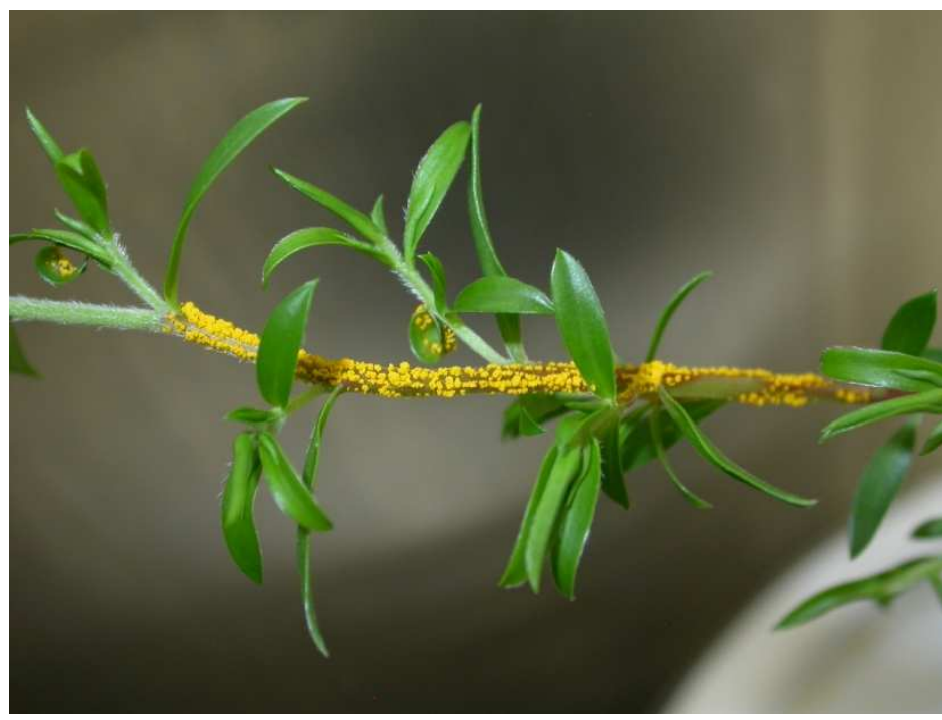

Leptospermum 'Love Affair'

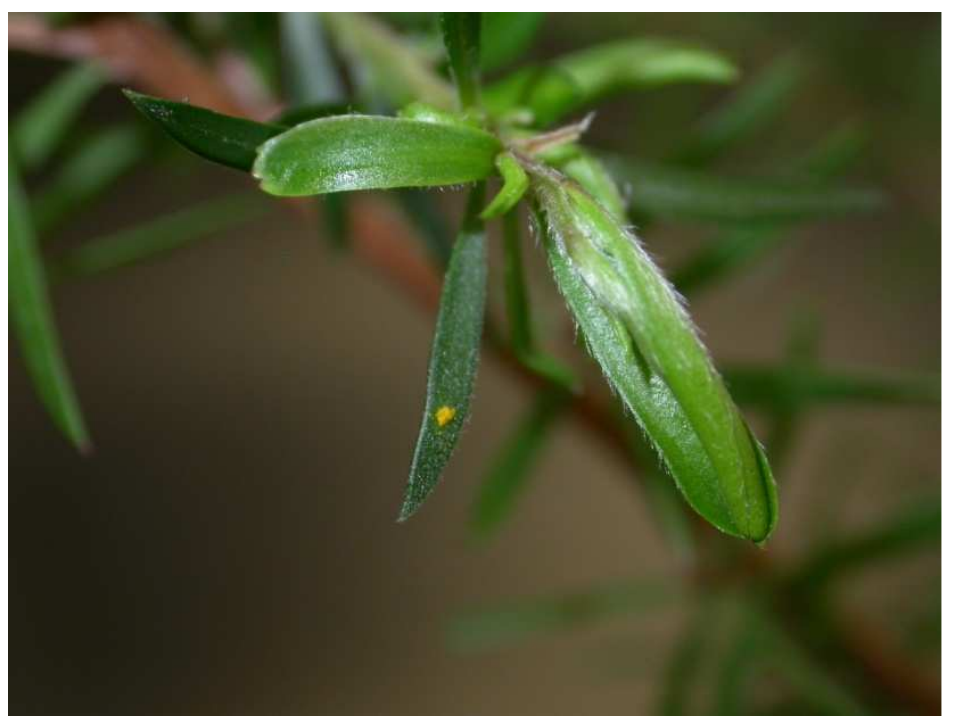

Leptospermum 'Pink Cascade' 


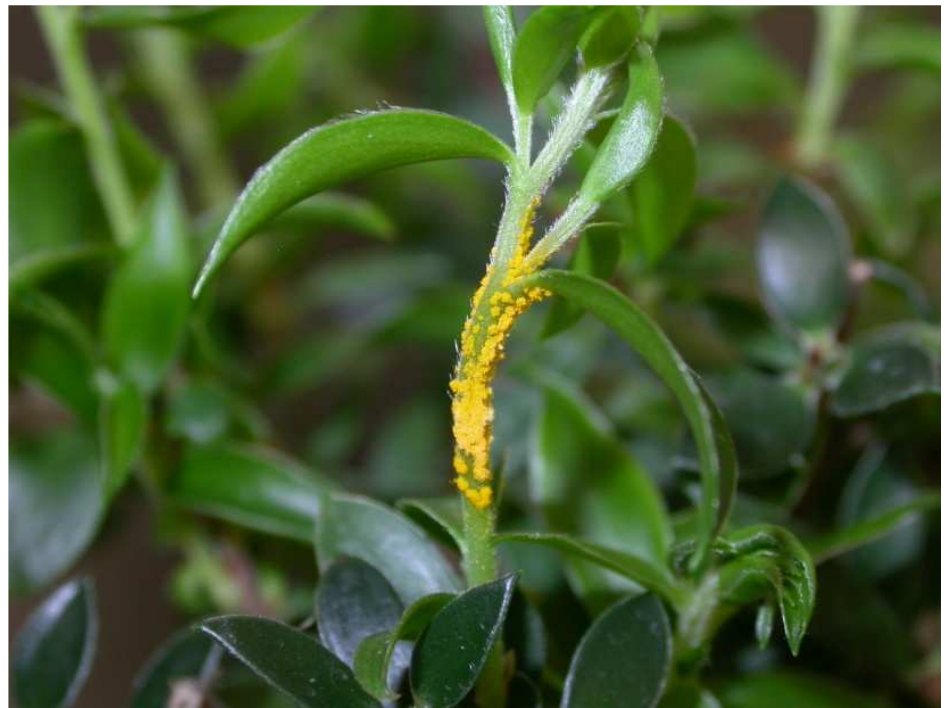

Leptospermum 'Rhiannon'

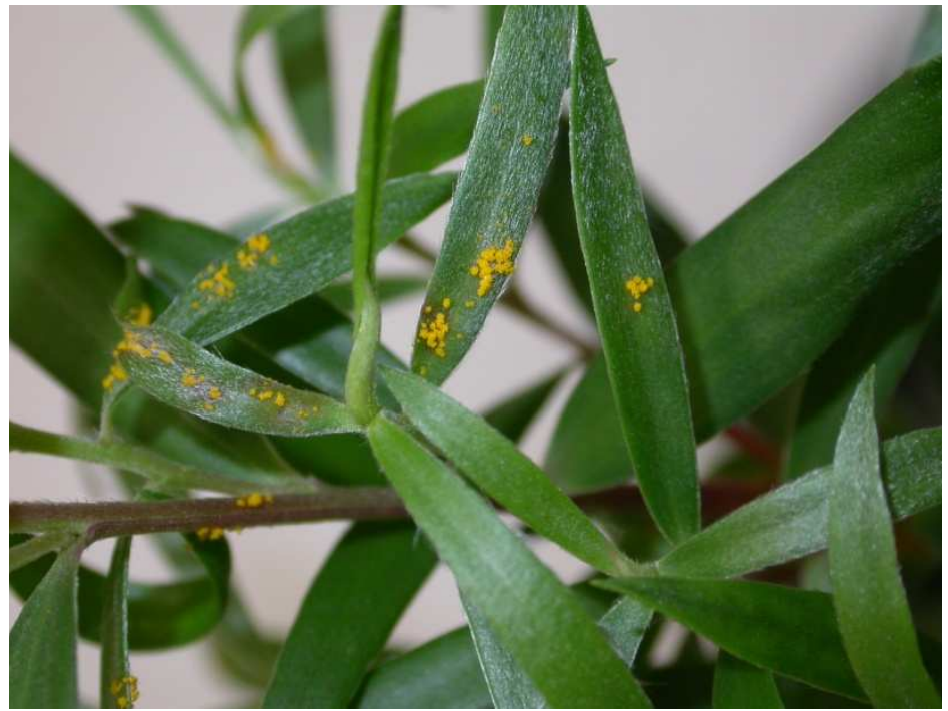

Leptospermum 'Rudolph'

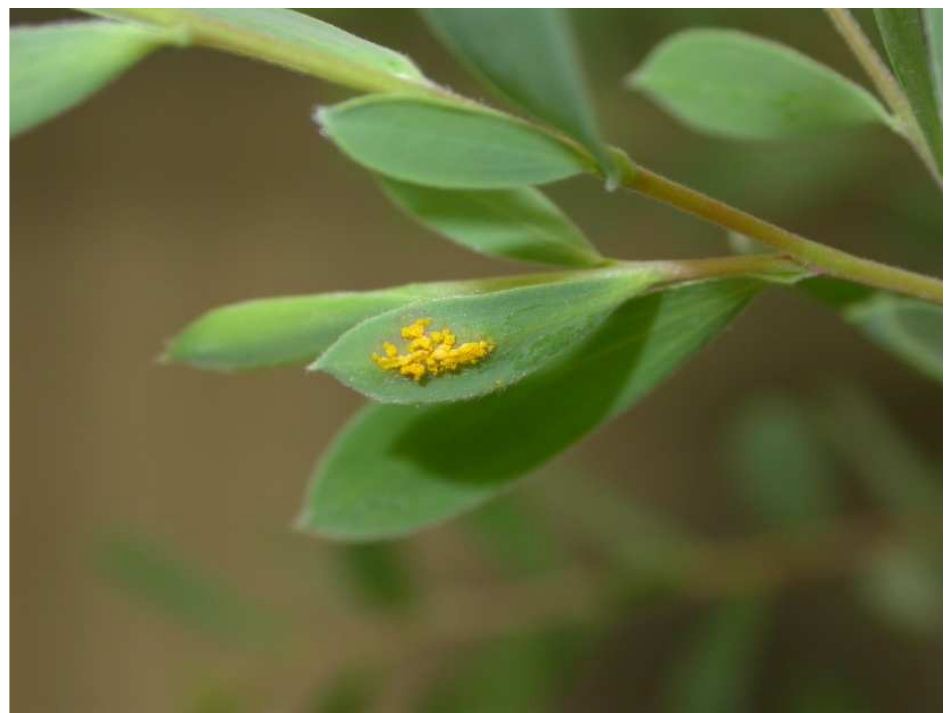

Leptospermum laevigatum

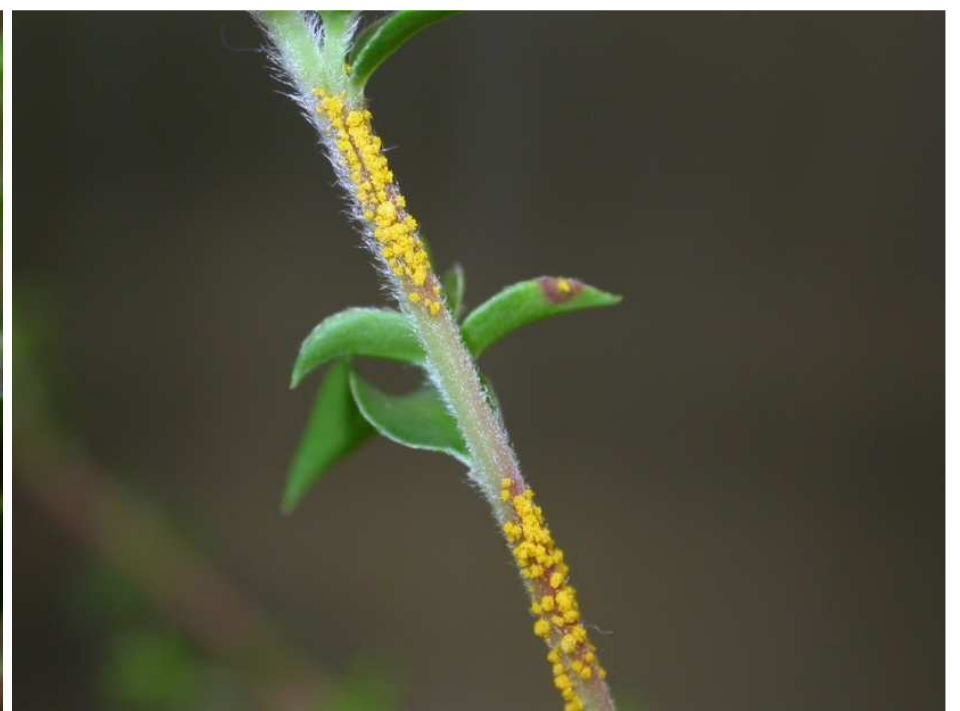

Leptospermum 'Riot'

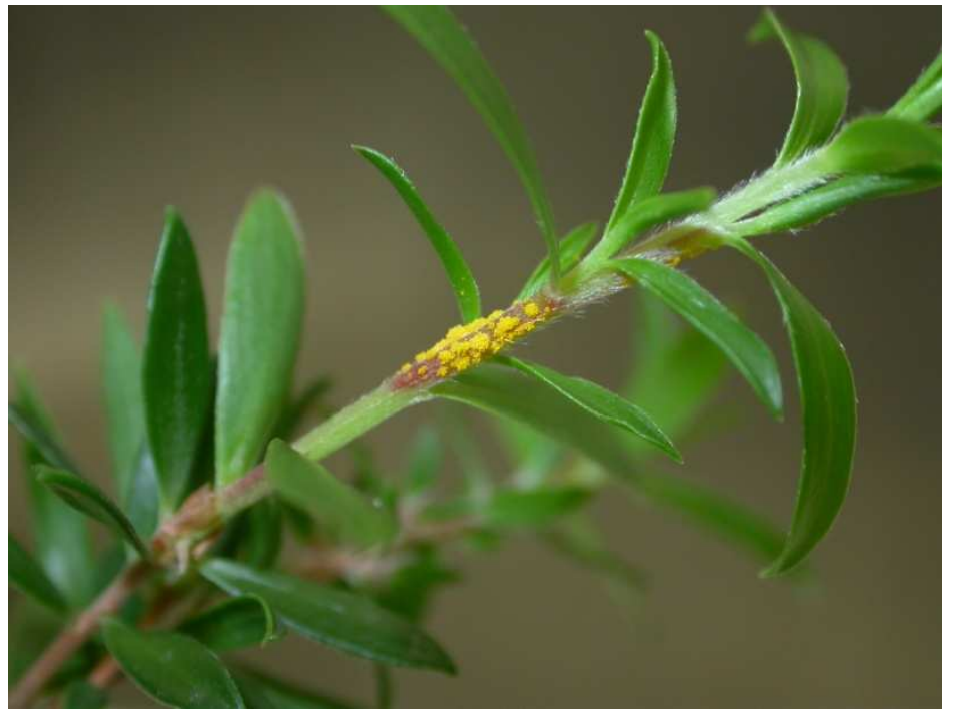

Leptospermum 'White Wave'

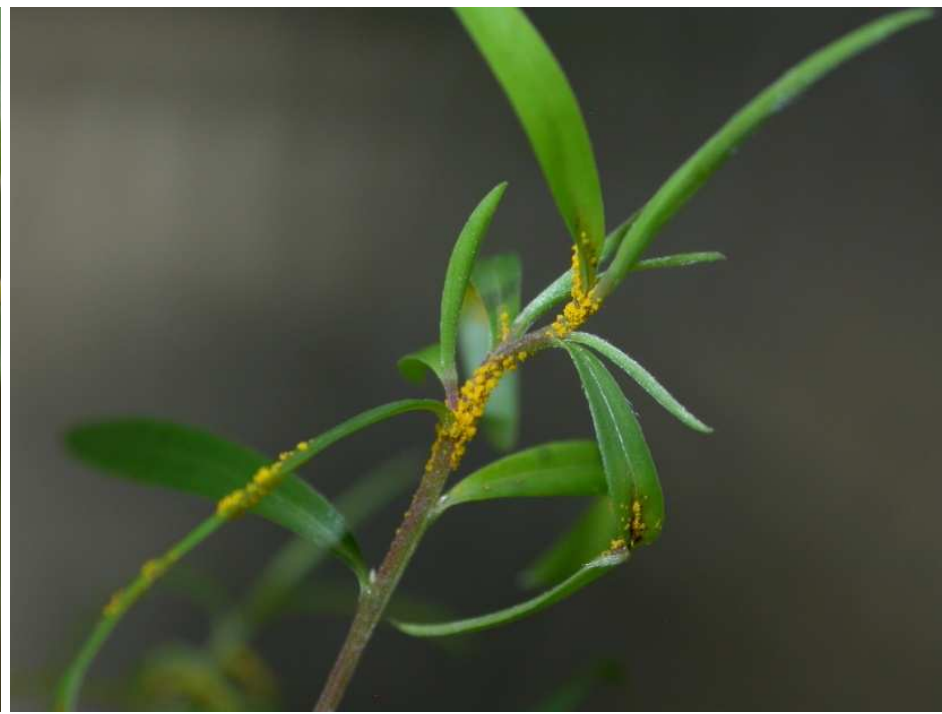

Leptospermum morrisonii 'Burgundy' 

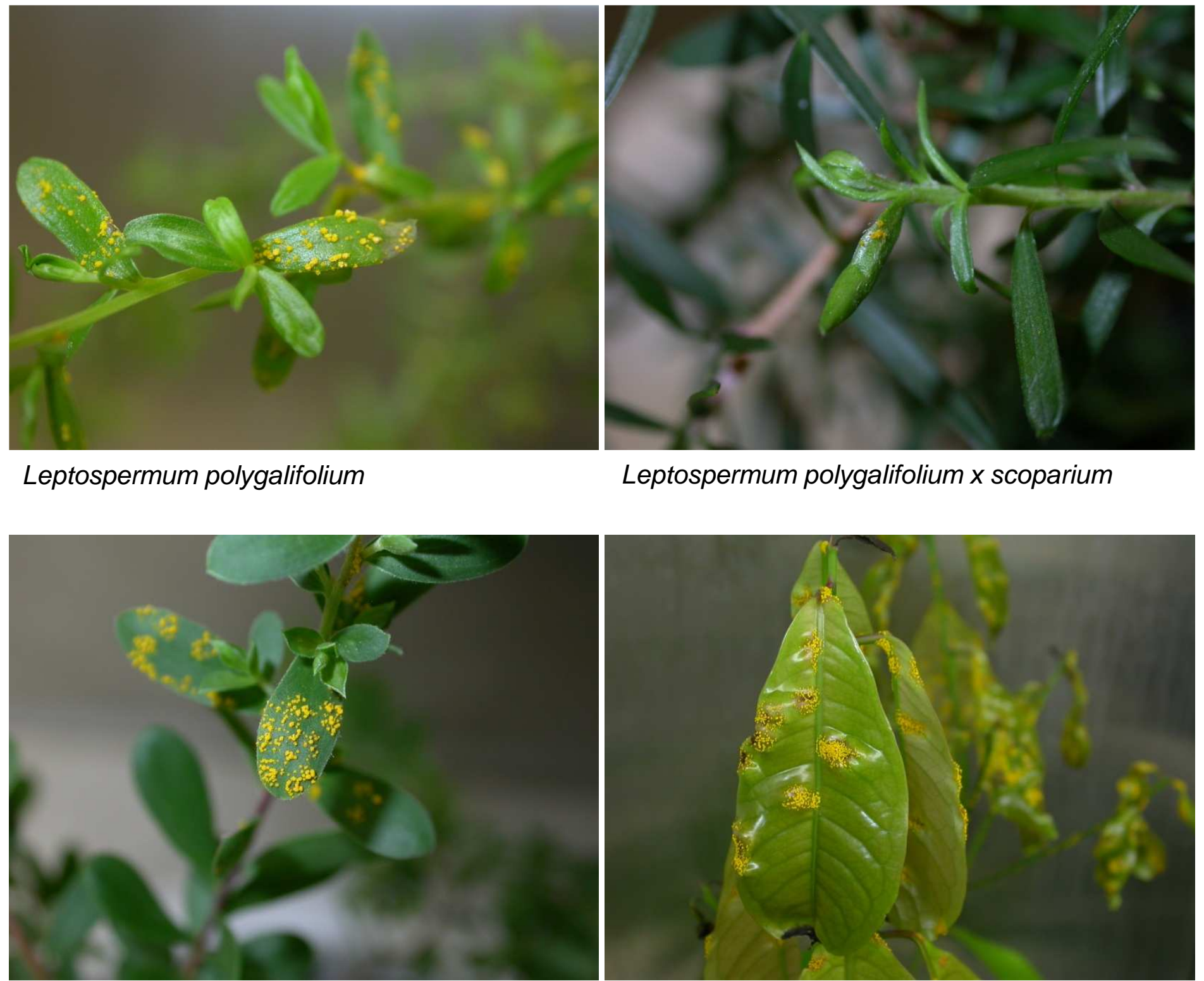

Leptospermum trinervium

\section{Lindsayomyrtus racemoides}

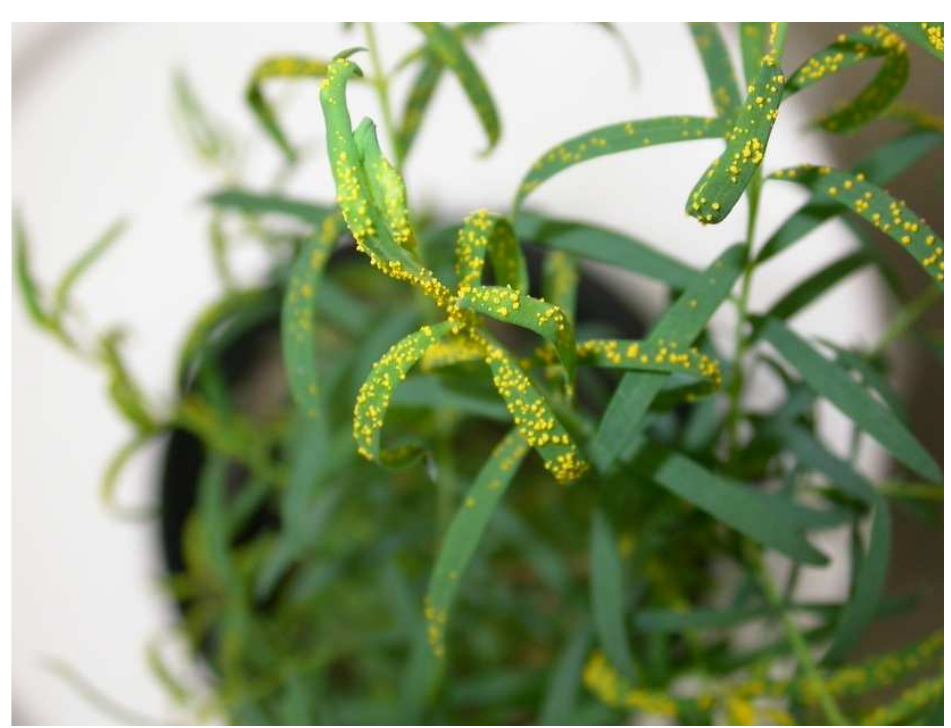




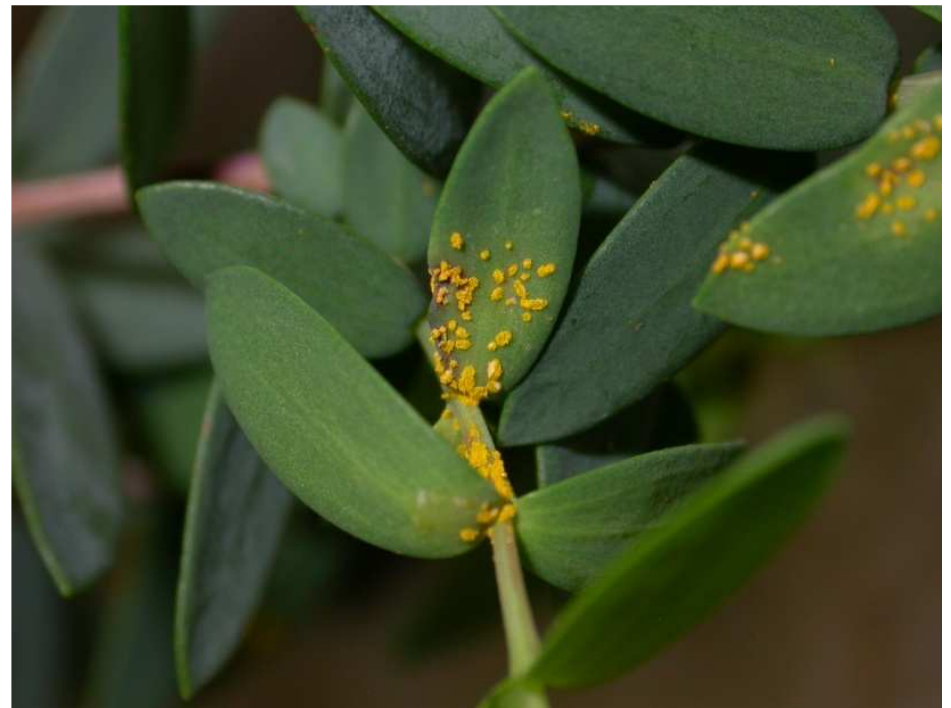

Melaleuca howeana

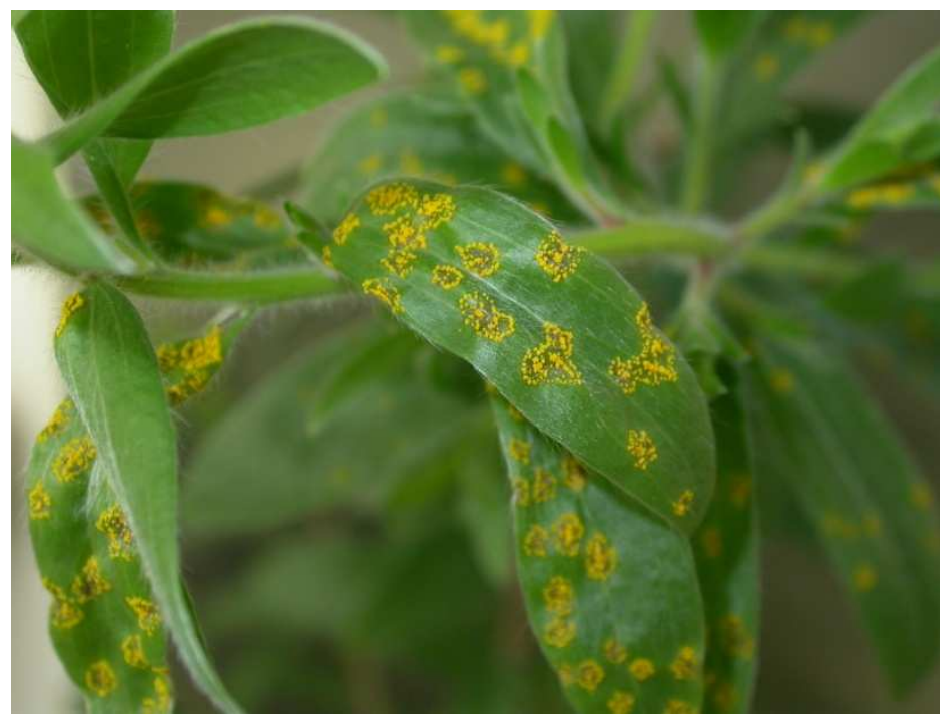

Melaleuca quinquenervia

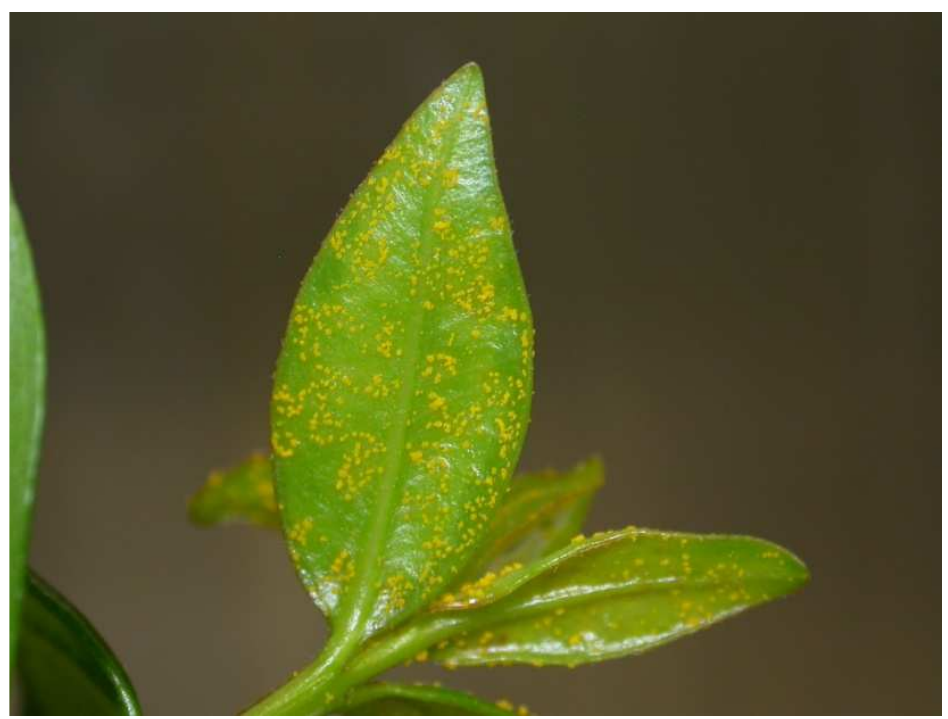

Metrosideros excelsa 'Golden Dawn'

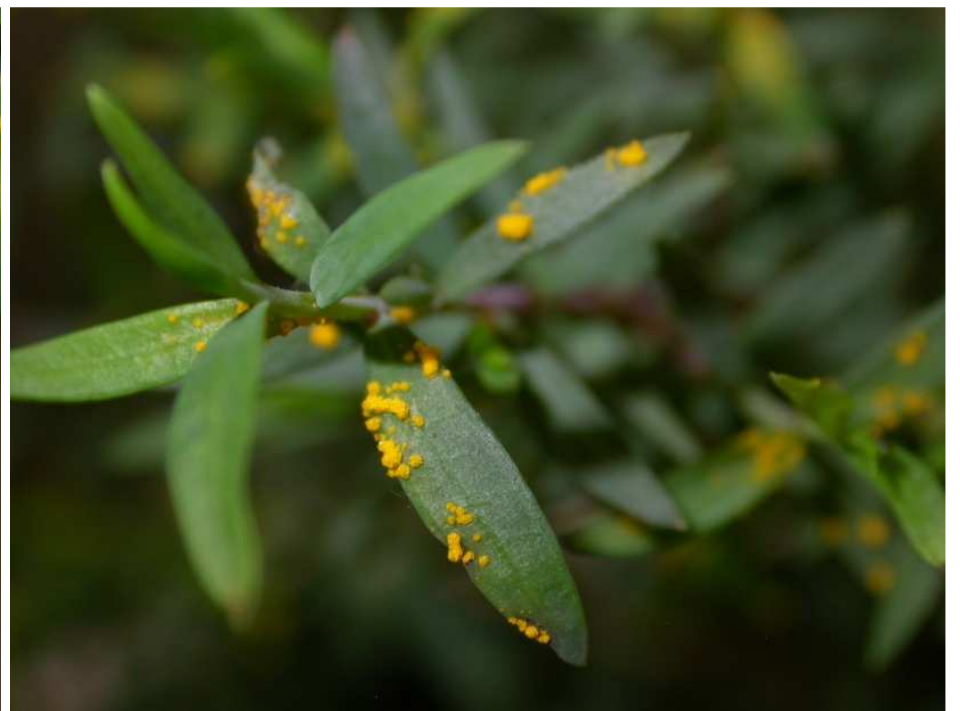

Melaleuca linariifolia

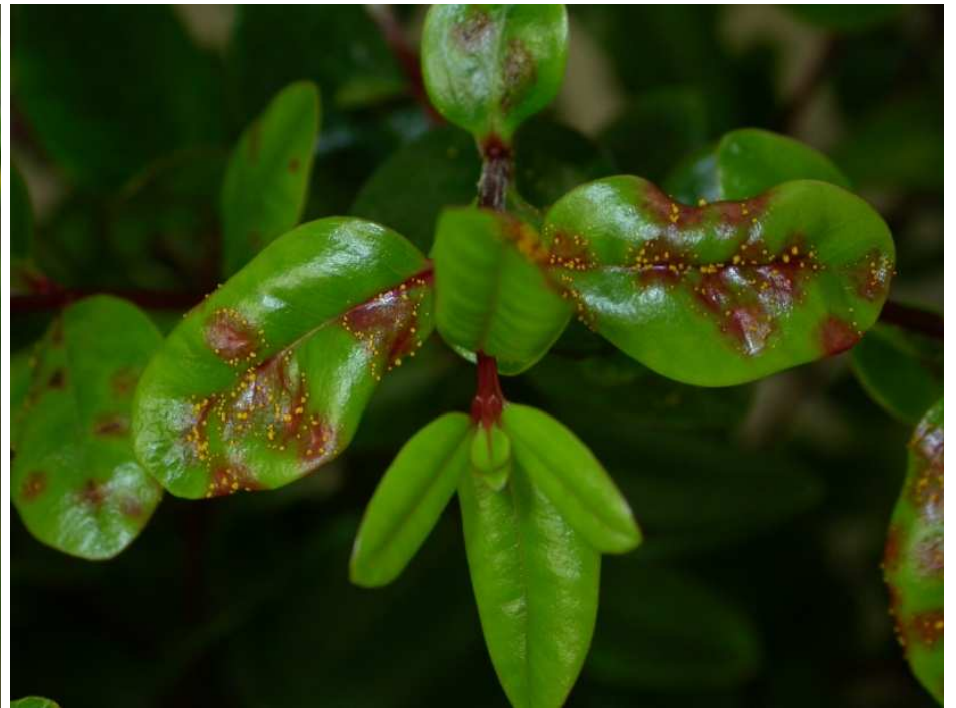

Metrosideros collina 'Tahiti'

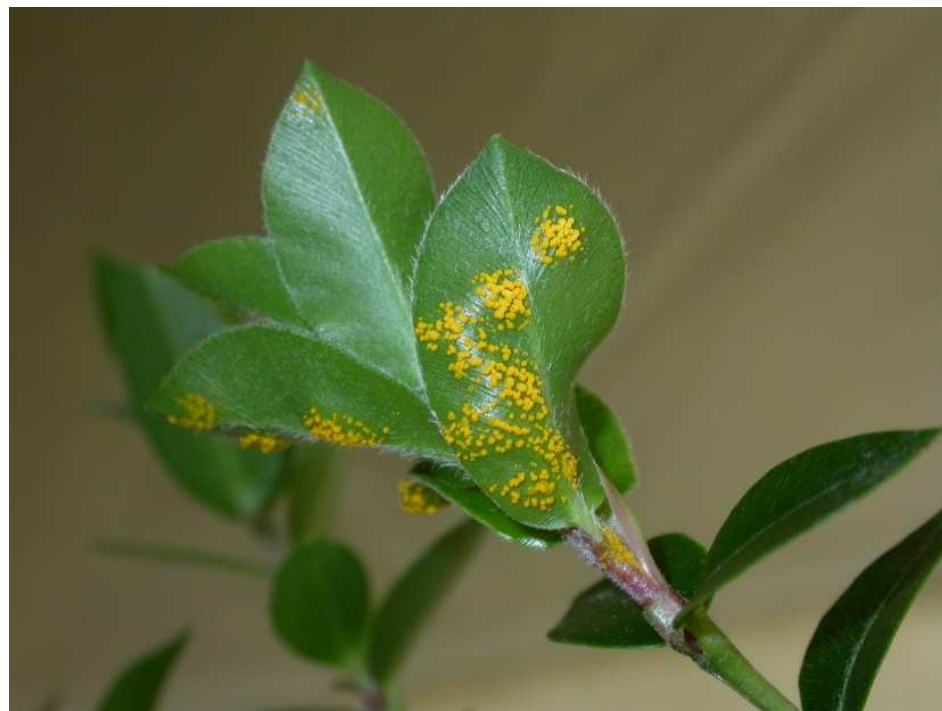

Metrosideros nervulosa 


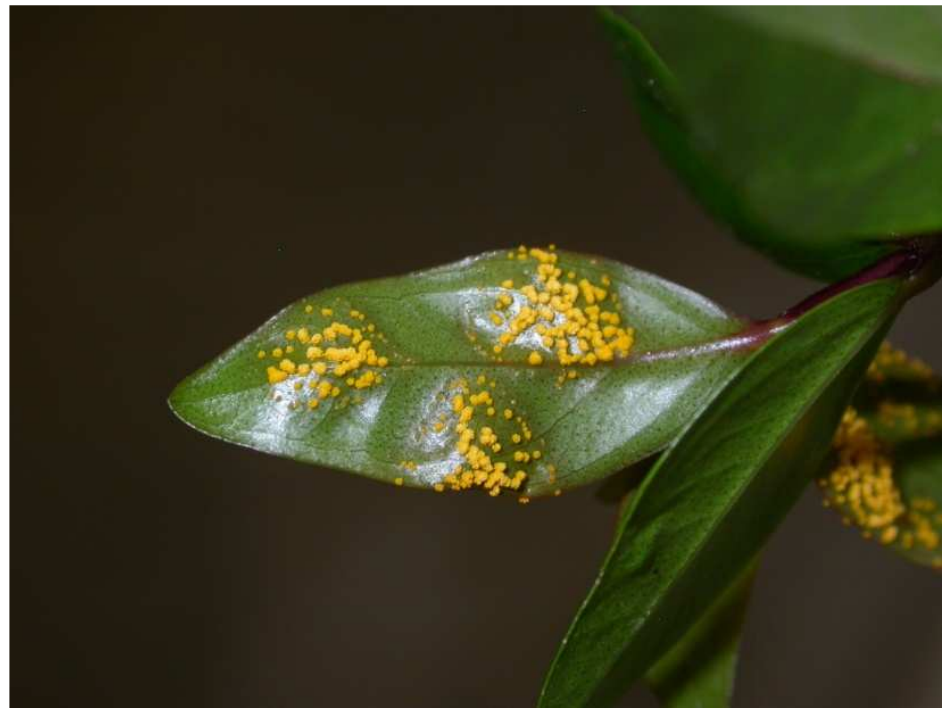

Metrosideros sclerocarpa

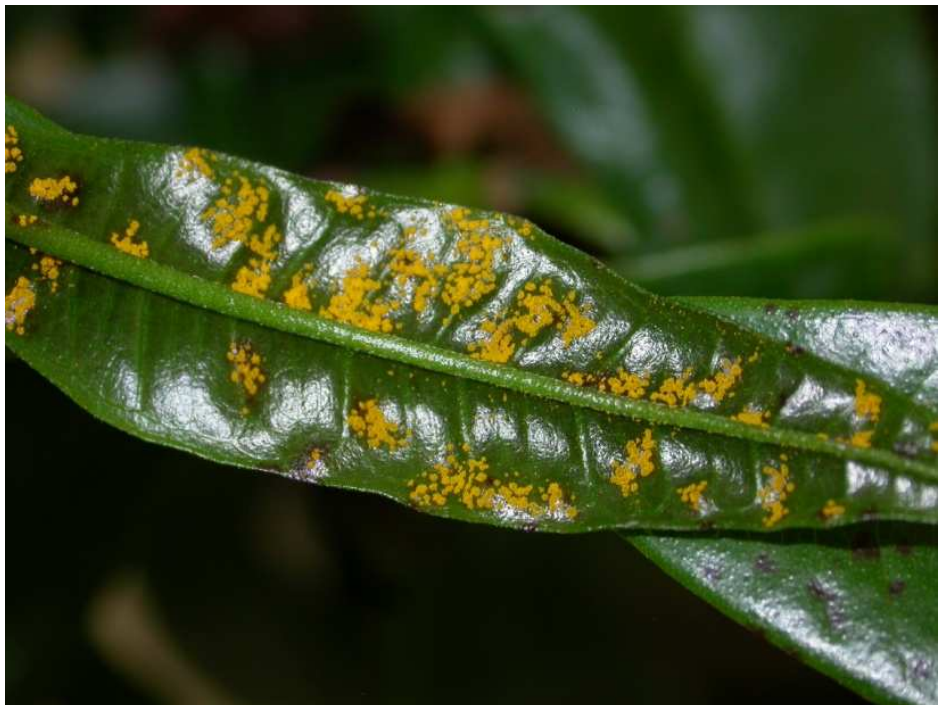

Pimenta dioica

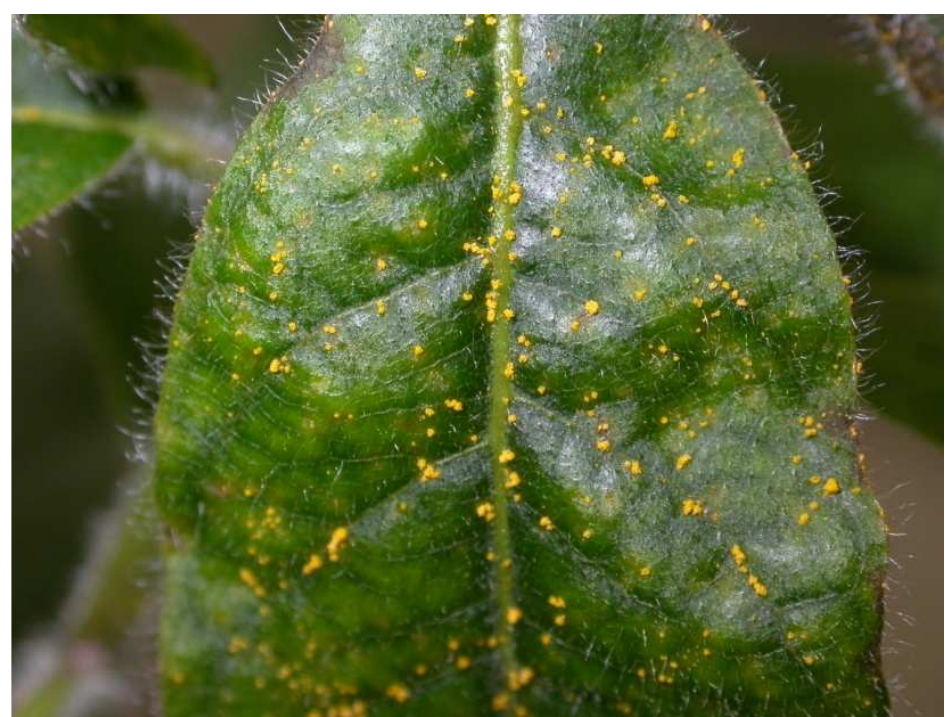

Syncarpia glomulifera

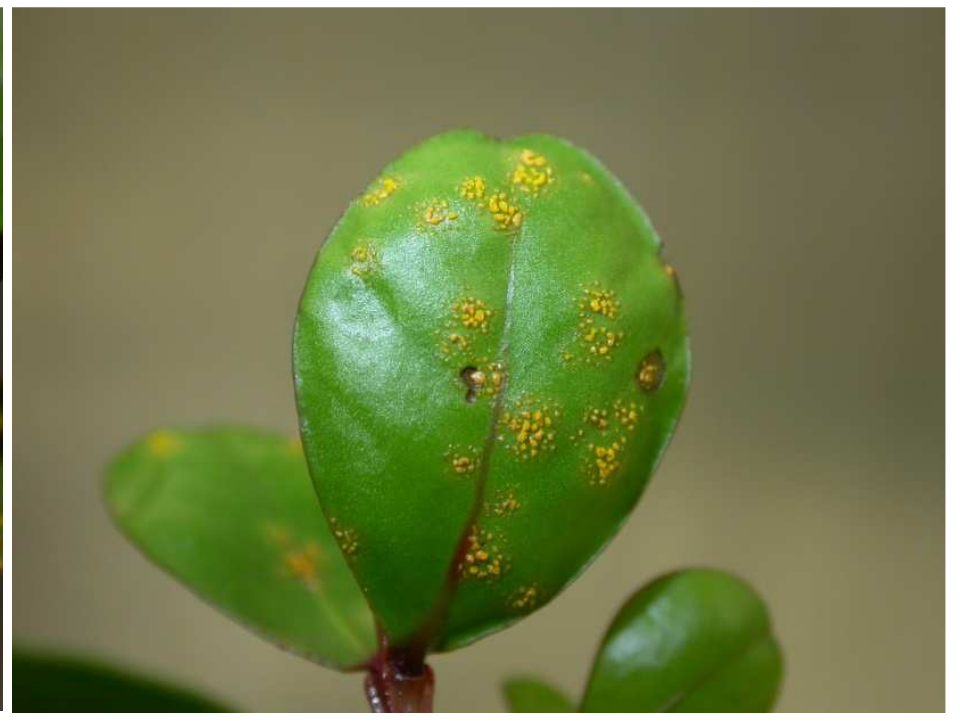

Osbornia octodonta

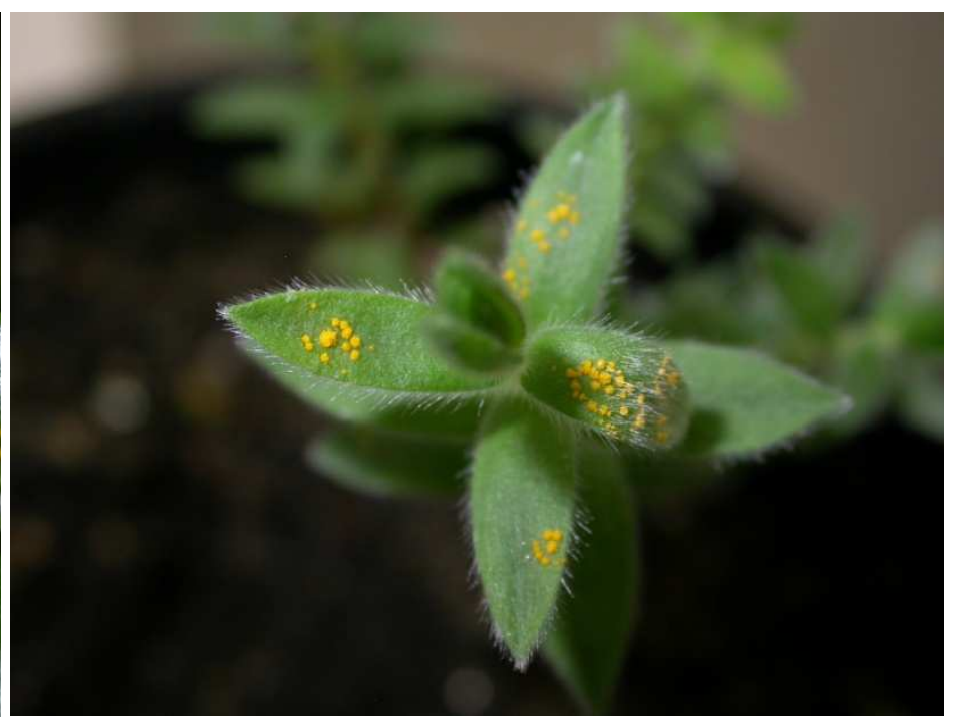

Regelia velutina

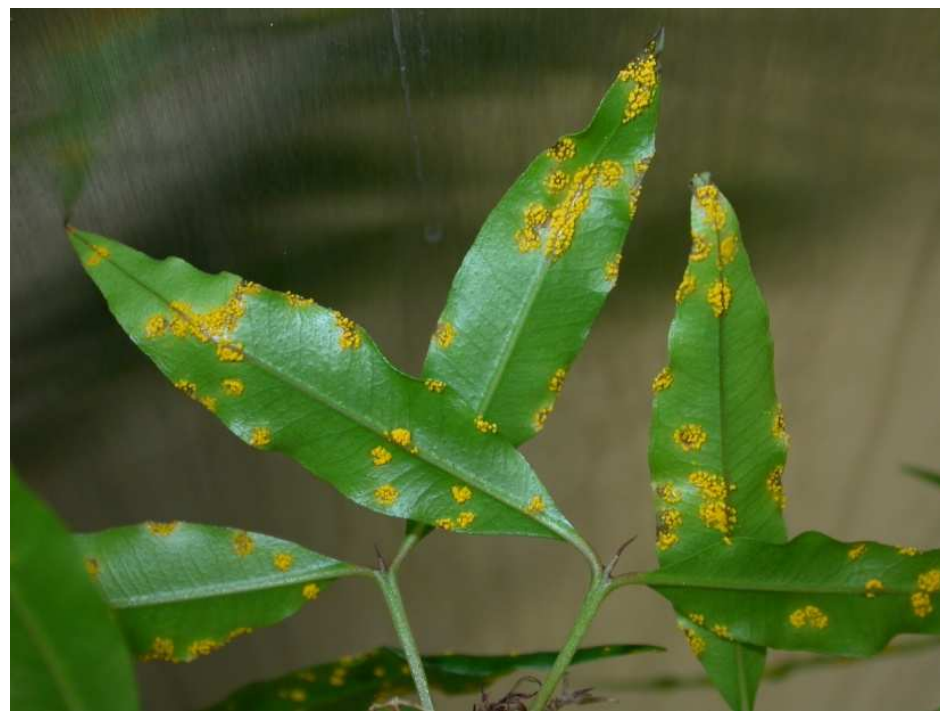

Syzygium anisatum 


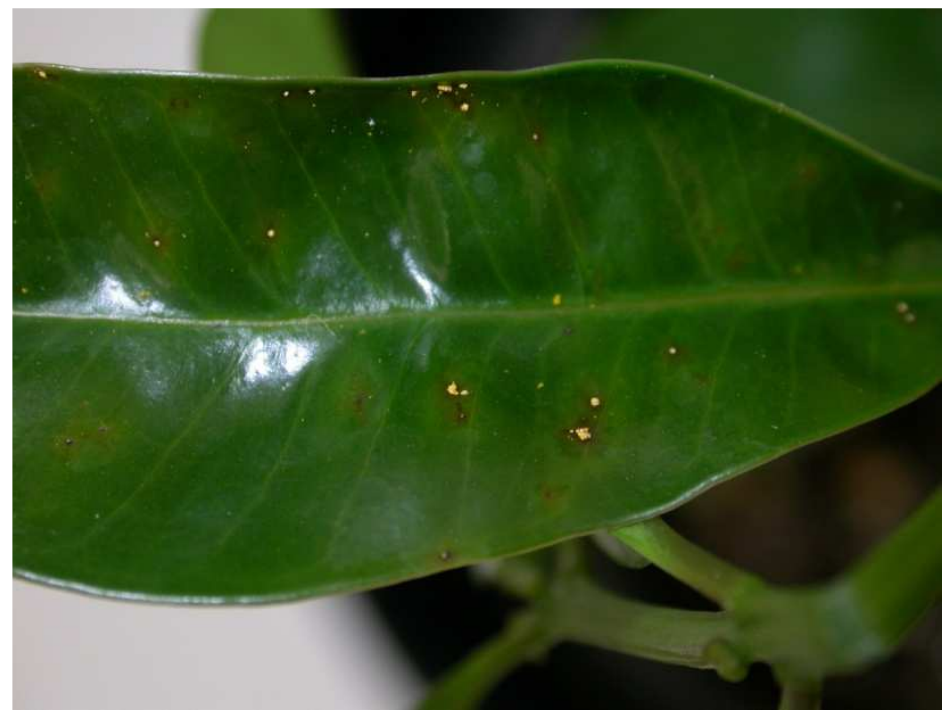

Syzygium australe 'Captain Cook'

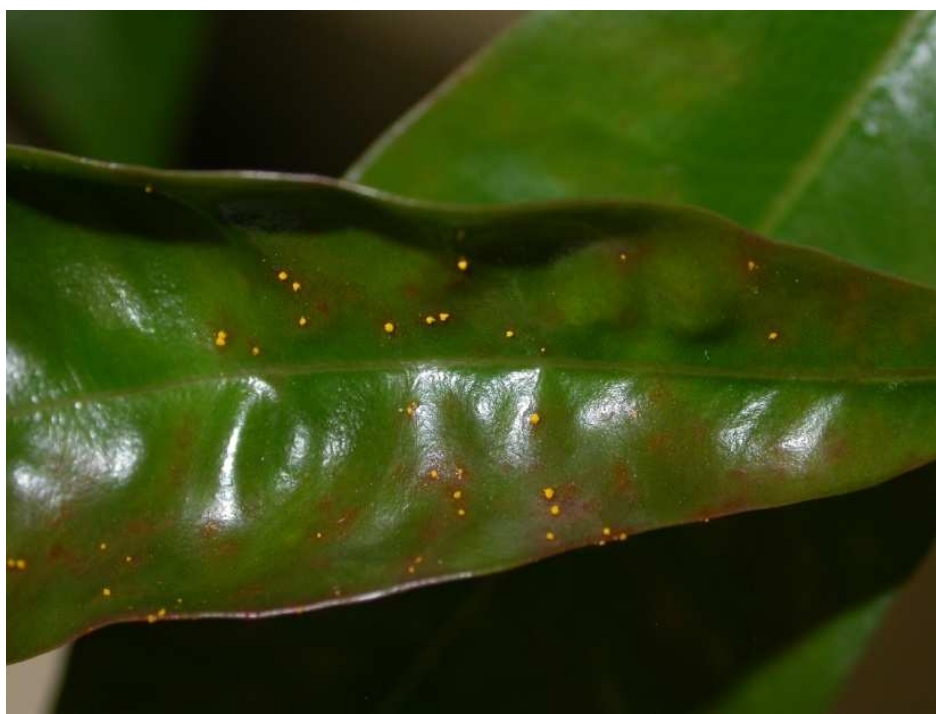

Syzygium fibrosum

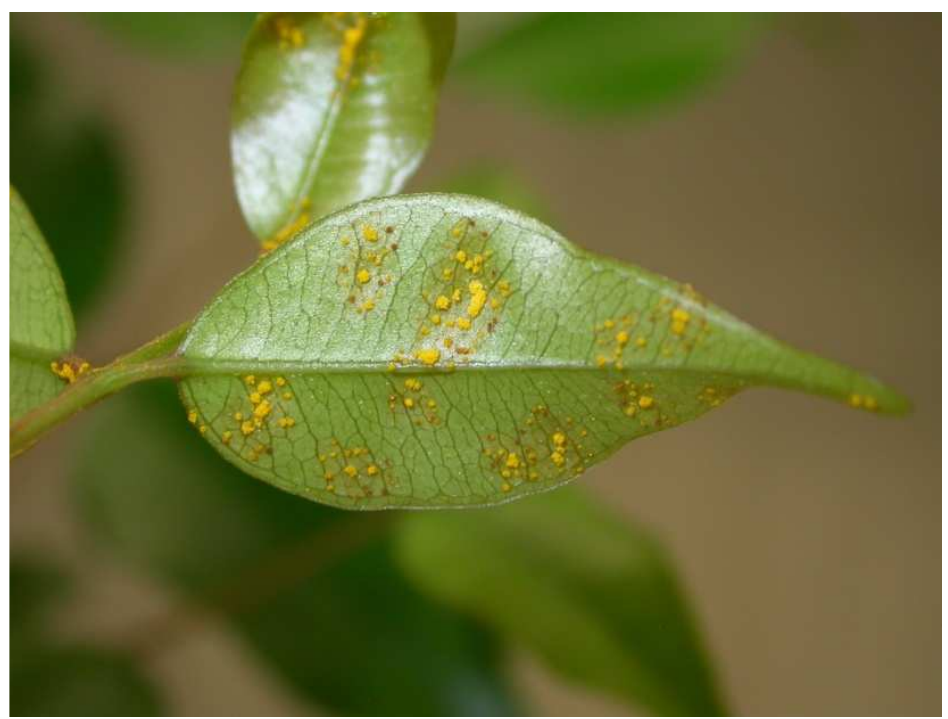

Syzygium francisii

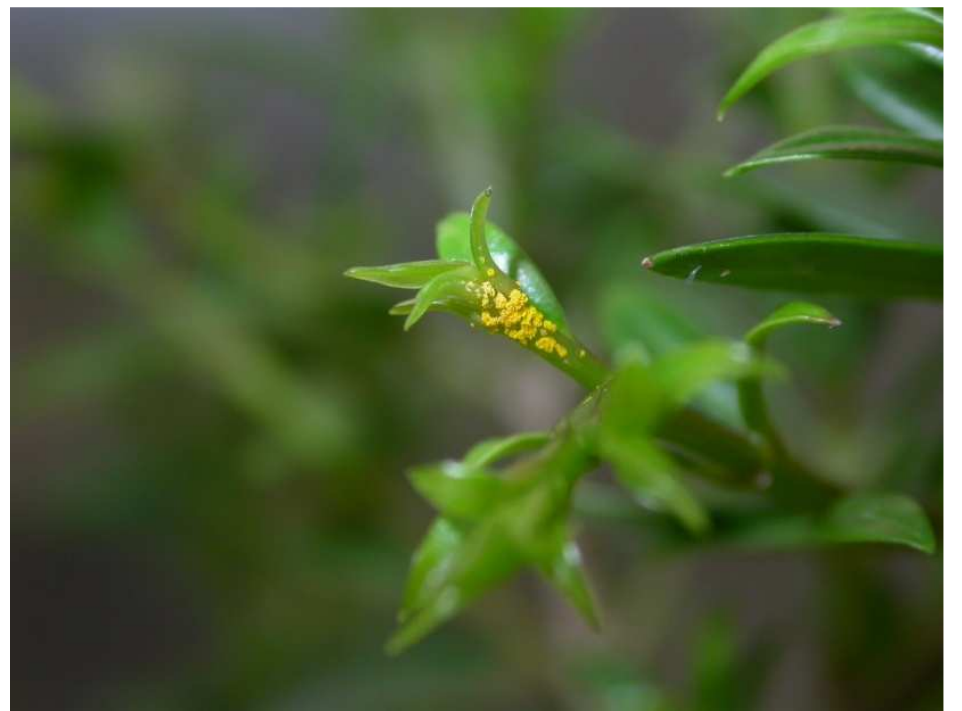

Syzygium australe 'Meridian Midget'

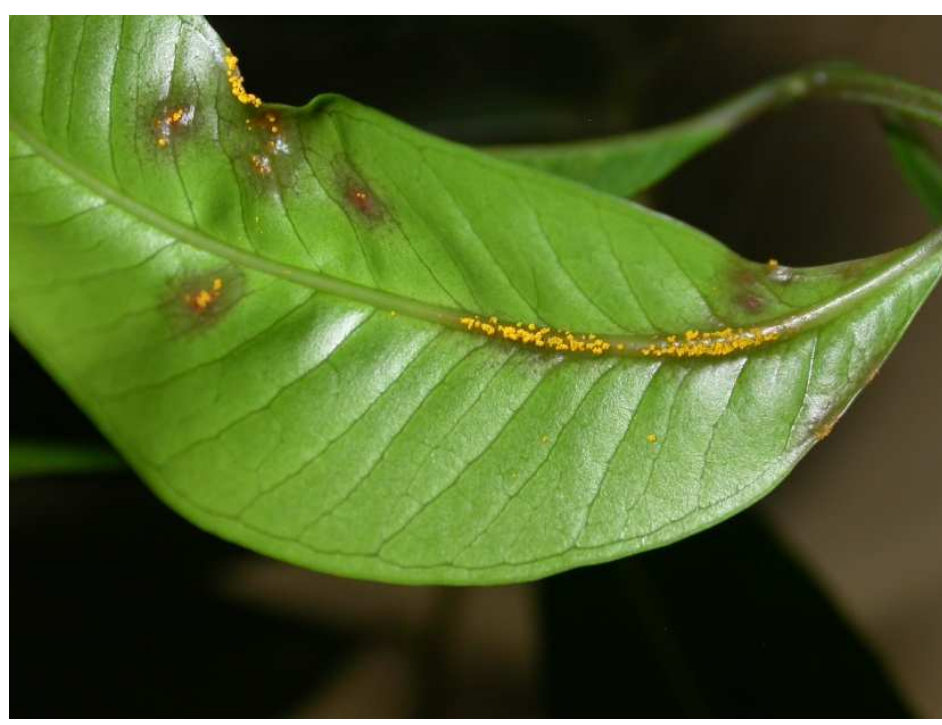

Syzygium floribundum

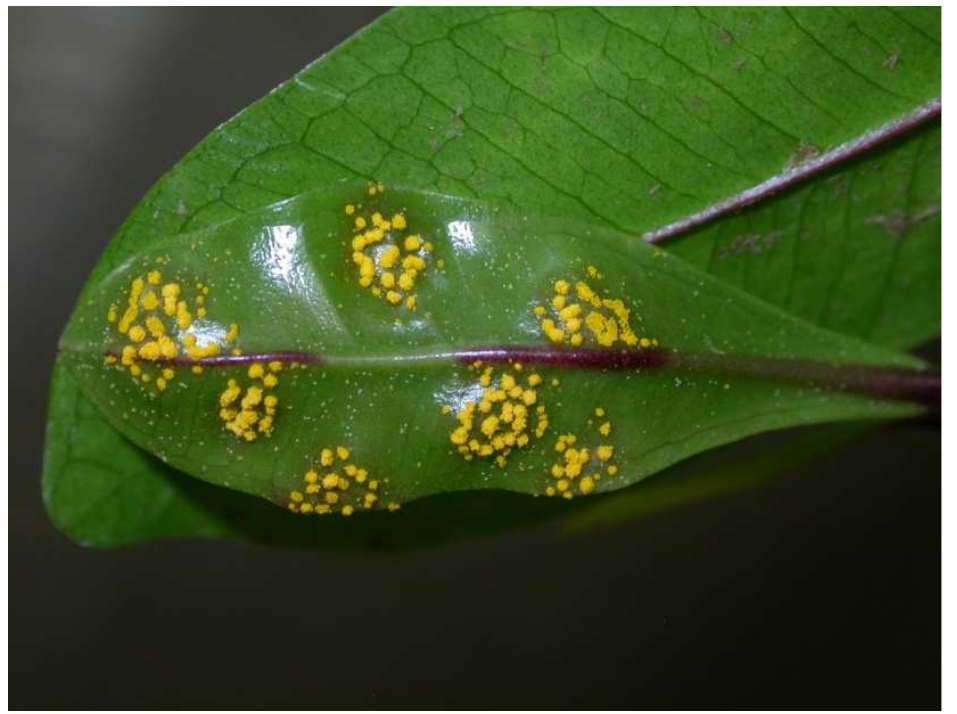

Syzygium fullagarii 


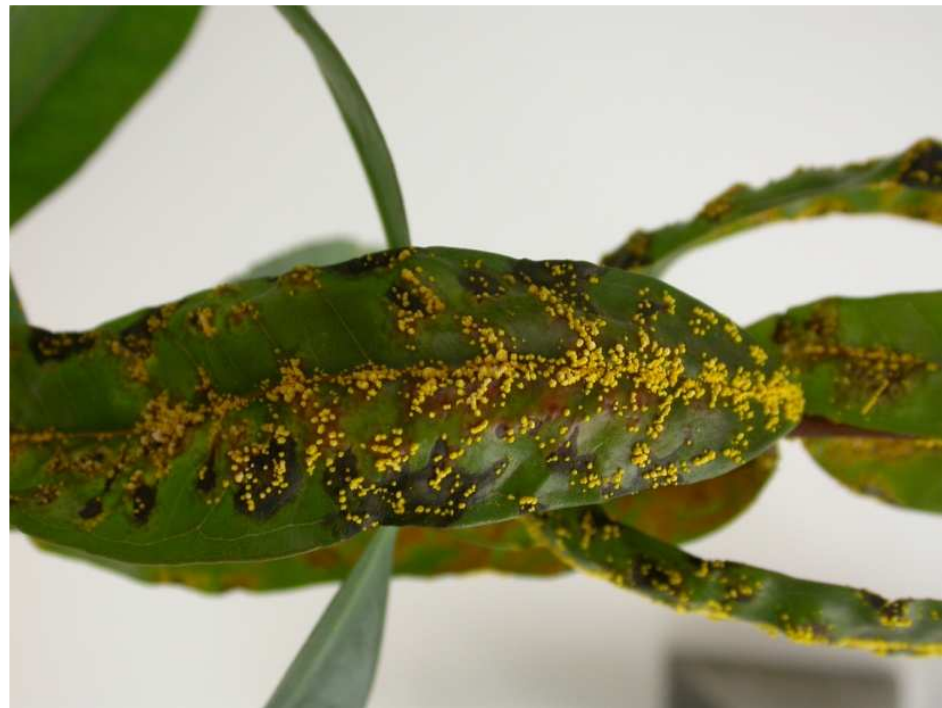

Syzygium jambos

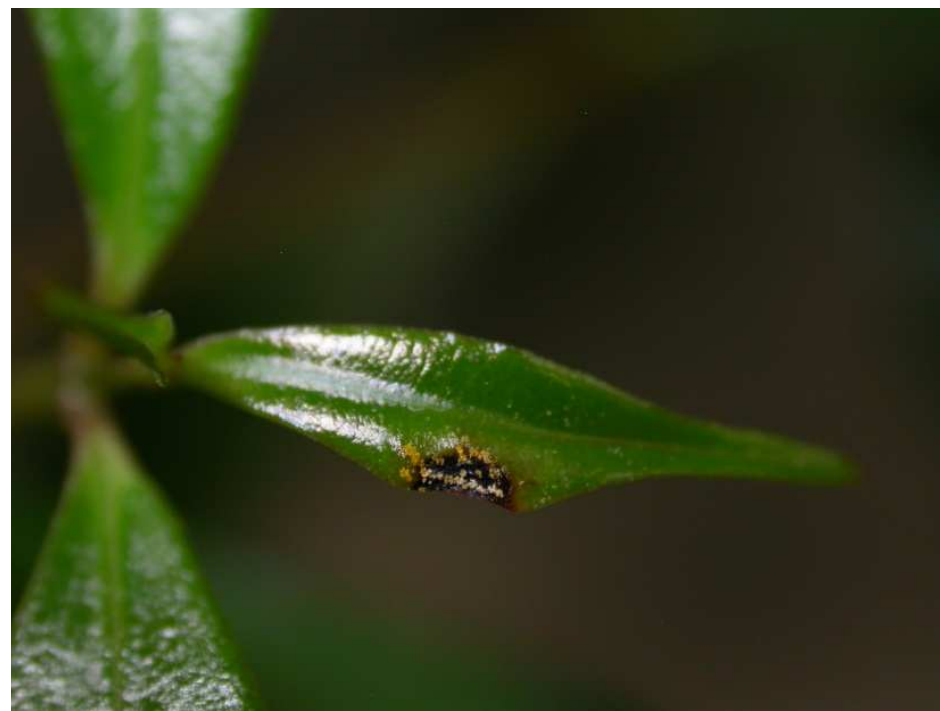

Syzygium oleosum

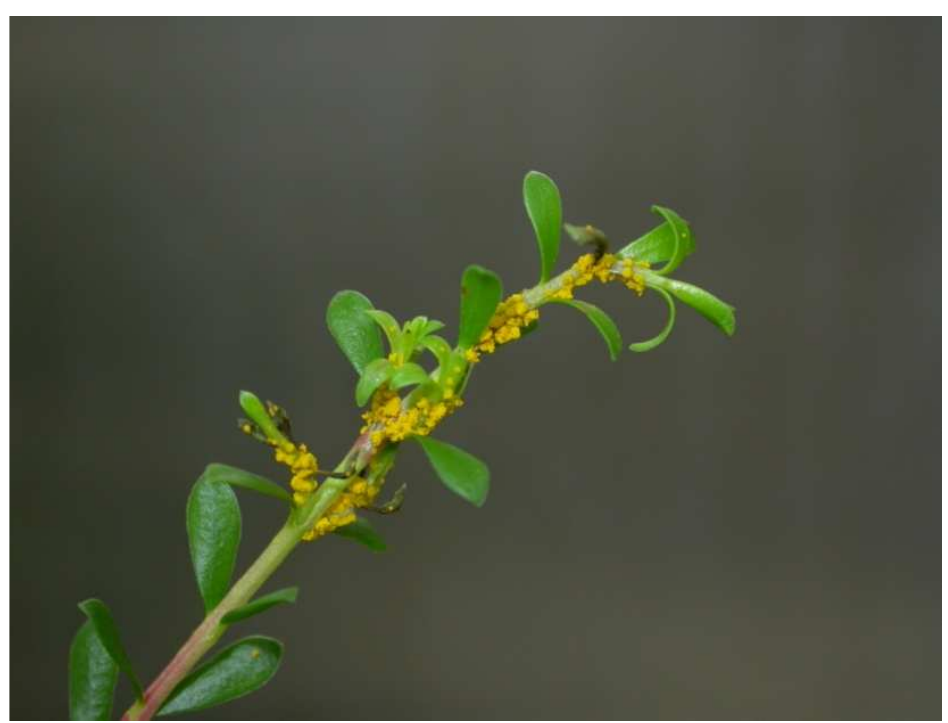

Thryptomene calycina

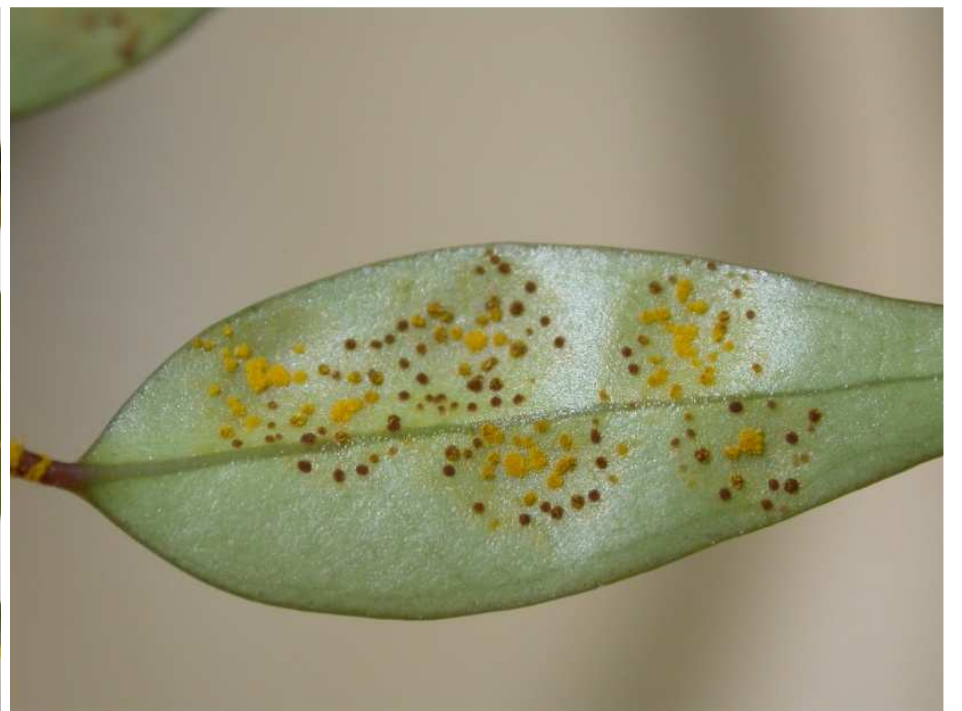

Syzygium luehmannii

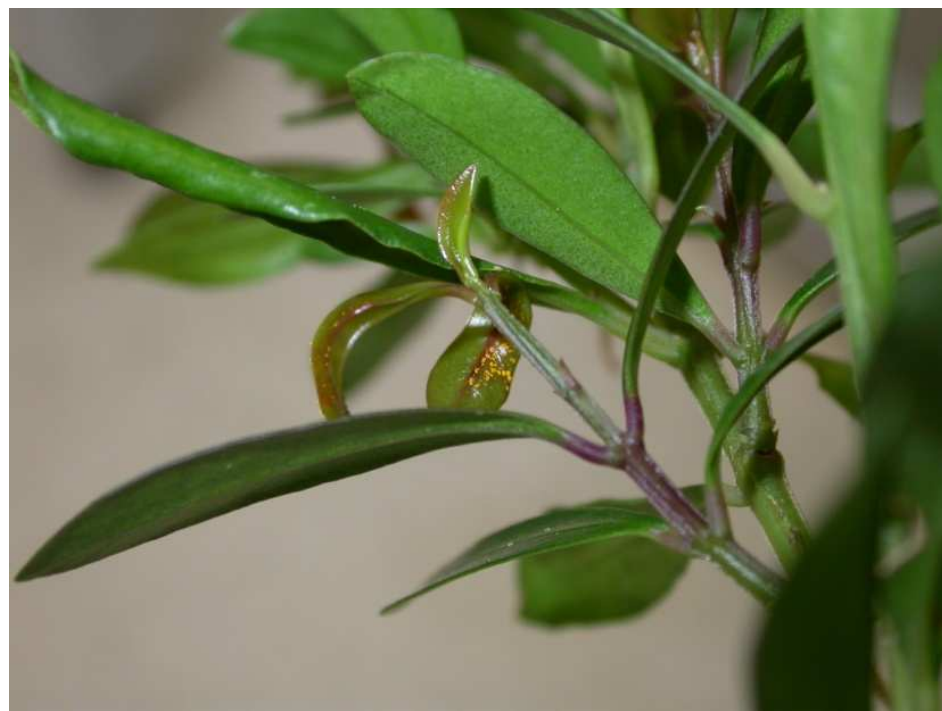

Syzygium smithii rheophytic form

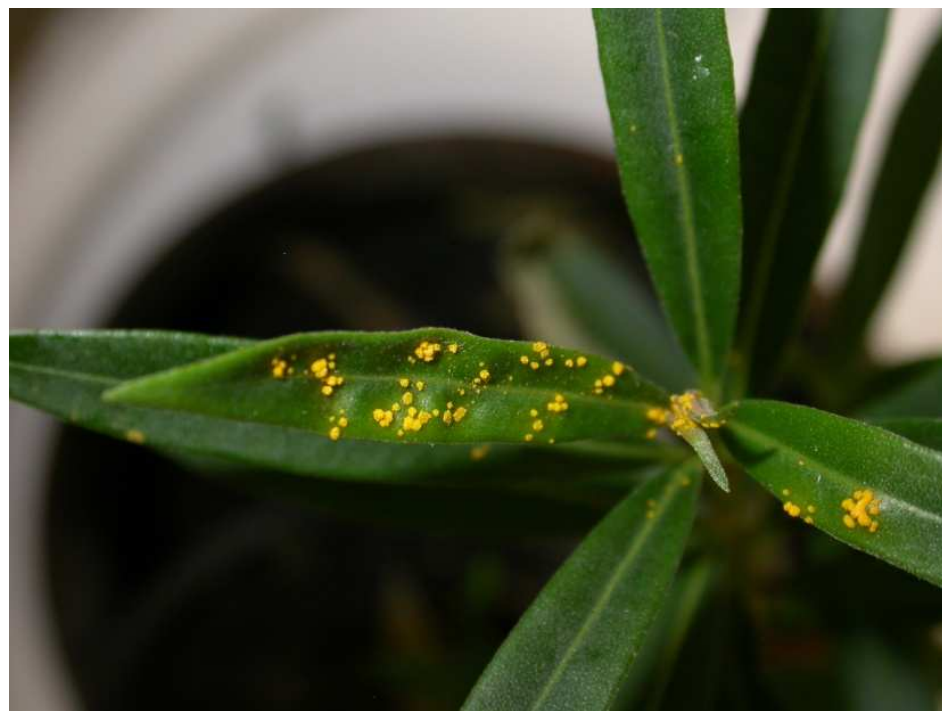

Tristania neriifolia 


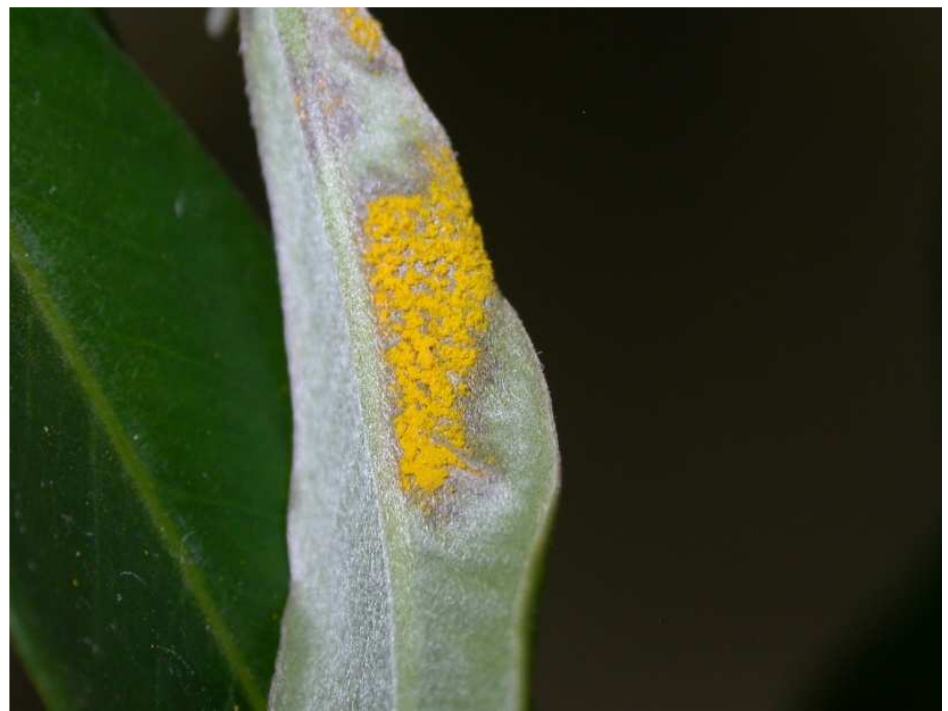

Tristaniopsis laurina

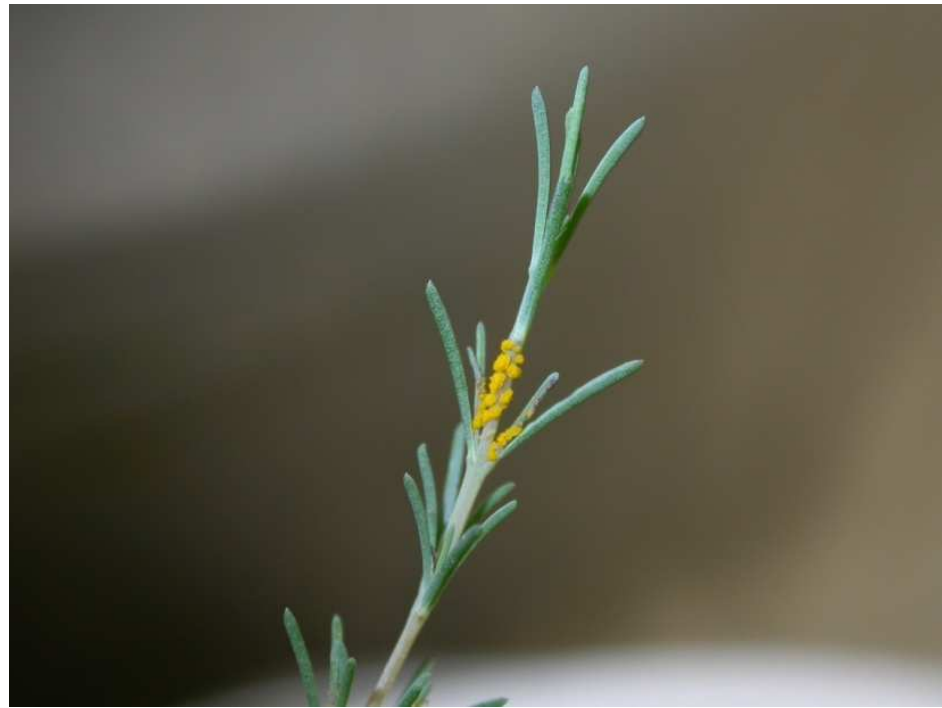

Verticordia plumosa

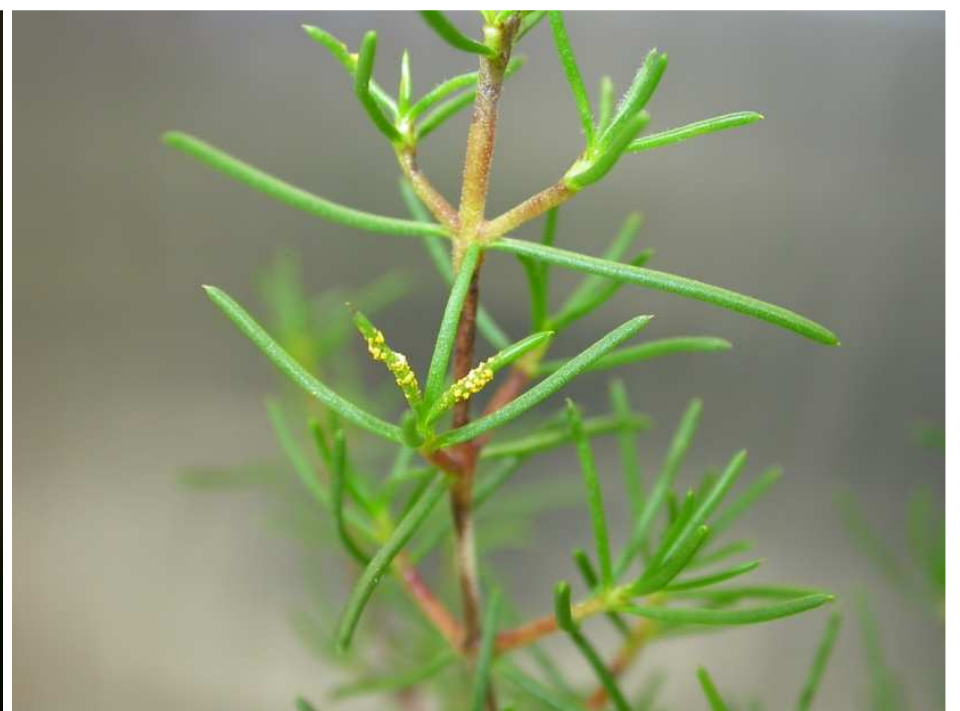

Verticordia chrysantha

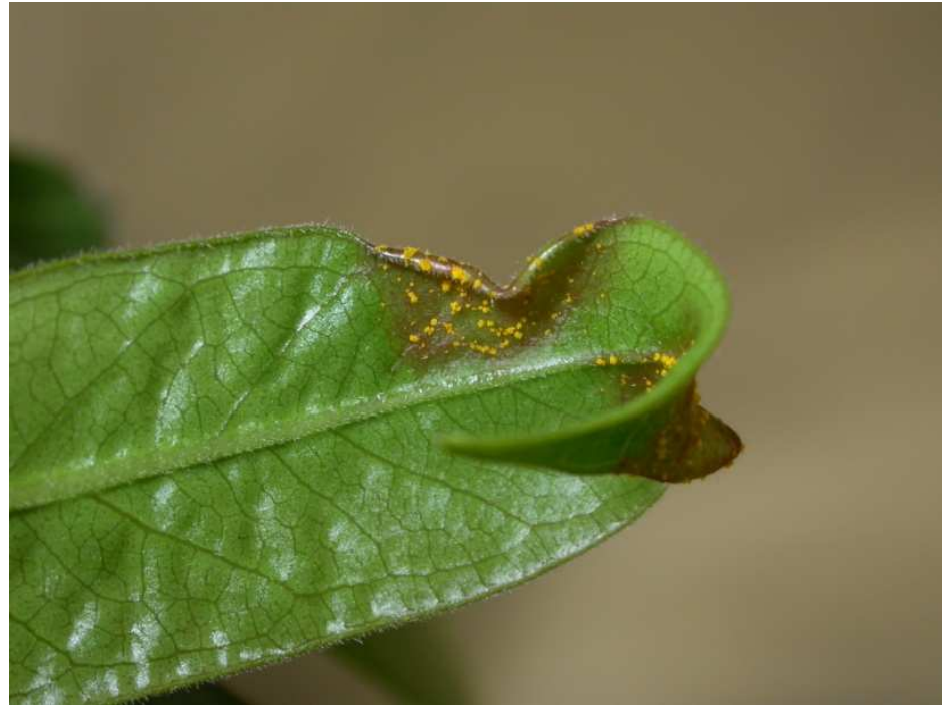

Xanthostemon chrysanthus 